\title{
Valor do teste de dosagem do Dímero - D plasmático no diagnóstico do tromboembolismo venoso agudo
}

Tese apresentada à Faculdade de

Medicina da Universidade de São

Paulo para obtenção do título de

Doutor em Ciências

Área de concentração: Cardiologia

Orientadora: Profa. Dra. Silvia

Helena Gelás Lage Pasqualucci

Co-orientador: Dr. Roberto Abi

Rached

São Paulo 
Dados Internacionais de Catalogação na Publicação (CIP)

Preparada pela Biblioteca da

Faculdade de Medicina da Universidade de São Paulo

Creprodução autorizada pelo autor

De Piano, Luciana Pereira Almeida

Valor do teste de dosagem do Dímero - D plasmático no diagnóstico do tromboembolismo venoso agudo / Luciana Pereira Almeida De Piano. -- São Paulo, 2007.

Tese(doutorado)--Faculdade de Medicina da Universidade de São Paulo. Departamento de Cardio-Pneumologia.

Área de concentração: Cardiologia.

Orientadora: Silvia Helena Gelás Lage Pasqualucci.

Co-orientador: Roberto Abi Rached.

Descritores: 1.Testes de coagulação sanguínea 2.ELISA 3.Valor preditivo dos testes 4.Tromboembolismo/diagnóstico 5.Embolia pulmonar/diagnóstico 6.Trombose venosa/diagnóstico

USP/FM/SBD-333/07 
"Aprender em grupo significa uma leitura crítica da realidade, uma apropriação ativa dessa realidade. É uma atitude investigadora, na qual cada resposta obtida se transforma, imediatamente, numa nova pergunta". 
"Não sabendo que era impossível, ele foi lá e fez".

\section{Provérbio oriental}


Dedicatória

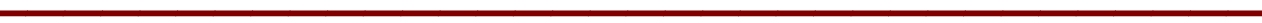


Ao meu amado Pai Vital e minha amada Mãe Maria Dulcina que com o seu incondicional amor, em todos os momentos da nossa existência, muitas vezes abdicaram das suas próprias vidas em meu favor e de meus dois irmãos.

Aos meus queridos irmãos, Adriana e Fábio, que por tantas vezes foram cúmplices e tolerantes em momentos importantes de minha vida. 
Ao meu amado esposo Marcelo, companheiro de todos os momentos, agradeço por toda sua compreensão nos meu momentos de ausência e ansiedade, mas principalmente pelo seu amor e dedicação, fundamentais para a conclusão dessa etapa de nossas vidas.

Ao meu amado filho Giovanni, razão do meu viver, que tão pequenino contribuiu desde seu nascimento, na conclusão desse trabalho, o qual iniciei e terminei pensando no seu futuro e no de seus irmãos... que ainda estão por vir. 
Aos meus afilhados Gustavo e Samantha, que me dão alegria e incentivo, mesmo sem ainda saberem o seu significado!!!

Aos meus amados sobrinhos Bruno, Gustavo, Marcelinho, Samantha e Vitória, motivo de muito orgulho e muitas alegrias na minha vida e de minha família. 
Agradecimentos especiais 
À Deus, pela vida repleta de saúde, alegrias e dons.

Aos pacientes, que em seus momentos de dor e sofrimento confiam sua vida aos profissionais da saúde, sendo o grande motivo da realização desse trabalho. 


\section{Profa. Dra. Silvia Gelas Lage Pasqualucci.}

Minha orientadora, agradeço por todo incentivo e apoio na realização desse trabalho. Agradeço pela oportunidade de aprender mais e mais a cada dia. Agradeço pela fundamental orientação para conclusão dessa tese.

\section{Dr. Roberto Abi Rached:}

Meu co-orientador, amigo, mentor, confidente, enfim, exemplo de profissional íntegro e dedicado. Minha imensa gratidão por todas as oportunidades oferecidas ao longo desses anos, desde a graduação, ocasião que me aceitou como estagiária e aonde meu amor pela pesquisa se iniciou...

Agradeço por todos os ensinamentos de vida e profissionais, essencias para meu amadurecimento e formação pessoal e profissional.

\section{Prof. Dr. Whady Armindo Hueb:}

Exemplo singular de ética e profissionalismo. Agradeço por todo tempo dedicado em analisar minha tese, tendo sido de uma imensa contribuição para a elaboração e conclusão desse trabalho.

\section{Dr. Cyrillo Cavalheiro Filho:}

Por todo apoio e solidariedade nos mais diversos momentos, pela amizade e pelas oportunidades oferecidas.

\section{Dra. Célia Maria Cassaro Strunz:}

Pelo tempo dedicado em analisar e contribuir na minha tese.

Ao meu sogro Sr. Giuseppe e minha sogra Sra. Ivone que, gentilmente, me incentivaram a estudar e traçar objetivos. 
A toda minha família, exemplo de honestidade e bondade, agradeço por toda a ajuda em todas as etapas da minha vida. 
Agradecimentos 
Prof. Dr. Dario Birollini e Dr. Francisco Cardoso, por permitirem a realização desse estudo em suas áreas.

Ao Dr. Fábio Fernandes, por todo apoio e dedicação ao analisar essa tese.

A equipe MASS por toda atenção e auxílio nas aulas para apresentação da tese.

A equipe do laboratório clínico do InCor pela essencial importância na realização dos exames para o andamento do projeto.

Ao setor de exames por imagem do InCor e Instituto Central $\boldsymbol{H C}$, pela realização dos exames confirmatórios nos pacientes.

A Neusa, Juliana e Eva, equipe de pós - graduação da área de Cardiologia, por todo trabalho e atenção aos doutorandos.

A bibliotecária Maria do Carmo, por me auxiliar tão prontamente nas referências bibliográficas.

A minha irmã e revisora oficial, Adriana Pereira de Almeida, pela revisão de ortografia dessa tese.

A minha querida prima, amiga e nutricionista, Aline de Piano, que em minhas consultas, que se tornaram verdadeiras terapias, sempre ouviu pacientemente os meus anseios e as minhas perspectivas. 
A minha amiga Maria Cristina Vasconcellos Affonso, pela tolerância nos momentos mais críticos e pelo apoio, incentivo e amizade... e por minhas ausências também.

As estagiárias Helena Scavone, Camila Ciccone Paccola e Juliana Moura, do serviço de hemoterapia do InCor que me auxiliaram na coleta de dados dessa tese.

As estagiárias Joyce Constâncio, Camilla Nunes e Karen Hirakawa, pela amizade e pela compreensão nos meus momentos mais ansiosos.

Ao Durval Nascimento, funcionário do serviço de hematologia, pela amizade e prestatividade nesse trabalho.

A todos colegas e funcionários do InCor - HC FMUSP e da Fundação Pró - Sangue do Hemocentro de São Paulo, que literalmente doaram amostras de sangue para o início desse trabalho. 
Esta tese está de acordo com:

Referências: adaptado de International Comitee of Medical Journals Editors (Vancouver).

Universidade de São Paulo. Faculdade de Medicina. Serviço de Biblioteca e Documentação. Guia de apresentação de dissertações, teses e monografias. Elaborado por Annelise Carneiro da Cunha, Maria Júlia de A. L. Freddi, Maria F. Crestana, Marinalva de Souza Aragão, Suely Campos Cardoso, Valéria Vilhena. São Paulo: Serviço de Biblioteca e Documentação; 2005.

Abreviatura dos títulos dos periódicos de acordo com List of Journals Indexed in Index Medicus. 
Sumário 
Lista de abreviaturas e siglas

Lista de figuras

Lista de tabelas

Lista de gráficos

Resumo

Abstract

1 INTRODUÇÃO....................................................................... 1

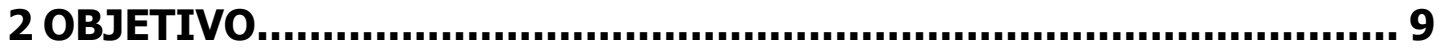

3 METODOLOGIA..................................................................... 11

3.1 Aprovação do protocolo............................................ 12

3.2 Delineamento do estudo.............................................. 12

3.3 Critérios de inclusão............................................... 13

3.4 Critérios para não inclusão e para exclusão........................... 14

3.5 Condução do estudo.............................................. 15

3.6 Coleta de amostra de sangue para realização da dosagem de dímero - D pelo método ELFA/ equipamento $\operatorname{VIDAS}^{\circledR} \ldots \ldots \ldots \ldots \ldots \ldots . . \ldots 16$

3.7 Realização da dosagem do dímero - D plasmático................ 17

3.7.1 Princípio do método.......................................... 18

3.7.2 Comportamento funcional.............................. 20

3.7.3 Valores esperados........................................ 21

3.8 Exames por imagem.................................................... 21 


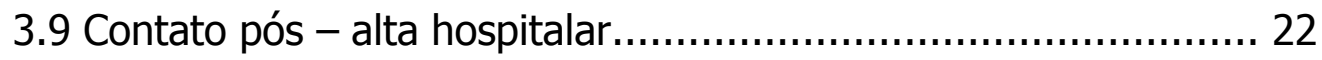

3.10 Tratamento estatístico..................................................... 23

4 RESULTADOS.................................................................... 27

4.1 Caracterização dos pacientes................................................ 28

4.2 Confirmação/ exclusão de evento tromboembólico agudo........... 33

4.3 Comparação entre o dímero - D plasmático e trombose............. 38

4.4 Estudo qualitativo do dímero - D plasmático............................ 41

4.5 Curva "Receiver Operating Characteristic" - Curva ROC............ 45

4.6 Análise das variáveis....................................................... 50

4.6.1 Faixa etária........................................................... 50

4.6.1.1 Curva ROC.............................................. 62

4.6.2 Índice de Massa Corporal (IMC)................................ 66

4.6.2.1 Curva ROC................................................. 73

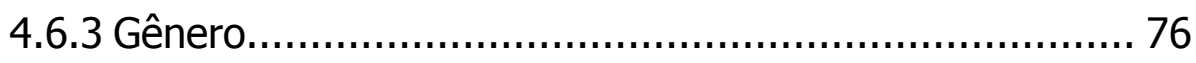

4.6.3.1 Curva ROC............................................... 84

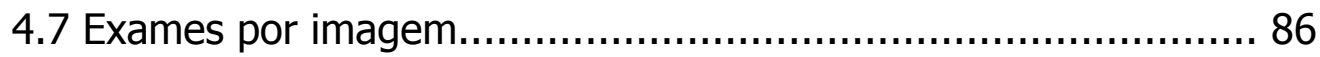

4.8 Avaliações pós - alta hospitalar............................................ 86

5 DISCUSSÃO

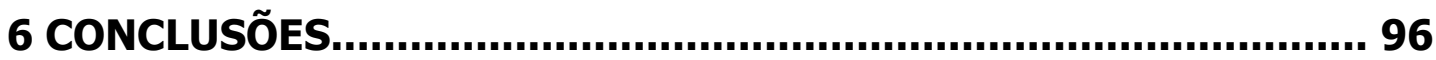

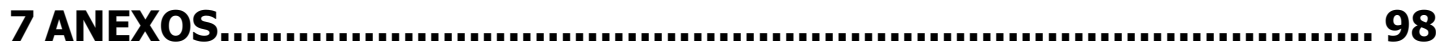

8 REFERÊNCIAS BIBLIOGRÁFICAS........................................... 122

Apêndices 
Listas 


\section{LISTA DE ABREVIATURAS E SIGLAS}

\begin{tabular}{|c|c|}
\hline ABESO & Associação Brasileira para o \\
\hline & $\begin{array}{l}\text { Estudo da Obesidade e da } \\
\text { Síndrome Metabólica }\end{array}$ \\
\hline ASC & Área Sob a Curva \\
\hline $\mathrm{cm}$ & centímetros \\
\hline Curva ROC & $\begin{array}{l}\text { Receive Operator } \\
\text { Characteristic Curve }\end{array}$ \\
\hline ELFA & $\begin{array}{l}\text { Enzyme Linked Fluorescent } \\
\text { Assay }\end{array}$ \\
\hline ELISA & $\begin{array}{l}\text { Enzyme Linked } \\
\text { Immunosorbent Assay }\end{array}$ \\
\hline FN & Falso Negativo \\
\hline FP & Falso Positivo \\
\hline HAS & Hipertensão Arterial Sistêmica \\
\hline IMC & Índice da Massa Corporal \\
\hline $\mathrm{kg}$ & quilogramas \\
\hline $\mathrm{m}$ & metros \\
\hline$m^{2}$ & metros elevado ao quadrado \\
\hline
\end{tabular}


MI

$\mathrm{ml}$

ng

PPP

rpm

TEP

TEP+TVP

TEV

TVP

USG

VPN

VPP

$\operatorname{VIDAS}^{\circledR}$
Membro Inferior

Mililitros

Nanogramas

Plasma Pobre em Plaquetas

Rotações por Minuto

Tromboembolismo Pulmonar

Tromboembolismo pulmonar

associado à Trombose Venosa

Profunda

Tromboembolismo Venoso

Trombose Venosa Profunda

Ultrassonografia

Valor Preditivo Negativo

Valor Preditivo Positivo

Vitro Immunofluorescent

Diagnosis Assay System 


\section{LISTA DE FIGURAS}

Figura 1 - Mecanismo de formação dos dímeros - D................................. 5

Figura 2 - Equipamento Mini VIDAS - BioMérieux.................................. 18 


\section{LISTA DE TABELAS}

Tabela 1 - Parâmetros antropométricos dos pacientes......................... 29

Tabela 2 - Parâmetros antropométricos dos pacientes com suspeita de

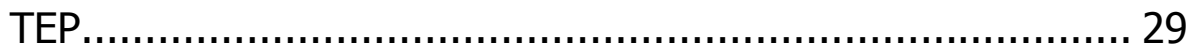

Tabela 3 - Parâmetros antropométricos dos pacientes com suspeita de

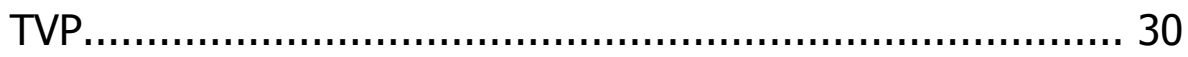

Tabela 4 - Parâmetros antropométricos dos pacientes com suspeita de TEP+TVP 30

Tabela 5 - Comparação das variáveis idade, estatura, peso e IMC entre os pacientes estudados, segregados pelo tipo de suspeita clínica 31

Tabela 6 - Medidas de tendência central e dispersão dos valores de característica dos pacientes sem e com evento tromboembólico agudo 34

Tabela 7 - Medidas de tendência central e dispersão dos valores de característica dos pacientes com suspeita de TEP sem e com evento tromboembólico agudo. 35

Tabela 8 - Medidas de tendência central e dispersão dos valores de característica dos pacientes com suspeita de TVP sem e com evento tromboembólico agudo 36 
Tabela 9 - Medidas de tendência central e dispersão dos valores de característica dos pacientes com suspeita de TEP+TVP sem e com evento tromboembólico agudo.

Tabela 10 - Valores de dímero - D como variável quantitativa segregado pelo tipo de suspeita clínica 40

Tabela 11 - Freqüência dos resultados do teste dímero - $\mathrm{D}$ e diagnósticos

Tabela 12 - Freqüência dos resultados do teste dímero - D e diagnósticos dos pacientes com suspeita de TEP 42

Tabela 13 - Freqüência dos resultados do teste dímero - D e diagnósticos dos pacientes com suspeita de TVP 43

Tabela 14 - Freqüência dos resultados do teste dímero - D e diagnósticos dos pacientes com suspeita de TEP+TVP 43

Tabela 15 - Análise qualitativa do dímero - D segregados por tipo de evento tromboembólico agudo

Tabela 16 - Freqüência da ocorrência de tromboembolismo venoso agudo, grupado pela faixa etária e tipo de evento agudo. 51

Tabela 17 - Medidas de tendência central e dispersão dos valores de características dos pacientes com ausência de evento agudo estratificados pela faixa etária 53

Tabela 18 - Medidas de tendência central e dispersão dos valores de características dos pacientes com presença de evento agudo estratificados pela faixa etária 54 
Tabela 19 - Medidas de tendência central e dispersão dos valores de características dos pacientes com até 40 anos. 55

Tabela 20 - Freqüência dos resultados do teste dímero - D e diagnósticos nos pacientes com até 40 anos 56

Tabela 21 - Medidas de tendência central e dispersão dos valores de características dos pacientes maiores de 40 anos e até 60 anos. 57

Tabela 22 - Freqüência dos resultados do teste dímero - D e diagnósticos nos pacientes maiores de 40 anos e até 60 anos 58

Tabela 23 - Medidas de tendência central e dispersão dos valores de características dos pacientes maiores de 60 anos. 59

Tabela 24 - Freqüência dos resultados do teste dímero - D e diagnósticos nos pacientes maiores de 60 anos 60

Tabela 25 - Análise da variável qualitativa do teste dímero - D $\left(\right.$ VIDAS $\left.^{\circledR}\right)$ em pacientes segregados pela faixa etária. 61

Tabela 26 - Freqüência da ocorrência de tromboembolismo venoso agudo, grupado pelo IMC e tipo de evento agudo. 66

Tabela 27 - Medidas de tendência central e dispersão dos valores de características dos pacientes com ausência de evento agudo, estratificados pelo IMC. 67

Tabela 28 - Medidas de tendência central e dispersão dos valores de características dos pacientes com presença de evento agudo, estratificados pelo IMC 
Tabela 29 - Medidas de tendência central e dispersão dos valores de características dos pacientes com Índice de Massa Corporal $\left(\right.$ IMC) $<30 \mathrm{~kg} / \mathrm{m}^{2}$ 68

Tabela 30 - Freqüência dos resultados do teste dímero - D e diagnósticos dos pacientes com Índice de Massa Corporal (IMC) $<30$ $\mathrm{kg} / \mathrm{m}^{2}$ 69

Tabela 31 - Medidas de tendência central e dispersão dos valores de características dos pacientes com Índice de Massa Corporal (IMC) $\geq 30 \mathrm{~kg} / \mathrm{m}^{2}$ 70

Tabela 32 - Freqüência dos resultados do teste dímero - D e diagnósticos dos pacientes com Índice de Massa Corporal (IMC) $\geq 30 \mathrm{~kg} / \mathrm{m}^{2}$ 71

Tabela 33 - Análise da variável qualitativa do teste dímero - D (VIDAS) nos pacientes segregados pelo Índice de Massa Corporal (IMC). 72

Tabela 34 - Freqüência da ocorrência de tromboembolismo venoso agudo, grupado pelo gênero e tipo de evento agudo. 77

Tabela 35 - Medidas de tendência central e dispersão dos valores de características dos pacientes com ausência de evento agudo segregado pelo gênero. 78

Tabela 36 - Medidas de tendência central e dispersão dos valores de características dos pacientes com presença de evento agudo segregado pelo gênero. 78 
Tabela 37 - Medidas de tendência central e dispersão dos valores de características dos pacientes do gênero feminino

Tabela 38 - Freqüência dos resultados do teste dímero - D e diagnósticos dos pacientes do gênero feminino 80

Tabela 39 - Medidas de tendência central e dispersão dos valores de características dos pacientes do gênero masculino 81

Tabela 40 - Freqüência dos resultados do teste dímero - D e diagnósticos dos pacientes do gênero masculino. 82

Tabela 41 - Análise da variável qualitativa do teste dímero - D (VIDAS) em pacientes segregados pelo gênero. 83

Tabela 42 - Freqüência dos exames por imagem realizados nos

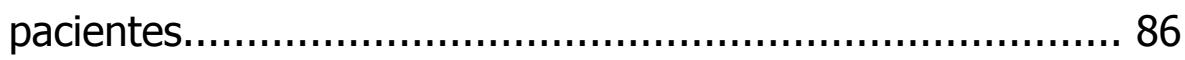




\section{LISTA DE GRÁFICOS}

Gráfico 1 - Curva "Receiver Operating Characteristic" - Curva ROC........ 45

Gráfico 2 - Probabilidade estimada de TEV com base nos valores de dímero - D plasmático. 46

Gráfico 3 - Curva "Receiver Operating Characteristic" - Curva ROC para os pacientes com suspeita de TEP

Gráfico 4 - Curva "Receiver Operating Characteristic" - Curva ROC para os pacientes com suspeita de TVP 48

Gráfico 5 - Curva "Receiver Operating Characteristic" - Curva ROC para os pacientes com suspeita de TVP+TEP.

Gráfico 6 - Curva "Receiver Operating Characteristic" - Curva ROC para os pacientes com menos de 40 anos

Gráfico 7 - Curva "Receiver Operating Characteristic" - Curva ROC para os pacientes na faixa etária entre 40 e 60 anos. 63

Gráfico 8 - Curva "Receiver Operating Characteristic" - Curva ROC para os pacientes com mais de 60 anos. 64

Gráfico 9 - Curva "Receiver Operating Characteristic" - Curva ROC para os pacientes com IMC menor do que $30 \mathrm{~kg} / \mathrm{m}^{2}$ 73

Gráfico 10 - Curva "Receiver Operating Characteristic" - Curva ROC para os pacientes com IMC $\geq 30 \mathrm{~kg} / \mathrm{m}^{2}$

Gráfico 11 - Curva "Receiver Operating Characteristic" - Curva ROC para as pacientes do gênero feminino 
Gráfico 12 - Curva "Receiver Operating Characteristic" - Curva ROC para os pacientes do gênero masculino.......................................... 85 
Resumo

$\longrightarrow$ 
De Piano LPA. Valor do teste de dosagem do dímero - D plasmático no diagnóstico do tromboembolismo venoso agudo [tese]. São Paulo: Faculdade de Medicina, Universidade de São Paulo; 2007. 130 p.

Introdução: A doença tromboembólica é um distúrbio complexo multicausal com sinais e sintomas inespecíficos, confundindo-se com outras enfermidades. Devido à sua gravidade buscam-se estratégias objetivando obter um diagnóstico precoce. $\mathrm{O}$ teste de dosagem do dímero - $\mathrm{D}$ plasmático parece ser uma alternativa para exclusão do diagnóstico de tromboembolismo venoso agudo. Objetivo: Avaliar o valor do teste de dosagem de dímero - D plasmático, utilizando o método Enzyme Linked Fluorescent Assay (ELFA), na rotina diagnóstica de tromboembolismo venoso agudo. Métodos: Em 89 pacientes com sinais e sintomas sugestivos de tromboembolismo pulmonar e/ou trombose venosa profunda foram realizadas dosagens do dímero - D pela técnica ELFA no equipamento VIDAS $^{\circledR}$ - BioMérieux. Foram calculados os valores da sensibilidade, especificidade, valores preditivos positivo e negativo e acurácia do teste, bem como a curva ROC da amostra estudada. Todos os pacientes foram submetidos a exame por imagem para confirmação do evento tromboembólico agudo. Foi calculado o índice kappa para analisar o resultado do teste dímero - $D$ versus resultados de exames por imagem. Resultados: Entre os 89 pacientes estudados (média de idade 54,3 anos; 51 mulheres), 36 (40,4\%) apresentaram TEV e 53 não apresentaram trombose aguda $(59,6 \%)$. Entre os pacientes sem trombose aguda 15 $(28,3 \%)$ apresentaram resultado de dímero - D negativo. Todos pacientes com trombose apresentaram resultado de dímero - $\mathrm{D}$ positivo. $\mathrm{O}$ teste apresentou sensibilidade de $100 \%$; especificidade de $28,3 \%$; valor preditivo positivo de $48,6 \%$; valor preditivo negativo de $100 \%$ e exatidão de $57,3 \%$. A ASC para a amostra total estudada foi igual a 0,734 , indicando que o teste é um bom preditor de trombose aguda. O valor do índice kappa para a amostra total foi igual a $0,24(p<0,001)$, indicando uma concordância fraca entre dímero - $\mathrm{D}$ e diagnóstico confirmatório de trombose. Conclusão: $\mathrm{A}$ dosagem do dímero - $D$ pelo método ELFA foi capaz de excluir o diagnóstico de tromboembolismo venoso agudo nessa amostra estudada. Os resultados obtidos nessa amostra estudada permitiram concluir que o uso do teste dímero - D em pacientes com suspeita de tromboembolismo venoso revelou alta sensibilidade no diagnóstico dessa enfermidade.

Descritores: 1. Testes de coagulação sangüínea 2. ELISA 3. Valor preditivo dos testes 4. Tromboembolismo/ diagnóstico 5. Embolia pulmonar/ diagnóstico 6. Trombose venosa/ diagnóstico. 
Abstract 
De Piano LPA. Value of measure plasmatic $D$ Dimer test to diagnosis of the acute thrombolism venous [thesis]. São Paulo: "Faculdade de Medicina, Universidade de São Paulo"; 2007. 130 p.

Introduction: The thromboembolic disease is a multicausal complex disturb with signals and symptoms that confusing itself with other diseases. Because its gravity strategies search objecting to get a faster diagnosis. The measure plasmatic $D$ dimer test seems to be an alternative for exclusion of the diagnostic of acute venous thromboembolism. Objectives: To evaluate the value of the measure plasmatic $D$ dimer test, using the method Enzyme Linked Fluorescent Assay (ELFA), in the diagnostic of acute venous thromboembolism. Methods: In 89 patients with signals and symptoms suggestive of pulmonary thromboembolism and/or deep vein thrombosis had been carried through measure $D$ dimer by technique ELFA equipment VIDAS $^{\circledR}$ - BioMérieux. The values of sensibility, accuracy specificity, predictive values positive and negative and of the test had been calculated, as well as curve ROC of the sample studied. All the patients had been submitted the image exams for the confirmation of the acute thromboembolism event. It was calculated kappa ratio to compare D dimer test results with image exams results. Results: Between 89 studied patients (mean of age 54.3 years; 51 women), $36(40.4 \%)$ they had presented and 53 had not presented acute thrombosis (59.6\%). It enters the patients without acute thromboembolism 15 (28.3\%) had presented resulted negative of $D$ dimer. All patients with thrombosis had presented resulted positive of $D$ dimer. The test presented $100 \%$ sensibility; $28.3 \%$ of specificity; positive predictive value was $48.6 \% ; 100 \%$ of negative predictive value and accuracy value was $57.3 \%$. The area under the curve (AUC) to total sample studied was 0.734 , it was showed that the test have a good prediction to acute thrombosis. The kappa ratio value was $0.24(p<0.001)$ showing a bad concordat $\mathrm{n}$ to thrombosis diagnostic. Conclusion: The measure of $\mathrm{D}$ dimer by method ELFA was able to exclude the diagnostic of acute venous thromboembolism in this sample studied. The results obtained in this sample studied let to conclude that the $\mathrm{D}$ dimer test in patients with suspected of acute thromboembolism presented high sensibility to diagnostic of this disease.

Key words: 1 . Blood coagulation tests 2. Enzyme - linked immunosorbent assay 3. Predictive value of tests 4. Thromboembolism/ diagnostic 5. Pulmonary embolism/ diagnostic 6 . Venous Thrombosis/ diagnostic. 
1 Introdução 
O tromboembolismo pulmonar (TEP) foi descrito pela primeira vez em 1819 por Laennec, que utilizou o termo "apoplexia pulmonar" descrevendo as alterações da doença. Entre 1830 e 1842 Cruveilhier descreveu a trombose periférica e a trombose central, mas não descreveu a ligação entre Trombose Venosa Profunda (TVP) e Tromboembolismo Pulmonar (TEP). Por volta de 1858 Virchow descreveu a TVP e sua relação com o TEP e também teorizou três importantes componentes dessa etiologia: estase sangüínea, lesão vascular e hipercoagulabilidade (1). O termo tromboembolismo foi utilizado por autores subseqüentes (2-6).

A TVP pode ocorrer de forma isolada com sintomas inespecíficos, ou associada de uma temível e potencialmente grave complicação: o TEP (711). A TVP é considerada a principal fonte de êmbolos para os pulmões e, ocorre principalmente por complicações das grandes veias dos membros inferiores acima dos joelhos (veias ilíacas, femoral e poplítea), com risco de TEP próximo a 45\% (3).

Dependendo das dimensões do êmbolo, um maior ou menor território do pulmão poderá ficar comprometido (12-14). Desta forma, um êmbolo grande tende a causar uma maior hipertensão pulmonar, ocasionando sobrecarga do ventrículo direito aliado a diferentes graus de insuficiência respiratória e, nos casos mais graves, determinar a morte do paciente $(3,13-$ 18). 
Os principais fatores de risco associados aos fenômenos tromboembólicos são as grandes cirurgias, o período pós-parto (estado de hipercoagulabilidade da gestante associado ao fator mecânico da descompressão da veia cava inferior pelo útero), insuficiência cardíaca congestiva, tabagismo, hipertensão, fraturas ósseas em membros inferiores, insuficiência venosa crônica dos membros inferiores, trauma, uso de anticoncepcional oral, terapêutica de reposição hormonal na mulher, câncer, quadros infecciosos disseminados e repouso ou imobilizações por tempo prolongado (11, 19-28). Destacam - se também deficiência de antirombina III, deficiência da proteína $C$, deficiência da proteína $S$, presença de fator $V$ de Leiden, presença de protrombina mutante, anticorpo antifosfolipíco e hipofibrinólise $(11,19,20)$.

Vários estudos relataram uma incidência de Tromboembolismo Venoso (TEV) próximo a 1/ 1.000 habitantes/ ano, ocorrendo um aumento na incidência de TEV nos pacientes mais idosos $(14,19,27)$. No Brasil, Rollo e cols. (7) estimaram uma prevalência de TEV de 0,6 casos/ 1.000 habitantes/ ano.

Todavia cifras menores que $35 \%$ dos pacientes que apresentam suspeita clínica, recebem o diagnóstico de TEV confirmado (7, 27). Assim, expressiva parte dos pacientes que foram submetidos a uma extensa investigação laboratorial e que, muitas vezes, receberam tratamento antitrombótico, não apresentava trombose aguda (29-31). Por outro lado, cerca de $50 \%$ dos pacientes, com trombose venosa profunda, em membros 
inferiores são assintomáticos e não demonstram alterações ao exame físico $(32,33)$.

O quadro clínico de trombose venosa aguda apresenta baixo valor preditivo positivo. Assim, na prática diária, os pacientes que comparecem a uma unidade de emergência com sinais e sintomas sugestivos de TEV, freqüentemente são submetidos a uma ampla investigação diagnóstica (3335). Esse quadro impõe um diagnóstico precoce e correto face à gravidade da condição.

Porém, situações imprevisíveis podem ocorrer, tais como: demora no diagnóstico e consequentemente no tratamento específico, permanência prolongada na unidade de emergência, tratamento antitrombótico e investigação diagnóstica desnecessários com conseqüente elevação dos custos hospitalares.

Em função disso, tem - se buscado estratégias diagnósticas de certeza visando corrigir essa falha, principalmente naqueles pacientes com quadro clínico sugestivo de TEV e que não apresentavam evento agudo.

Atualmente, vários estudos têm demonstrado que a dosagem do dímero - D plasmático (quantitativo e qualitativo), na rotina diagnóstica, pode contribuir com um diagnóstico de exclusão do TEV (36-41).

O dímero - D se comporta como marcador de ativação da coagulação e da fibrinólise secundária, ou seja, ele está invariável e precocemente aumentado sempre que houver formação de coágulo de fibrina intravascular $(8,39,42)$. Dessa forma, em conseqüência da lise do coágulo de fibrina, o 
dímero - D será uma das substâncias inicialmente presente nos eventos agudos de tromboembolismo. Figura 1.

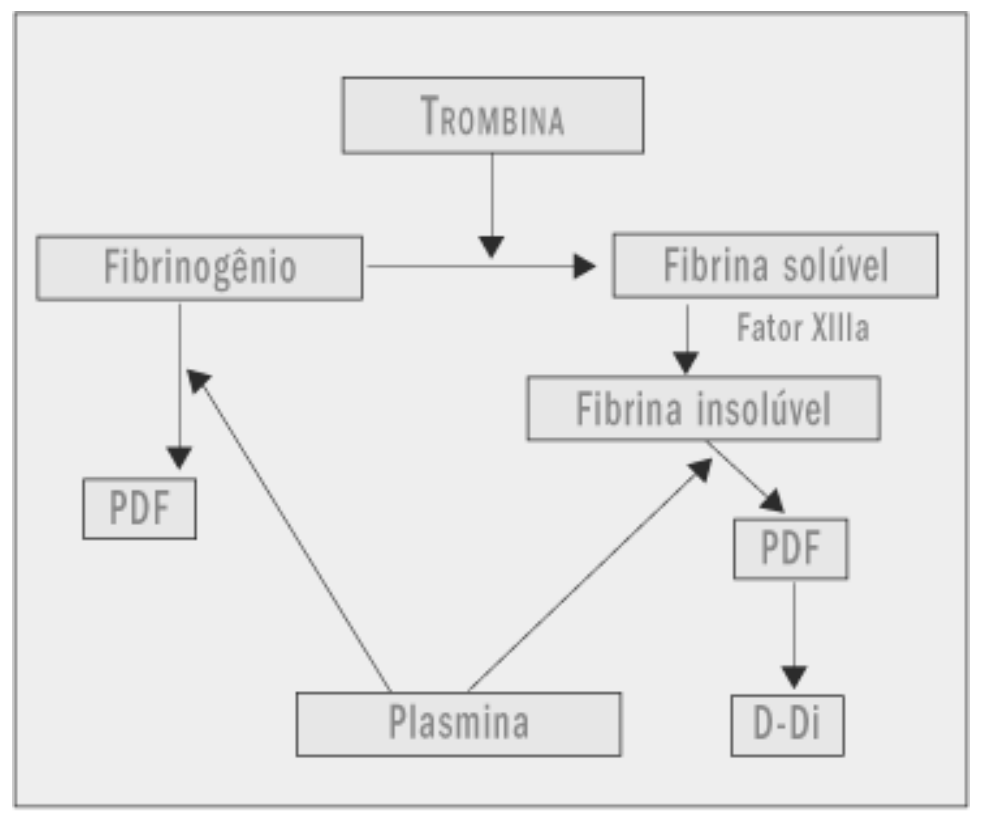

Figura 1 - Meconismo de formaçồo de dímeros $D$

A partir do conceito do mecanismo de aumento do dímero - $D$, entendemos que muitas outras situações, além da trombose aguda, podem elevar o seu nível sangüíneo, como por exemplo: indivíduos idosos, infecções graves, neoplasia e trauma (43-45). Sabe - se que o valor preditivo negativo do dímero - D é alto, ou seja, a elevação do nível plasmático do dímero - D não permite afirmar que houve TEV agudo, porém, o não aumento do seu nível permite afirmar que não houve formação de coágulo intravascular (5, $26,34)$.

Assim, objetivando utilizar um exame de realização rápida, com custo acessível e que permita excluir trombose aguda, foi proposto implantar o teste de dímero - D na primeira etapa da investigação laboratorial diagnóstica do tromboembolismo venoso. 
Para a implantação da dosagem do dímero - D na estratégia diagnóstica de TEV agudo, diferentes métodos laboratoriais foram estudados e assim, aqueles que se mostraram seguros para excluir o tromboembolismo venoso agudo puderam ser utilizados na prática clínica $(26,40$, 46-48).

Para cada tipo de método de dosagem de dímero - D avaliado estão disponíveis vários kits comerciais diferentes em diversos aspectos, incluindo: captura de anticorpos, amostras que requerem diluições, limitações nas detecções de anticorpos, tempo de incubação, custos, entre outros (49). Entre os métodos laboratoriais, destacamos o qualitativo látex, o quantitativo enzyme linked immunosorbent assay (ELISA) e os métodos derivados do ELISA: enzyme linked fluorescent assay (ELFA) como os mais completos (40, 50-52).

O método látex é pouco utilizado nos grandes centros devido a sua baixa sensibilidade $(78-87 \%)$ e baixo valor preditivo negativo (VPN) (84 91\%) quando comparado às técnicas enzimáticas (52). Por outro lado, o método ELISA é considerado o padrão - ouro para dosagem de dímero - D plasmático, bem como suas derivações: o método ELFA.

Diversos estudos demonstraram a similaridade entre o teste realizado pelo método ELFA (equipamento VIDAS ${ }^{\circledR}$ - Vitro Immunofluorescent Diagnosis Assay System) o ELISA clássico $(r=0,73)$. Esses trabalhos comprovaram também a superioridade do teste pelo equipamento VIDAS ${ }^{\circledR}$ (sensibilidade e VPN) em relação aos demais testes $(26,40,49,51)$. 
Em estudos recentes Perrier et al. (52), compararam, o método ELISA clássico (1337 pacientes) com o método ELFA pelo equipamento $\operatorname{VIDAS}^{\circledR}$ (785 pacientes) e observou valores de sensibilidade (95 a 99\% versus 96 a $100 \%$, respectivamente), especificidade (32 a 38\% versus 36 a 49\%, respectivamente) e VPN (93 a 99\% versus 95 a 100\%, respectivamente) muito próximos entre eles. As demais metodologias comparadas nesse estudo, obtiveram valores abaixo daqueles encontrados para o ELISA clássico e para o ELFA $\left(\operatorname{VIDAS}^{\circledR}\right)$.

Em outro estudo comparativo entre 13 tipos de dosagens de dímero - D com diferentes técnicas e fabricantes, somente com 0 teste pelo equipamento $\operatorname{VIDAS}^{\circledR}$ foram observados sensibilidade e VPN de $100 \%$ para os pacientes com TVP proximal, além de um coeficiente kappa $>0,5$, tendo uma boa reprodutibilidade $(27,28,53)$.

Além disso, Freyburger et al. (40) compararam 8 métodos (padrão ouro) e observaram que apenas o dímero - D pelo equipamento $\operatorname{VIDAS}^{\circledR}$ apresentou sensibilidade de $100 \%$, relatando a importância do teste nas circunstâncias emergenciais.

Devido à similaridade entre os métodos ELFA e ELISA, alguns estudos comparativos entre os diversos equipamentos destinados à dosagem plasmática do dímero - D, vêm utilizando o equipamento VIDAS ${ }^{\circledR} \operatorname{como}$ referência, considerando - o como padrão - ouro para essa dosagem (29, $40,52)$. 
Assim, pelos valores de sensibilidade e VPN e por possuir acurácia próxima de $60 \%$ e também pela redução de custos, quando comparado com o método ELISA clássico, o método ELFA pelo equipamento VIDAS ${ }^{\circledR}$ poderia ser utilizado como exame auxiliar numa primeira abordagem da investigação diagnóstica nos pacientes com sinais e sintomas sugestivos de TEV $(40,54$, $55)$. 
2 Objetivo 
Avaliar a eficácia do teste de dosagem de dímero - D plasmático, utilizando o método Enzyme Linked Fluorescent Assay (ELFA), na rotina diagnóstica de tromboembolismo venoso agudo. 
3 Metodologia 


\subsection{Aprovação do Protocolo}

Este protocolo de estudo foi avaliado e aprovado pelas Comissões Científica e de Ética das Instituições envolvidas - Instituto do Coração (InCor - HC FMUSP) e Hospital das Clínicas da Faculdade de Medicina da Universidade de São Paulo (HC FMUSP), conforme documento de aprovação emitido pelas Instituições ( ANEXO A e B, páginas 99 e 100, respectivamente).

\subsection{Delineamento do estudo}

No período de 01 de dezembro de 2001 a 30 de setembro de 2002 foram selecionados prospectivamente e de forma seqüencial, pacientes que compareceram aos setores de emergência do Instituto do Coração (InCor) e do Instituto Central (IC) do Hospital das Clínicas da Faculdade de Medicina da Universidade de São Paulo (HC FMUSP) com sinais e sintomas sugestivos de tromboembolismo venoso agudo, TEP e/ou TVP. 
Para maior adesão ao estudo, foram realizadas reuniões de iniciação com as unidades de emergência envolvidas no estudo: InCor e IC HC. Cartazes foram afixados com intenção de alertar e lembrar os profissionais das referidas unidades assistenciais, sobre o protocolo de estudo, fornecendo diretrizes sobre o contato com a equipe do protocolo.

As unidades de emergência InCor e IC HC foram orientadas a contatar os profissionais ligados a este protocolo (médico ou biomédico pertencentes ao serviço de hematologia do InCor) imediatamente após a identificação de pacientes com os sinais e sintomas descritos nos critérios de inclusão. Além disto, os investigadores deste protocolo realizaram, diariamente, no mínimo três visitas, nos períodos da manhã e tarde, nos respectivos setores.

\subsection{Critérios de inclusão}

Foram incluídos os pacientes que concordaram em participar do estudo e assinaram o termo de consentimento pós - informação (ANEXO C, página 101)

Para admissão nesse estudo, os pacientes deveriam apresentar sinais e sintomas sugestivos de TEP ou TVP, segundo estabelecidos neste protocolo: 
- Para TEP: dor torácica não relacionada a esforços e/ou dispnéia ou piora do padrão respiratório, na ausência de antecedentes pessoais de asma brônquica.

- Para TVP: dor constante na perna com piora à deambulação e/ou edema unilateral no membro inferior e/ou hiperemia unilateral no membro inferior.

\subsection{Critérios para não inclusão e para exclusão}

Não foram incluídos no estudo os pacientes que se encontravam nas seguintes condições: uso de heparina antes da coleta da amostra de sangue para a realização da dosagem plasmática do dímero - $\mathrm{D}$ e/ou antecedentes de asma brônquica e/ou impossibilidade de retorno para avaliação de 30 e 60 dias após a alta hospitalar.

Além disso, foram excluídos da análise, os pacientes não submetidos a exames por imagem confirmatórios para TEP e TVP mesmo que submetidos a exames de sangue iniciais. 


\subsection{Condução do estudo}

Os pacientes foram submetidos a um questionário (ANEXO D, página 106) aplicado por um profissional ligado ao estudo, que continha as seguintes informações: dados demográficos, dados clínicos relacionados a TEP e/ ou TVP, fatores de risco e antecedentes pessoais e/ou familiares para TEV.

Foram também registradas data e hora da admissão no setor de emergência, peso $(\mathrm{kg})$ e estatura $(\mathrm{m})$ para obtenção do índice de massa corporal (IMC em $\mathrm{kg} / \mathrm{m}^{2}$ ), data e horário da alta hospitalar.

Nesse mesmo anexo foram também obtidas informações referentes à internação do paciente: medicamentos utilizados durante a internação, número de exames e procedimentos realizados, pesquisador responsável pela coleta de dados e diagnóstico conclusivo da unidade que assistiu o paciente referente à presença ou ausência de evento tromboembólico, informado pelo médico assistente.

Esses pacientes foram acompanhados durante toda a permanência intra - hospitalar por um profissional pertencente ao protocolo. Além disso, as informações adicionais contidas no questionário foram também obtidas pelo 
paciente e/ou acompanhante, e se necessário, complementadas com o médico assistente da unidade e/ou prontuário do paciente.

\subsection{Coleta de amostra de sangue para realização da dosagem do dímero - D pelo método ELFA/ equipamento VIDAS ${ }^{\circledR}$.}

Independentemente dos exames coletados na rotina do atendimento, os pacientes foram submetidos a uma coleta adicional de sangue para a realização da dosagem plasmática do dímero - D.

Os tubos foram identificados previamente à coleta com etiqueta contendo nome do paciente, hora e data da coleta. Foram colhidos $9 \mathrm{ml}$ de sangue obtidos através de punção venosa ou por catéter segundo as normas estabelecidas pela Seção de Coleta do InCor (APÊNDICE A, página 132).

As coletas foram realizadas pela equipe de enfermagem da unidade ou por profissional ligado ao protocolo. O sangue coletado foi, imediatamente, transferido para dois tubos contendo anticoagulante citrato de sódio 3,8 g\%, a uma proporção de 9 partes de sangue para 1 de anticoagulante (proporção 1:10) em cada tubo. Os tubos foram invertidos, suavemente, para homogeneização.

Em seguida, as amostras foram centrifugadas em centrífuga da marca Excelsa modelo Baby por 15 minutos a uma velocidade de 3.000 rotações 
por minuto (rpm) para se obter plasma pobre em plaquetas (PPP). Uma amostra desse material foi utilizada para a dosagem do dímero - D plasmático. Quando a dosagem foi realizada, após 24 horas da coleta do sangue, o plasma foi conservado em geladeira a uma temperatura de $2^{\circ}$ a $8^{\circ} \mathrm{C}$, conforme orientação do fabricante (56). Amostras adicionais (segunda amostra) foram aliquotadas e mantidas à temperatura de $-35^{\circ} \mathrm{C}$ pelo período de 12 meses para eventual repetição.

A presença de hemólise, lipemia, bilirrubinemia e fator reumatóide não influenciam o doseamento do dímero - $D$ de forma significativa no doseamento do dímero - $\mathrm{D}$ pelo método ELFA.

\subsection{Realização da dosagem do dímero - D plasmático}

As dosagens do dímero - D, para este protocolo, foram efetuadas no laboratório de Análises Clínicas do InCor HC FMUSP pelo equipamento da marca BioMérieux, modelo VIDAS $^{\circledR}$ D - Dimer New (figura 2). 0 teste consiste em um ensaio por Enzyme Linked Fluorescent Assay (ELFA) totalmente automatizado com detecção por fluorescência, realizado no imunoanalisador.

A fluorescência emitida é resultado de uma série de reações e é proporcional à quantidade de antígenos presentes na amostra. 
A empresa BioMérieux forneceu, sem ônus para a Instituição, o equipamento VIDAS $^{\circledR}$ e todos os kits reagentes utilizados neste protocolo de estudo.

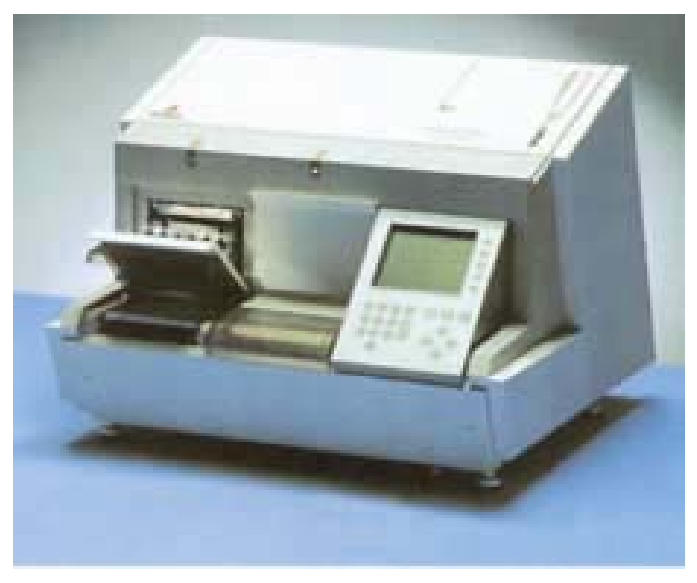

Figura 2 - Equipamento Mini VIDAS ${ }^{\circledR}-$ BioMérieux

\subsubsection{Princípio do método}

O princípio do doseamento associa o método imunoenzimático tipo sanduíche em 2 etapas com uma detecção final em fluorescência.

Um cone apropriado para a fase sólida apresenta o anticorpo anti dímero - D adsorvido na sua superfície e é utilizado também como de suporte de pipetagem. Os outros reagentes encontram - se prontos para o uso e pré - repartidos na barrete/ tira. Todas as etapas de reações foram realizadas automaticamente no aparelho, pois o método é constituído por uma sucessão de ciclos de aspiração e dispensação do meio reacional. 
Em uma primeira etapa, a amostra é colhida e transferida para o poço que contém o anticorpo anti - dímero - D marcado com fosfatase alcalina. A mistura amostra/ conjugado é aspirada e dispensada várias vezes no cone para aumentar a velocidade de reação. Esta operação permite ao antígeno ligar - se por um lado, às imunoglobulinas fixadas no cone, e por outro, ao conjugado, formando assim um sanduíche.

Na segunda etapa, dá - se a saturação dos locais do antígeno que ficaram livres efetuadas por meio da aspiração e dispensação do conjugado. As etapas de lavagem eliminam os componentes não fixados.

Em seguida são efetuadas duas etapas de revelação sucessivas. Em cada etapa, o substrato (4 - Metil - umbeliferil fosfato) é aspirado e dispensado no cone. A enzima do conjugado catalisa a reação de hidrólise deste substrato num produto (4 - Metil - umbeliferona) cuja fluorescência emitida é medida a $450 \mathrm{~nm}$. Esta é proporcional à concentração de antígeno presente na amostra.

Terminado o teste, os resultados são calculados automaticamente pelo equipamento $\operatorname{VIDAS}^{\circledR}$ em relação a duas curvas de calibração memorizadas correspondentes às duas etapas de revelação. Um sinal limiar gera a escolha da curva de calibração utilizada para cada amostra. Em seguida, os resultados são impressos.

Os procedimentos de calibração e controles de qualidade, inclusos nas embalagens dos kits, são realizados de acordo com a recomendação do fabricante (56). 
Os dados são calculados automaticamente pelo sistema informático em relação às curvas de calibração memorizadas e impressas. As concentrações de dímero - D serão expressas em ng/ ml.

As amostras superiores a $10.000 \mathrm{ng} / \mathrm{ml}$ devem ser novamente dosadas a $1 / 5$ no diluente da embalagem e, os resultados, multiplicados pelo fator de diluição para obter a concentração da amostra.

Os profissionais que assistem os pacientes não terão acesso aos dados do nível plasmático do dímero - D. Esse acesso ficará restrito aos profissionais ligados ao protocolo. Desta forma, os resultados, ainda em estudo, não influenciarão a equipe que assiste o paciente, mantendo assim, a rotina das Instituições.

\subsubsection{Comportamento funcional}

O limite de detecção do teste, definido como sendo a menor concentração em dímero - D significativamente diferente da concentração zero com um risco a de $5 \%$ é de $\leq 45 \mathrm{ng} / \mathrm{ml}(56)$.

O coeficiente de variação observado para uma faixa de concentração de 264 a 7283 foi de $57 \%$ a $71 \%(56)$. 


\subsubsection{Valores esperados}

O fabricante recomenda que cada laboratório estabeleça os seus próprios valores de referência sobre uma população rigorosamente selecionada. Por outro lado, amostras de 200 unidades de plasma originário de doadores voluntários foram testadas pelo fabricante, onde encontrou $96 \%$ dos valores com índices inferiores a $500 \mathrm{ng} / \mathrm{ml}$ e que foram considerados normais (56). Esses dados serão considerados em nosso estudo.

\subsection{Exames por imagem}

Somente foram incluídos para análise dos dados, os pacientes submetidos à pelo menos um exame por imagem, considerado adequado para confirmação de presença ou ausência do diagnóstico de tromboembolismo venoso agudo.

Os exames por imagem considerados adequados para a confirmação de presença ou ausência de TEP aguda foram: tomografia computadorizada de 
tórax e/ ou tomografia computadorizada de alta resolução de tórax e/ ou tomografia computadorizada de abdômen superior e/ ou cintilografia pulmonar inalação perfusão e/ ou arteriografia pulmonar.

Os exames por imagem considerados adequados para a confirmação de presença ou ausência de TVP aguda foram: ultra-sonografia vascular venosa com Doppler e/ ou flebografia.

\subsection{Contato pós - alta hospitalar}

Os pacientes foram contatados 30 e 60 dias após alta hospitalar. 0 contato pós - alta hospitalar objetivou pesquisar se o paciente com resultado de dímero - $\mathrm{D}$ negativo teve um fenômeno tromboembólico agudo após sua alta. Todos os pacientes que não apresentaram tromboembolismo venoso agudo foram contatados, mesmo aqueles que apresentaram o valor do dímero - $\mathrm{D}$ positivo.

Durante esse contato, o profissional ligado ao estudo solicitou informações sobre a evolução clinica. (ANEXO E, página 108): 


\subsection{Tratamento Estatístico}

Foi criado um banco de dados no programa Excel (Microsoft). Os dados foram analisados de uma maneira geral e também estratificando os pacientes segundo a presença e ausência de evento agudo e segundo as variáveis: dímero - D, faixa etária, IMC e gênero.

A estratificação da faixa etária foi definida conforme a intensidade do risco trombótico, sendo considerado: até 40 anos - baixo risco; mais de 40 e até 60 anos - médio risco; mais de 60 anos - alto risco (57).

A estratificação do IMC foi definida conforme recomendação da Associação Brasileira para o Estudo da Obesidade e da Síndrome Metabólica (ABESO).

O IMC foi estratificado, nesse estudo, em não obesos (IMC $<30 \mathrm{~kg} /$ $\mathrm{m}^{2}$ ) e obesos (IMC $\left.\geq 30 \mathrm{~kg} / \mathrm{m}^{2}\right)$.

Inicialmente todas as variáveis foram analisadas descritivamente. Para as variáveis quantitativas, esta análise foi feita através da observação dos valores mínimos e máximos e do cálculo de médias, desvios - padrão e medianas. Para as variáveis qualitativas foram calculadas as freqüências absolutas e relativas. 
Além disso, foi calculada a sensibilidade definida como a proporção de pessoas com a doença de interesse que tem o resultado do teste positivo. A sensibilidade indica quão bom é o teste para identificar os indivíduos doentes, da seguinte maneira:

Verdadeiro Positivo (VP)

Verdadeiro Positivo (VP) + Falso Negativo (FN)

A especificidade é a proporção de pessoas sem a doença que tem o teste negativo. Ela indica quão bom é o teste para identificar os indivíduos não doentes, segundo a equação:

Verdadeiro Negativo (VN)

Verdadeiro Negativo (VN) + Falso Positivo (FP)

Além disso, valor preditivo negativo, que é a proporção de pessoas com resultado do teste negativo que não tem a doença, indica a segurança do teste de se excluir o diagnóstico da doença, segundo a equação:

$$
\frac{V N}{V N+F N}
$$


Enquanto que o valor preditivo positivo é a proporção de pessoas com resultado do teste positivo que tem a doença. Indica a segurança do teste em se diagnosticar a presença da doença, visto na equação:

$$
\frac{V P}{V P+F P}
$$

Por fim, a acurácia é a freqüência de exames com resultado concordante com o diagnóstico confirmado por um exames padrão - ouro:

$$
V P+V N
$$

$\overline{\text { Total de pacientes estudados }}$

Para testar a homogeneidade entre proporções de grupos foi utilizado o teste qui - quadrado ou o teste exato de Fisher.

O qui - quadrado é um teste que tem como princípio básico comparar proporções, isto é, as possíveis divergências entre as freqüências observadas e esperadas para certo evento. Pode-se dizer que dois grupos se comportam de forma semelhante se as diferenças entre as freqüências observadas e as esperadas, em cada categoria, forem muito pequenas, próximas a zero (58).

O teste exato de Fisher permite calcular a probabilidade de associação das características que estão em análise, ou seja, a probabilidade de tais características serem independentes, quando o número total de dados é 
pequeno. Assim, em amostras pequenas deve-se executar esse teste, pois produz erro menor que o teste de qui - quadrado (58).

Para a obtenção de um ponto de corte para o dímero - D relacionado à presença ou não de trombose, foi utilizada a "Receive Operator Characteristic Curve"(curva ROC) $(59,60)$.

A curva ROC é a melhor maneira de estabelecer o ponto de corte, otimizando a sensibilidade e especificidade do teste diagnóstico. Para construção das curvas ROC's foram calculados os valores de sensibilidade e especificidade (regressão logística) em cada ponto de dosagem do dímero D plasmático da população estudada, observando assim o nível de corte ideal, ou seja, aonde se obtém uma melhor sensibilidade e especificidade.

Para se avaliar a concordância entre duas abordagens diagnósticas (exames por imagem vs dímero - D), foi utilizado o índice de concordância Kappa (59). Também, o índice Kappa é um teste que mede a diferença interobservador e que varia de 0 a 1 sendo que:

Kappa $\leq 0,45=$ reprodutibilidade marginal, 0,45 $<$ Kappa $<0,75=$ boa reprodutibilidade e, Kappa $\geq 0,75=$ ótima reprodutibilidade O nível de significância utilizado para os testes foi de $5 \%$. 
4 Resultados 
Primeiramente, todos os pacientes foram submetidos à análise dos dados, independente da suspeita clínica. Posteriormente, esses pacientes foram segregados de acordo com a hipótese diagnóstica: TEP, TVP e TEP + TVP.

Em uma terceira análise, os pacientes foram segregados pela faixa etária, IMC e gênero.

\subsection{Caracterização dos Pacientes}

De 131 pacientes selecionados com suspeita diagnóstica de TEV, oitenta e nove deles (68\%) preenchiam os critérios de inclusão, enquanto que 42 (32\%) pacientes apresentavam critérios de exclusão, não sendo, portanto acompanhados no estudo.

Os 89 pacientes incluídos nessa amostra, com sinais e sintomas sugestivos de TEV, 51 (57,3\%) eram do gênero feminino e $38(42,7 \%)$ do gênero masculino. Nessa amostra, trinta e seis pacientes (40,4\%) apresentaram trombose aguda.

Os pacientes estudados estão relacionados no APÊNDICE B (página 135). 
As características dos pacientes estudados quanto aos valores antropométricos estão descritas na tabela $\mathbf{1}$

Tabela 1 - Parâmetros antropométricos dos pacientes.

\begin{tabular}{lccccc}
\hline Variável & Média & Desvio Padrão & Mediana & Mínimo & Máximo \\
\hline Idade (anos) & 54,3 & 19,2 & 55 & 13 & 95 \\
Estatura $(\mathrm{cm})$ & 164,3 & 8,6 & 162 & 148 & 187 \\
Peso $(\mathrm{kg})$ & 68,5 & 17,9 & 64 & 33 & 130 \\
IMC $\left(\mathrm{kg} / \mathrm{m}^{2}\right)$ & 25,4 & 6,3 & 23,7 & 15,1 & 45,5 \\
\hline
\end{tabular}

Legenda: IMC $=$ índice de massa corporal

Os três grupos formados de acordo com a suspeita clínica eram constituídos por: 43 pacientes com TEP (48,3\%), 31 com TVP (34,8\%) e 15 com TEP + TVP (16,9\%)

As características antropométricas dos pacientes de cada grupo encontram-se descritas nas tabelas 2, 3 e 4, respectivamente.

Tabela 2 - Parâmetros antropométricos dos pacientes com suspeita de TEP.

\begin{tabular}{lccccc}
\hline Variável & Média & Desvio Padrão & Mediana & Mínimo & Máximo \\
\hline Idade (anos) & 54,9 & 19,5 & 55 & 13 & 95 \\
Estatura $(\mathrm{cm})$ & 164,5 & 10 & 162 & 148 & 187 \\
Peso $(\mathrm{kg})$ & 66,4 & 19,4 & 63 & 33 & 118 \\
IMC $\left(\mathrm{kg} / \mathrm{m}^{2}\right)$ & 24,4 & 6,6 & 22,2 & 15,1 & 45,5 \\
\hline
\end{tabular}


Tabela 3 - Parâmetros antropométricos dos pacientes com suspeita de TVP.

\begin{tabular}{lccccc}
\hline Variável & Média & Desvio Padrão & Mediana & Mínimo & Máximo \\
\hline Idade $($ anos $)$ & 50 & 18,6 & 51 & 20 & 81 \\
Estatura $(\mathrm{cm})$ & 164,5 & 7 & 162 & 151 & 177 \\
Peso $(\mathrm{kg})$ & 70,3 & 16 & 67 & 52 & 130 \\
$\mathrm{IMC}\left(\mathrm{kg} / \mathrm{m}^{2}\right)$ & 26 & 5 & 25,4 & 18,2 & 45 \\
\hline \multicolumn{1}{c}{ Legenda: $\mathrm{IMC}=$ índice de massa corporal } & & & &
\end{tabular}

Tabela 4 - Parâmetros antropométricos dos pacientes com suspeita de TEP + TVP.

\begin{tabular}{lccccc}
\hline Variável & Média & Desvio Padrão & Mediana & Mínimo & Máximo \\
\hline Idade $($ anos $)$ & 61,6 & 17 & 69 & 20 & 80 \\
Estatura $(\mathrm{cm})$ & 163,1 & 7 & 160 & 150 & 180 \\
Peso $(\mathrm{kg})$ & 71,1 & 17,4 & 74 & 44 & 100 \\
IMC $\left(\mathrm{kg} / \mathrm{m}^{2}\right)$ & 26,7 & 6,8 & 24,1 & 17,2 & 39,3 \\
\hline
\end{tabular}


A tabela 5 apresenta a comparação dos dados antropométricos entre os pacientes selecionados de acordo com a suspeita clínica.

Os pacientes com suspeita de TVP apresentaram idades significativamente menores do que os pacientes com suspeita de TEP+TVP $(p=0,047)$.

Tabela 5 - Comparação das variáveis idade, estatura, peso e IMC entre os pacientes estudados, segregados pelo tipo de suspeita clínica.

\begin{tabular}{lccc}
\hline & \multicolumn{3}{c}{ Suspeita clínica } \\
Variável & $\mathrm{p}$ TEP $\times$ TVP & $\mathrm{p}$ TEP $\times$ TEP+TVP & $\mathrm{p}$ TVP $\times$ TEP+TVP \\
\hline Idade $(\mathrm{anos})$ & 0,285 & 0,240 & $\mathbf{0 , 0 4 7}$ \\
Estatura $(\mathrm{cm})$ & 0,989 & 0,608 & 0,532 \\
Peso $(\mathrm{kg})$ & 0,360 & 0,412 & 0,881 \\
IMC $\left(\mathrm{kg} / \mathrm{m}^{2}\right)$ & 0,291 & 0,256 & 0,705 \\
\hline
\end{tabular}


Nos APÊndices C, D, E e F (páginas 138, 139, 140 e 141, respectivamente) estão apresentadas as freqüências de presença de sinais e sintomas nos pacientes estudados e estratificados por TEP, TVP e TEP+TVP respectivamente.

Com relação aos fatores de risco, segundo o teste exato de Fisher, há associação entre o dímero - $D$ e antecedentes pessoais de trombose ( $p=$ $0,007)$, anticoagulação oral $(p=0,014)$ e quadro de tromboembolismo venoso agudo $(p=0,007)$.

No APÊNDICE G (página 142) estão apresentadas as freqüências dos antecedentes de trombose pessoal e familiar.

A utilização de medicamentos rotineiramente antes da internação, freqüência de hipertensão arterial sistêmica HAS, de tabagismo, de sedentarismo e de presença de trombofilia, segregado pelo tipo de suspeita clínica e ausência e presença de trombose aguda estão apresentados nos APÊNDICES H, I, J, K e L ,(página 143), respectivamente.

As freqüências dos fatores de risco não relacionados com o quadro atual, doenças crônicas, utilização de medicamentos durante a internação e quantidade de dias de internação estão relacionados nos APÊNDICES M (página 144), N (página 145), 0 (página 146) e Q (página 148), respectivamente.

A análise estatística dos medicamentos utilizados durante a internação e dos dias de internação estão apresentados nos APÊNDICES P (página 147) e $\mathbf{R}$ (página 149), respectivamente. 


\subsection{Confirmação/ Exclusão de Evento Tromboembólico Agudo}

Quarenta e três (48,3\%) pacientes apresentaram suspeita de TEP, sendo 17 (39,5\%) confirmados. Trinta e um (34,8\%) pacientes apresentaram suspeita de TVP, sendo 12 (38,7\%) confirmados. Quinze (16,9\%) pacientes apresentaram suspeita de TEP + TVP, sendo $7(46,7 \%)$ confirmados.

A tabela 6 descreve os valores de média, desvio - padrão, mediana, mínimo e máximo (medidas de tendência central e dispersão) das características dos pacientes, estratificados pela presença e ausência de evento tromboembólico agudo. 
Tabela 6 - Medidas de tendência central e dispersão dos valores de característica dos pacientes sem e com evento tromboembólico agudo.

\begin{tabular}{lccc}
\hline \multicolumn{4}{c}{ Evento Agudo } \\
\\
\hline $\mathrm{N}(\%)$ & $53(59,6 \%)$ & Presença & $\mathrm{p}$ \\
Estatura $(\mathrm{cm})$ & $164 \pm 8 ; 161(150-186)$ & $164,7 \pm 9 ; 160,4 \%)$ & - \\
Peso $(\mathrm{kg})$ & $67 \pm 16,6 ; 62(44-118)$ & $70,8 \pm 19,6 ; 66(33-130)$ & 0,714 \\
$\mathrm{IMC}\left(\mathrm{kg} / \mathrm{m}^{2}\right)$ & $24,8 \pm 6 ; 22,1(15,6-42,2)$ & $26,1 \pm 7 ; 25(15,1-45,5)$ & 0,319 \\
Idade $($ anos $)$ & $56,1 \pm 19,8 ; 55(20-95)$ & $51,6 \pm 17,8 ; 51(13-80)$ & 0,279 \\
\hline Legenda: IMC= índice de massa corporal & &
\end{tabular}


A tabela 7 descreve os valores de média, desvio - padrão, mediana, mínimo e máximo (medidas de tendência central e dispersão) das características dos pacientes com suspeita de TEP, estratificados pela presença e ausência de evento tromboembólico agudo.

Os pacientes sem TEP apresentaram idade significativamente maior do que os pacientes com TEP $(p=0,021)$.

Tabela 7 - Medidas de tendência central e dispersão dos valores de característica dos pacientes com suspeita de TEP sem e com evento tromboembólico agudo.

\begin{tabular}{lccc}
\hline \multicolumn{4}{c}{ Tromboembolismo Pulmonar } \\
& Ausência & Presença & p \\
\hline $\mathrm{N}(\%)$ & $26(60,5 \%)$ & $17(39,5 \%)$ & -- \\
Estatura $(\mathrm{cm})$ & $164 \pm 11 ; 161(150-186)$ & $166,6 \pm 10 ; 167(148-187)$ & 0,455 \\
Peso $(\mathrm{kg})$ & $67,9 \pm 2160,5(45-118)$ & $67,8 \pm 19,7 ; 64(33-115)$ & 0,989 \\
$\mathrm{IMC}\left(\mathrm{kg} / \mathrm{m}^{2}\right)$ & $25,4 \pm 7 ; 22,8(15,6-42,2)$ & $24,4 \pm 7 ; 22,8(15,1-45,5)$ & 0,674 \\
Idade (anos) & $60,4 \pm 19,5 ; 61(29-95)$ & $46,5 \pm 16,9 ; 47(13-78)$ & $\mathbf{0 , 0 2 1}$ \\
\hline Legenda: IMC= índice de massa corporal & &
\end{tabular}


A tabela 8 descreve os valores de média, desvio - padrão, mediana, mínimo e máximo (medidas de tendência central e dispersão) das características dos pacientes com suspeita de TVP, estratificados pela presença e ausência de evento tromboembólico agudo.

Tabela 8 - Medidas de tendência central e dispersão dos valores de característica dos pacientes com suspeita de TVP sem e com evento tromboembólico agudo.

\begin{tabular}{lccc}
\hline \multicolumn{4}{c}{ Trombose Venosa Profunda } \\
& Ausência & Presença & $\mathrm{p}$ \\
\hline $\mathrm{N}(\%)$ & $19(61,3 \%)$ & $12(38,7 \%)$ & -- \\
Estatura $(\mathrm{cm})$ & $165,2 \pm 7 ; 162(154-177)$ & $163,2 \pm 7 ; 161,5(151-176)$ & 0,521 \\
Peso $(\mathrm{kg})$ & $67,3 \pm 12,6 ; 62(52-96)$ & $75 \pm 20 ; 70,5(55-130)$ & 0,198 \\
IMC $\left(\mathrm{kg} / \mathrm{m}^{2}\right)$ & $24,7 \pm 5 ; 23,9(18,2-35,7)$ & $28,1 \pm 7 ; 27,5(19,4-45)$ & 0,112 \\
Idade (anos) & $49,1 \pm 19,2 ; 50(20-81)$ & $51,4 \pm 18,2 ; 55,5(25-79)$ & 0,742 \\
\hline
\end{tabular}

Legenda: IMC $=$ índice de massa corporal 
A tabela 9 descreve os valores de média, desvio - padrão, mediana, mínimo e máximo (medidas de tendência central e dispersão) das características dos pacientes com suspeita de TEP + TVP, estratificados pela presença e ausência de evento tromboembólico agudo.

Não houve diferença significativa em nenhum dos parâmetros analisados nesse grupo.

Tabela 9 - Medidas de tendência central e dispersão dos valores de característica dos pacientes com suspeita de TEP + TVP sem e com evento tromboembólico agudo.

\begin{tabular}{lccc}
\hline \multicolumn{4}{c}{ Tromboembolismo Pulmonar associado à } \\
Trombose Venosa Profunda & Presença & $\mathrm{p}$ \\
\hline $\mathrm{N}(\%)$ & $8(53,3 \%)$ & $7(46,7 \%)$ & -- \\
Estatura $(\mathrm{cm})$ & $163 \pm 5 ; 162,5(158-172)$ & $163 \pm 9 ; 160(150-180)$ & 0,974 \\
Peso $(\mathrm{kg})$ & $69,5 \pm 15 ; 73,5(44-84)$ & $72,8 \pm 21 ; 74(45-100)$ & 0,724 \\
$\mathrm{IMC}\left(\mathrm{kg} / \mathrm{m}^{2}\right)$ & $26,1 \pm 5 ; 26(17,2-33,6)$ & $27,5 \pm 8 ; 24,1(20-39,3)$ & 0,700 \\
$\mathrm{Idade}(\mathrm{anos})$ & $59 \pm 20 ; 64(20-77)$ & $64,6 \pm 13,8 ; 69(43-80)$ & 0,546 \\
\hline Legenda: $\mathrm{IMC}=$ índice de massa corporal & &
\end{tabular}




\subsection{Comparação do Dímero - D Plasmático e Trombose}

Entre os 53 pacientes sem trombose aguda, apenas $15(28,3 \%)$ apresentaram níveis plasmáticos de dímero - D abaixo de $500 \mathrm{ng} / \mathrm{ml}$ (negativo) e 38 (71,7\%) apresentaram concentrações de dímero - D acima de $500 \mathrm{ng} / \mathrm{ml}$.

Por outro lado, todos os $36(100 \%)$ pacientes com trombose aguda confirmada, apresentaram níveis plasmáticos de dímero - D acima de 500 $\mathrm{ng} / \mathrm{ml}$ (positivo).

Analisando-se esta concordância pelo índice kappa observamos um valor igual a $0,24(p<0,001)$ a partir do qual concluímos que há uma concordância fraca entre dímero - D e trombose.

A mesma análise foi realizada levando - se em conta os 3 grupos de pacientes divididos de acordo com a suspeita clínica:

- Suspeitas de TEP: 17 casos apresentaram confirmação do diagnóstico de trombose, apresentando $17(100,0 \%)$ pacientes com dímero - D positivos.

Vinte e seis pacientes não tiveram confirmação de trombose, apresentando 8 (30,8\%) pacientes com dímero - D negativo e 18 (69,2\%) pacientes com dímero - $\mathrm{D}$ positivos. 
Analisando-se esta concordância, pelo do índice kappa, observamos um valor igual a 0,26 ( $<<0,001)$ a partir do qual concluímos que há uma concordância fraca entre dímero - D e trombose.

- Suspeita de TVP: 12 casos tiveram confirmação do evento agudo, apresentando $12(100,0 \%)$ pacientes com dímero - D positivos.

Dezenove pacientes não tiveram o evento agudo confirmado, apresentando $6(31,6 \%)$ pacientes com dímero - D negativos e $13(68,4 \%)$ com resultado de dímero - D plasmático positivos.

Analisando-se esta concordância, pelo do índice kappa, observamos um valor igual a $0,26(p=0,015)$ a partir do qual concluímos que há uma concordância fraca entre dímero - D e trombose.

- Suspeita de TEP associada à TVP, 7 pacientes tiveram confirmação de trombose aguda, apresentando $7(100,0 \%)$ com dímero - D positivos.

Oito pacientes não tiveram confirmação do evento agudo, apresentando, 1 (12,5\%) paciente com dímero - D negativo e 7 (87,5\%) pacientes com resultado de dímero - D plasmático positivos.

Analisando-se esta concordância, pelo índice kappa, observamos um valor igual a $0,12(p=0,166)$ a partir do qual concluímos que há uma concordância fraca entre dímero - D e trombose.

A tabela 10 demonstra os valores de dímero - D, como variável quantitativa, segregando os pacientes pela hipótese diagnóstica. 
Houve uma diferença significativa no total de pacientes. Onde os pacientes com trombose aguda apresentaram valores de dímero - D significativamente maiores quando comparados com os pacientes sem trombose aguda $(p=0,004)$.

Os pacientes com TVP apresentaram a média da concentração de dímero - D plasmático significativamente maior do que os pacientes sem TVP $(p=0,008)$.

Tabela 10 - Valores de dímero - D (ng/ml) como variável quantitativa segregado pelo tipo de suspeita clínica.

Evento Agudo

\begin{tabular}{|c|c|c|c|}
\hline Suspeita Clínica - n & Ausência & Presença & $p$ \\
\hline Total - 89 & $\begin{array}{c}1867,6 \pm 2139,5 ; 1082 \\
(93-8091)\end{array}$ & $\begin{array}{l}3334,2 \pm 585,4 ; 2362 \\
\quad(707-10.000)\end{array}$ & 0,004 \\
\hline TEP* - 43 & $\begin{array}{c}1883,2 \pm 2127,1 ; 1077 \\
(103-8091)\end{array}$ & $\begin{array}{l}2798,4 \pm 2396 ; 1844 \\
\quad(707-8002)\end{array}$ & 0,197 \\
\hline TVP* - 31 & $\begin{array}{c}1249,3 \pm 1653,3 ; 788 \\
(93-7282)\end{array}$ & $\begin{array}{c}3432,2 \pm 2598,3 \\
2428(1100-10.000)\end{array}$ & 0,008 \\
\hline TEP + TVP* - 15 & $\begin{array}{c}3285,2 \pm 2735,2 ; 2562,5 \\
(212-7765)\end{array}$ & $\begin{array}{c}4467,3 \pm 2996 ; 3985 \\
(1222-10.000)\end{array}$ & 0,439 \\
\hline
\end{tabular}

*Legenda: TEP $=$ Tromboembolismo Pulmonar; TVP= Trombose Venosa Profunda; TEP+TVP= Tromboembolismo Pulmonar associado à Trombose Venosa Profunda. 


\subsection{Estudo qualitativo do Dímero - D Plasmático.}

O dímero - D como variável qualitativa, do total de pacientes com sinais e sintomas sugestivos de trombose aguda, está apresentado na tabela 11. A freqüência de trombose nessa população estudada foi de $40,4 \%$.

Tabela 11 - Freqüência dos resultados do teste dímero - D e diagnósticos. Diagnóstico de evento tromboembólico agudo

\begin{tabular}{lccc} 
Resultado dímero - D $\left(\right.$ VIDAS $\left.^{\circledR}\right)$ & Positivo & Negativo & Total \\
\hline Positivo & $36(100 \%)$ & $38(71,7 \%)$ & 74 \\
Negativo & 0 & $15(28,3 \%)$ & 15 \\
Total & $36(100 \%)$ & $53(100 \%)$ & 89 \\
\hline
\end{tabular}


O dímero - D como variável qualitativa nos pacientes com suspeita de TEP está apresentado na tabela 12. A freqüência de trombose nessa população estudada foi de $39,5 \%$.

Tabela 12 - Freqüência dos resultados do teste dímero - D e diagnósticos dos pacientes com suspeita de TEP.

\begin{tabular}{lccc}
\hline & \multicolumn{3}{c}{ Diagnóstico de TEP } \\
Resultado dímero - D $\left(\right.$ VIDAS $\left.^{\circledR}\right)$ & Positivo & Negativo & Total \\
\hline Positivo & $17(100 \%)$ & $18(69,2 \%)$ & 35 \\
Negativo & 0 & $8(30,8 \%)$ & 8 \\
Total & $17(100 \%)$ & $26(100 \%)$ & 43 \\
\hline
\end{tabular}


O dímero - D como variável qualitativa nos pacientes com suspeita de TVP está apresentado na tabela 13. A freqüência de trombose nessa população estudada foi de $38,7 \%$.

Tabela 13 - Frequêencia dos resultados do teste dímero - D e diagnósticos dos pacientes com suspeita de TVP.

\begin{tabular}{lccc}
\hline & \multicolumn{3}{c}{ Diagnóstico de TVP } \\
Resultado dímero - D $\left(\right.$ VIDAS $\left.^{\circledR}\right)$ & Positivo & Negativo & Total \\
\hline Positivo & $12(100 \%)$ & $13(68,4 \%)$ & 25 \\
Negativo & 0 & $6(31,6 \%)$ & 6 \\
Total & $12(100 \%)$ & $19(100 \%)$ & 31 \\
\hline
\end{tabular}

O dímero - D como variável qualitativa nos pacientes com suspeita de TEP + TVP está apresentado na tabela 14. A freqüência de trombose nessa população estudada foi de $46,7 \%$.

Tabela 14 - Freqüência dos resultados do teste dímero - D e diagnósticos dos pacientes com suspeita de TEP + TVP.

\begin{tabular}{lccc} 
& \multicolumn{3}{c}{ Diagnóstico de TEP + TVP } \\
Resultado dímero - D $\left(\right.$ VIDAS $\left.^{\circledR}\right)$ & Positivo & Negativo & Total \\
\hline Positivo & $7(100 \%)$ & $7(87,5 \%)$ & 14 \\
Negativo & 0 & $1(12,5 \%)$ & 1 \\
Total & $7(100 \%)$ & $8(100 \%)$ & 15 \\
\hline
\end{tabular}


Os valores de sensibilidade, especificidade, valor preditivo positivo (VPP), valor preditivo negativo (VPN), exatidão e freqüência de trombose aguda, segregados pelo tipo de suspeita clínica, estão descritos na tabela 15.

A análise qualitativa entre os grupos apresentou valores semelhantes entre si, com exceção do item especificidade no grupo TVP, que apresentou uma tendência a diminuição do valor em relação aos outros grupos.

Tabela 15 - Análise qualitativa do dímero - D segregados por tipo de evento tromboembólico agudo.

\begin{tabular}{lrrrr}
\hline & TEP & TVP & TEP+TVP & Total \\
\hline Sensibilidade & $100 \%$ & $100 \%$ & $100 \%$ & $100 \%$ \\
VPP & $32 \%$ & $50 \%$ & $48 \%$ & $48,6 \%$ \\
Especificidade & $48,6 \%$ & $12,5 \%$ & $31,6 \%$ & $28,3 \%$ \\
VPN & $100 \%$ & $100 \%$ & $100 \%$ & $100 \%$ \\
Acurácia & $58,1 \%$ & $53,3 \%$ & $58 \%$ & $57,3 \%$ \\
Freqüência TEV & $39,5 \%$ & $38,7 \%$ & $46,7 \%$ & $40,4 \%$ \\
\hline
\end{tabular}

Legenda: $\mathrm{TEP}=$ tromboembolismo pulmonar; $\mathrm{TVP}=$ trombose venosa profunda; $\mathrm{VPP}=$ valor preditivo positivo; $\mathrm{VPN}=$ valor preditivo negativo; $\mathrm{TEV}=$ tromboembolismo venoso. 


\subsection{Curva "Receiver Operating Characteristic" - Curva ROC}

O gráfico 1 representa a curva "Receiver Operating Characteristic" (ROC). Para construção da curva ROC foram utilizados os valores de corte do dímero - D apresentados no ANEXO F (página 109).

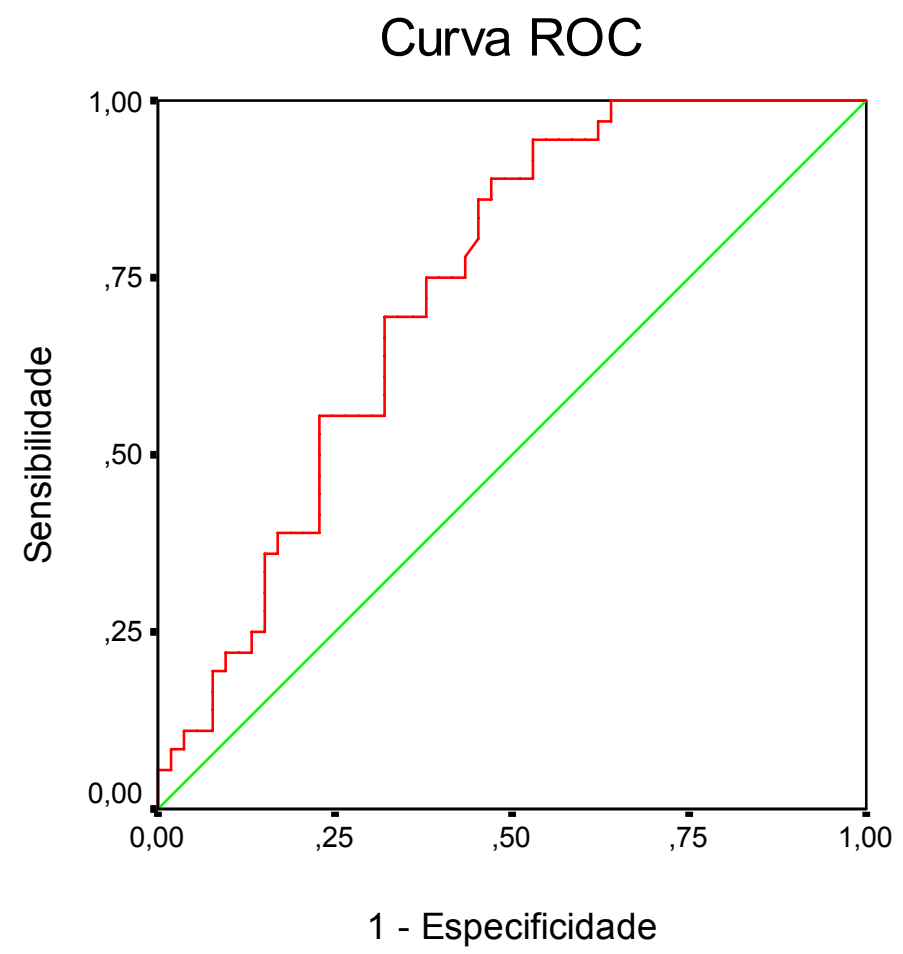

Gráfico 1. Curva "Receiver Operating Characteristic"- Curva ROC

A área abaixo da curva é igual a 0,734 . 
O ponto de corte é dado por $\geq 500$, pois é onde obtemos $100 \%$ de sensibilidade e $28,3 \%$ de especificidade.

O gráfico 2 apresenta a probabilidade estimada de trombose com base nos valores de dímero - D plasmático.

Podemos observar que a probabilidade de tromboembolismo venoso agudo é diretamente proporcional aos valores de dímero - D plasmático.

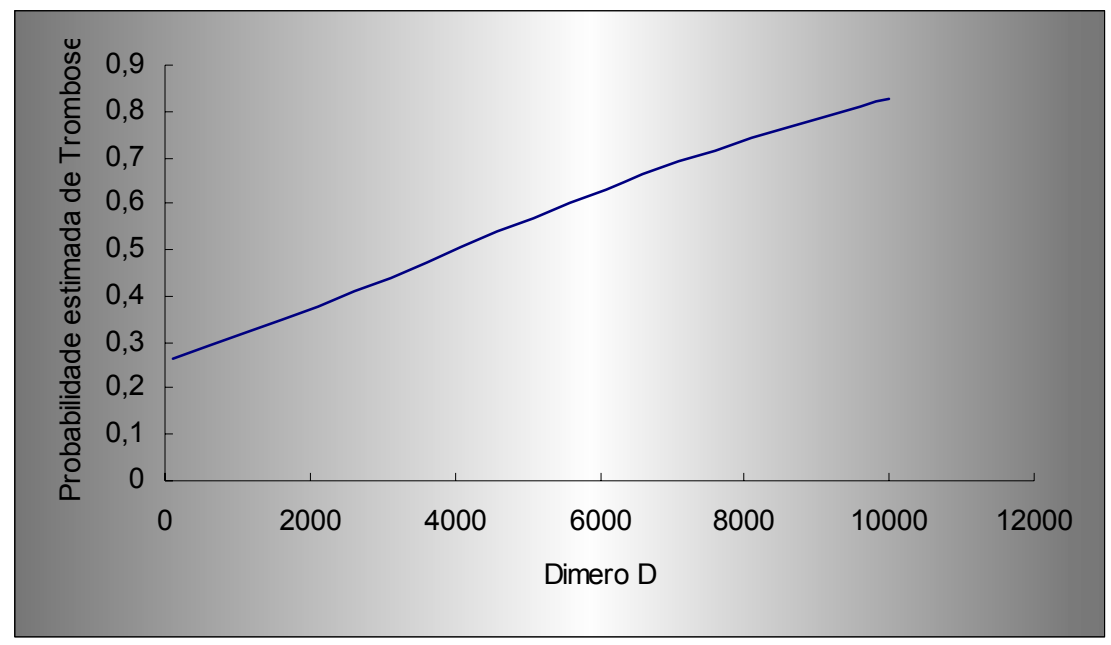

Gráfico 2 - Probabilidade estimada de TEV com base nos valores de dímero - D plasmático 
Os gráficos 3, 4 e 5 apresentam as curva ROC segregando os pacientes pelo tipo de suspeita clínica.

\section{Curva ROC}

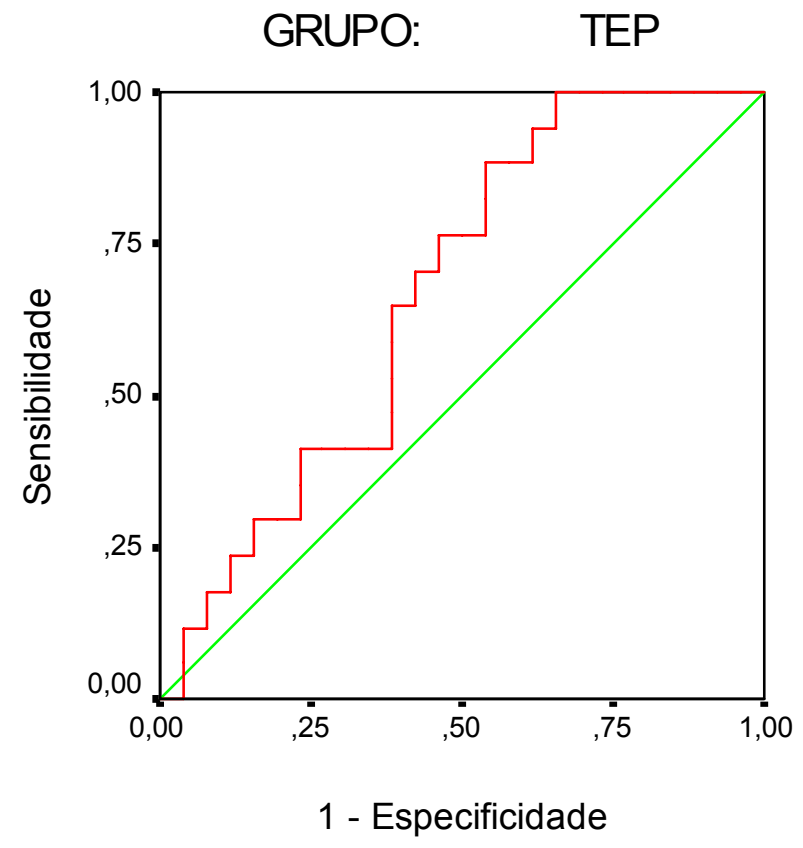

Gráfico 3 . Curva "Receiver Operating Characteristic" - Curva ROC para os pacientes com suspeita de TEP.

A área abaixo da curva $=0,667$.

Para construção da curva ROC pra pacientes com suspeita de TEP foram utilizados os valores de corte do dímero - D apresentados no ANEXO G (página 110). $O$ ponto de corte para o grupo TEP é dado por $\geq 1330$, pois é onde obtemos $64,7 \%$ de sensibilidade e $61,5 \%$ de especificidade. 


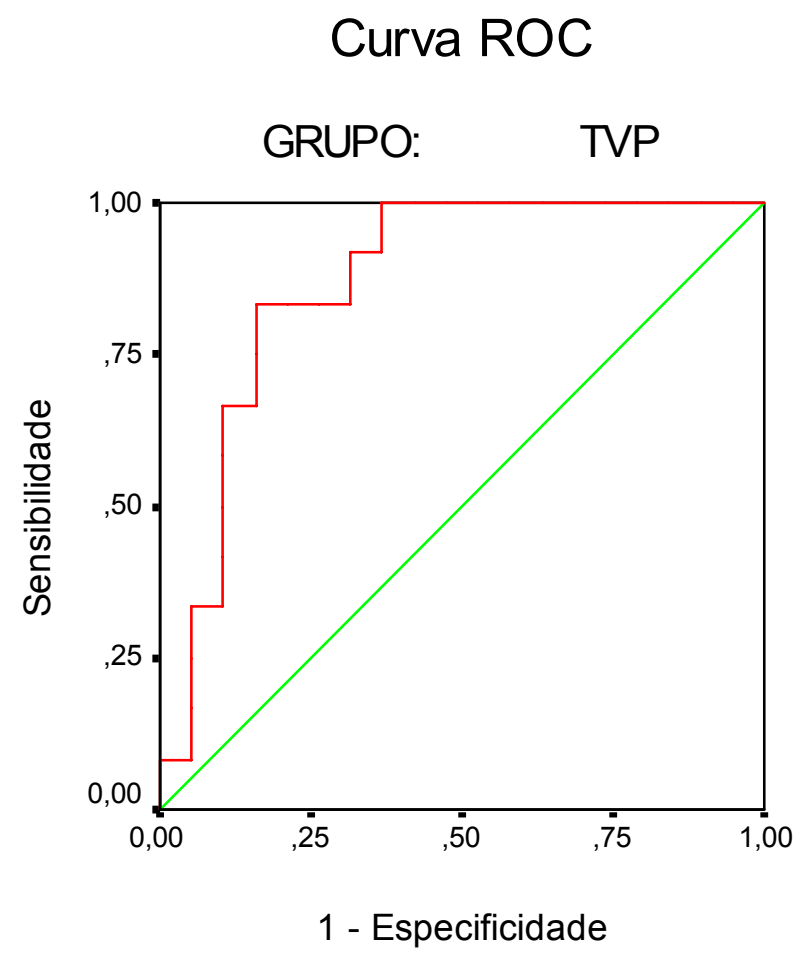

Gráfico 4 . Curva "Receiver Operating Characteristic"- Curva ROC para os pacientes com suspeita de TVP.

A área abaixo da curva $=0,868$.

Para construção da curva ROC pra pacientes com suspeita de TVP foram utilizados os valores de corte do dímero - D apresentados no ANEXO H (página 111). O ponto de corte para o grupo TVP é dado por $\geq 1564$, pois é onde obtemos $83,3 \%$ de sensibilidade e $84,2 \%$ de especificidade. 


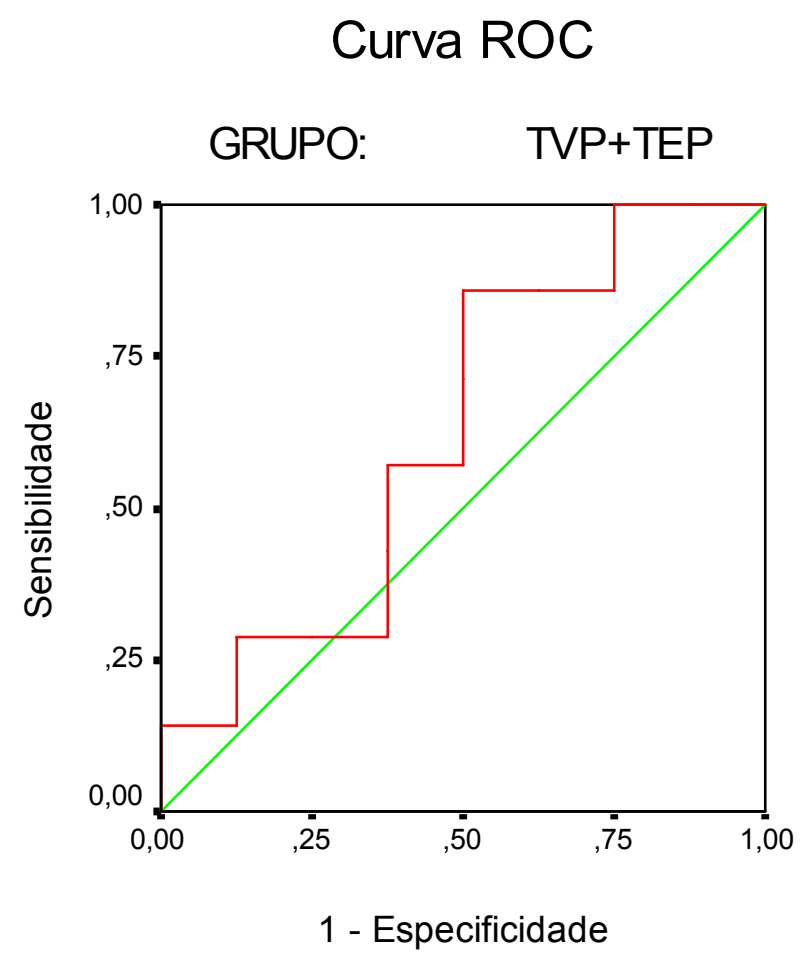

Gráfico 5 . Curva "Receiver Operating Characteristic" - Curva ROC para os pacientes com suspeita de TEP + TVP.

A área abaixo da curva $=0,625$.

Para construção da curva ROC para pacientes com suspeita de TEP + TVP foram utilizados os valores de corte do dímero - D apresentados no ANEXO I (página 112). O ponto de corte para o grupo TEP + TVP é dado por $\geq 3659,5$, pois é onde obtemos $57,1 \%$ de sensibilidade e $50 \%$ de especificidade. 


\subsection{Análise das variáveis}

Nessa análise, em relação a presença ou ausência de evento tromboembólico agudo, os pacientes foram estratificados pela faixa etária, índice de massa corporal (IMC) e gênero.

\subsubsection{Faixa etária:}

Os pacientes foram estratificados pela faixa etária, segundo o risco trombótico: até 40 anos (baixo risco trombótico), maiores de 40 anos e até 60 anos (médio risco trombótico) e maiores de 60 anos (alto risco trombótico).

Os pacientes com presença e ausência de trombose aguda, grupados pela faixa etária, estão descritos na tabela 16.

Os pacientes mais jovens (menos de 40 anos) apresentaram uma tendência maior para ocorrência de TVP. 
Tabela 16 - Freqüência da ocorrência de tromboembolismo venoso agudo, grupado pela faixa etária e tipo de evento agudo.

$$
\begin{aligned}
& \text { TEP }=43 \quad \text { TVP }=31 \quad \text { TEP }+ \text { TVP }=15 \quad \text { TOTAL }=89 \\
& \begin{array}{llllllll}
(-) & (+) & (-) & (+) & (-) & (+) & (-) & (+)
\end{array}
\end{aligned}
$$

Total

(n)

$$
26
$$

$17 \quad 19$

$\begin{array}{lll}19 & 12 & 8\end{array}$

7

$53 \quad 36$

(\%)

$60,5 \quad 39,5 \quad 61,3 \quad 38,7 \quad 53,3 \quad 46,7 \quad 59,6 \quad 40,5$

$<40$ anos

(n)

$$
4
$$

7

$\begin{array}{lll}9 & 4 & 1\end{array}$

0

$14 \quad 11$

(\%)

$$
36,4
$$

63,6

$69,2 \quad 30,8 \quad 100$

$---\quad 56$

44

$40-60$ anos

$\begin{array}{lrrrrrrrr}(\mathrm{n}) & 9 & 6 & 5 & 4 & 3 & 3 & 17 & 13 \\ (\%) & 60 & 40 & 55,6 & 44,4 & 50 & 50 & 56,7 & 43,3\end{array}$

$>60$ anos

\begin{tabular}{lcccccccc} 
(n) & 13 & 4 & 5 & 4 & 4 & 4 & 22 & 12 \\
$(\%)$ & 76,5 & 23,5 & 55,6 & 44,4 & 50 & 50 & 64,7 & 35,3 \\
\hline
\end{tabular}

Legenda: $(-)$ = ausência de evento agudo; $(+)=$ presença de evento agudo; TEP $=$ tromboembolismo pulmonar; TVP $=$ trombose venosa profunda. 
As tabelas 17 e 18 descrevem os valores de características dos pacientes com presença e ausência de evento agudo respectivamente, estratificados pela faixa etária (menos de 40 anos, maiores de 40 anos e até 60 anos e maiores de 60 anos).

Os pacientes com até 40 anos e sem evento agudo apresentaram valores de dímero - $\mathrm{D}$ significativamente menores do que àqueles com mais de 60 anos $(p=0,005)$. 
Tabela 17 - Medidas de tendência central e dispersão dos valores de características dos pacientes com ausência de evento agudo estratificados pela faixa etária. Ausência de Evento Agudo

\begin{tabular}{|c|c|c|c|c|c|c|}
\hline & $\begin{array}{l}\text { Até } 40 \text { anos } \\
\text { (A) }\end{array}$ & $\begin{array}{l}>\text { de } 40 \text { e até } 60 \text { anos } \\
\text { (B) }\end{array}$ & $\begin{array}{l}\text { Maiores de } 60 \text { anos } \\
\text { (C) }\end{array}$ & $\begin{array}{c}\mathrm{p} \\
(\mathrm{AXB})\end{array}$ & $\begin{array}{c}\mathrm{p} \\
(\mathrm{AXC})\end{array}$ & $\underset{(B X C)}{p}$ \\
\hline $\mathrm{N}(\%)$ & $14(26,4 \%)$ & $17(32,1 \%)$ & $22(41,5 \%)$ & --- & --- & --- \\
\hline Estatura $(\mathrm{cm})$ & $166,3 \pm 7 ; 164(157-177)$ & $163,4 \pm 8 ; 160(151-178)$ & $162,9 \pm 9 ; 160,5(150-186)$ & 0,305 & 0,274 & 0,872 \\
\hline Peso (kg) & $65,4 \pm 13,4 ; 69,5(53-96)$ & $69,2 \pm 16,6 ; 71(49-106)$ & $66,2 \pm 18,8 ; 59,5(44-118)$ & 0,487 & 0,882 & 0,606 \\
\hline $\operatorname{IMC}\left(\mathrm{kg} / \mathrm{m}^{2}\right)$ & $23,6 \pm 4 ; 22,3(18,2-35,7)$ & $25,8 \pm 5 ; 24(18,7-34,8)$ & $24,9 \pm 7 ; 22,3(15,6-42,2)$ & 0,226 & 0,519 & 0,674 \\
\hline Dímero - D & $\begin{array}{c}739,9 \pm 899,1 ; 193(93- \\
3234)\end{array}$ & $\begin{array}{c}1624,6 \pm 2077,8 ; 657(212- \\
7282)\end{array}$ & $\begin{array}{c}2773 \pm 2406,3 ; 1680(453- \\
8091)\end{array}$ & 0,150 & 0,005 & 0,126 \\
\hline
\end{tabular}

Legenda: $\mathrm{IMC}=$ índice de massa corporal 
Tabela 18 - Medidas de tendência central e dispersão dos valores de características dos pacientes com presença de evento agudo estratificados pela faixa etária.

\begin{tabular}{|c|c|c|c|c|c|c|}
\hline & \multicolumn{3}{|c|}{ Presença de Evento Agudo } & \multirow[b]{2}{*}{$\begin{array}{c}p \\
(\mathrm{AXB})\end{array}$} & \multirow[b]{2}{*}{$\underset{(A X C)}{p}$} & \multirow[b]{2}{*}{$\begin{array}{c}P \\
(B X C)\end{array}$} \\
\hline & $\begin{array}{l}\text { Até } 40 \text { anos } \\
(\mathrm{A})\end{array}$ & $\begin{array}{c}\text { > de } 40 \text { e até } 60 \text { anos } \\
\text { (B) }\end{array}$ & $\begin{array}{l}\text { Maiores de } 60 \text { anos } \\
\text { (C) }\end{array}$ & & & \\
\hline$N(\%)$ & $11(30,6)$ & $13(36,1)$ & $12(33,3)$ & --- & --- & --- \\
\hline Estatura $(\mathrm{cm})$ & $164,3 \pm 11 ; 165(148-167)$ & $167,6 \pm 8 ; 170(151-180)$ & $161,8 \pm 7 ; 160(150-176)$ & 0,402 & 0,525 & 0,082 \\
\hline Peso $(\mathrm{kg})$ & $66 \pm 14,5 ; 73(33-81)$ & $77,1 \pm 22,4 ; 65(49-130)$ & $68,5 \pm 20 ; 63,5(45-115)$ & 0,177 & 0,740 & 0,325 \\
\hline $\operatorname{IMC}\left(\mathrm{kg} / \mathrm{m}^{2}\right)$ & $24,4 \pm 5 ; 25,3(15,1-30,1)$ & $27,6 \pm 8 ; 25(17,4-45)$ & $26,2 \pm 8 ; 23,6(19,4-45,5)$ & 0,274 & 0,516 & 0,686 \\
\hline Dímero - D & $\begin{array}{c}2594,1 \pm 1991,8 ; 2305(707- \\
7661)\end{array}$ & $\begin{aligned} 3140,4 \pm & 2617,3 ; 2314(768 \\
& -10.000)\end{aligned}$ & $\begin{array}{c}4222,5 \pm 2955,8 ; 3414,5 \\
(1222-10.000)\end{array}$ & 0,577 & 0,140 & 0,342 \\
\hline
\end{tabular}

Legenda: IMC= índice de massa corporal 
A tabela 19 mostra os valores de característica dos pacientes com até 40 anos.

Os pacientes sem trombose aguda apresentaram valores de dímero - $\mathrm{D}$ significativamente menores do que os pacientes com trombose aguda $(p=0,005)$

Tabela 19 - Medidas de tendência central e dispersão dos valores de características dos pacientes com até $\mathbf{4 0}$ anos.

\begin{tabular}{|c|c|c|c|}
\hline \\
\hline & Ausência & Presença & $\mathrm{p}$ \\
\hline $\mathrm{N}$ & $14(56 \%)$ & $11(44 \%)$ & --- \\
\hline & $(57-177)$ & $164,3 \pm 10,7 ; 165(148-167)$ & 0,584 \\
\hline & $53-96)$ & & 0,911 \\
\hline $\operatorname{IMC}\left(\mathrm{kg} / \mathrm{m}^{2}\right)$ & $4 ; 22,3(18,2-35,7)$ & $24,4 \pm 5 ; 25,3(15,1-30,1)$ & 0,694 \\
\hline Idade & $30,9 \pm 6 ; 31(20-40)$ & $30,6 \pm 8 ; 31(13-40)$ & 0,918 \\
\hline Dímero - D (ng/ml) & $\begin{array}{c}739,9 \pm 899,1 ; 193(93- \\
3234)\end{array}$ & $\begin{array}{c}2594,1 \pm 1991,8 ; 2305(707- \\
7661)\end{array}$ & 0,005 \\
\hline
\end{tabular}


A tabela $\mathbf{2 0}$ revela a freqüência dos resultados de dímero - D como variável qualitativa nos pacientes com até 40 anos.

Tabela 20 - Freqüência dos resultados do teste dímero - D e diagnósticos nos pacientes com até $\mathbf{4 0}$ anos.

\begin{tabular}{lccc}
\hline & \multicolumn{3}{c}{ Diagnóstico de evento tromboembólico agudo } \\
Resultado dímero - D $\left(\right.$ VIDAS $\left.^{\circledR}\right)$ & Positivo & Negativo & Total \\
\hline Positivo & $11(100 \%)$ & $6(42,9 \%)$ & 17 \\
Negativo & 0 & $8(57,1 \%)$ & 8 \\
Total & $11(100 \%)$ & $14(100 \%)$ & 25 \\
\hline
\end{tabular}


A tabela $\mathbf{2 1}$ revela os valores de característica dos pacientes maiores de 40 anos e até 60 anos.

Tabela 21 - Medidas de tendência central e dispersão dos valores de características dos pacientes maiores de $\mathbf{4 0}$ anos e até $\mathbf{6 0}$ anos.

\begin{tabular}{|c|c|c|c|}
\hline & \multicolumn{2}{|c|}{ Evento Agudo Total } & \multirow[b]{2}{*}{$p$} \\
\hline & Ausência & Presença & \\
\hline $\mathrm{N}$ & $17(56,7 \%)$ & $13(43,3 \%)$ & --- \\
\hline Estatura $(\mathrm{cm})$ & $163,4 \pm 8 ; 160(151-178)$ & $167,6 \pm 8 ; 170(151-180)$ & 0,169 \\
\hline Peso $(\mathrm{kg})$ & $69,2 \pm 16,6 ; 71(49-106)$ & $77,1 \pm 22,4 ; 65(49-130)$ & 0,279 \\
\hline $\mathrm{IMC}\left(\mathrm{kg} / \mathrm{m}^{2}\right)$ & $25,8 \pm 5 ; 24(18,7-34,8)$ & $27,6 \pm 8 ; 25(17,4-45)$ & 0,465 \\
\hline Idade & $50,9 \pm 6 ; 52(41-59)$ & $51,1 \pm 5 ; 51(43-60)$ & 0,929 \\
\hline Dímero - D (ng/ml) & $\begin{array}{c}1624,6 \pm 2077,8 ; 657(212- \\
7282)\end{array}$ & $\begin{array}{c}3140,4 \pm 2617,3 ; 2314(768 \\
-10.000)\end{array}$ & 0,088 \\
\hline
\end{tabular}

Legenda: $\mathrm{IMC}=$ índice de massa corporal 
A tabela 22 identifica a freqüência dos resultados de dímero - D como variável qualitativa nos pacientes maiores de 40 anos e até 60 anos.

Tabela 22 - Freqüência dos resultados do teste dímero - D e diagnósticos nos pacientes maiores de $\mathbf{4 0}$ anos e até $\mathbf{6 0}$ anos.

\begin{tabular}{lccc}
\hline & \multicolumn{3}{c}{ Diagnóstico de evento tromboembólico agudo } \\
Resultado dímero - D $\left(\right.$ VIDAS $\left.^{\circledR}\right)$ & Positivo & Negativo & Total \\
\hline Positivo & $13(100 \%)$ & $11(64,7 \%)$ & 24 \\
Negativo & 0 & $6(35,3 \%)$ & 6 \\
Total & $13(100 \%)$ & $17(100 \%)$ & 30 \\
\hline
\end{tabular}


A tabela $\mathbf{2 3}$ descreve os valores de característica dos pacientes maiores de 60 anos.

Tabela 23 - Medidas de tendência central e dispersão dos valores de características dos pacientes maiores de $\mathbf{6 0}$ anos.

\begin{tabular}{lccc}
\hline & \multicolumn{2}{c}{ Evento Agudo Total } & \\
& \multicolumn{4}{c}{ Ausência } & Presença & $\mathrm{p}$ \\
\hline $\mathrm{N}$ & $22(64,7 \%)$ & $12(35,3 \%)$ & --- \\
Estatura $(\mathrm{cm})$ & $162,9 \pm 9 ; 160,5(150-186)$ & $161,8 \pm 7 ; 160(150-176)$ & 0,724 \\
Peso $(\mathrm{kg})$ & $66,2 \pm 18,8 ; 59,5(44-118)$ & $68,5 \pm 20 ; 63,5(45-115)$ & 0,744 \\
$\mathrm{IMC}\left(\mathrm{kg} / \mathrm{m}^{2}\right)$ & $24,9 \pm 8 ; 22,3(15,6-42,2)$ & $26,2 \pm 8 ; 23,6(19,4-45,5)$ & 0,617 \\
Idade & $76,2 \pm 7 ; 76(63-95)$ & $71,5 \pm 7 ; 71(61-80)$ & 0,067 \\
Dímero - D (ng/ml) & $2773 \pm 2406,3 ; 1680(453-$ & $4222,5 \pm 2955,8 ; 3414,5$ & 0,131 \\
& $8091)$ & $(1222-10.000)$ & \\
\hline
\end{tabular}

Legenda: IMC $=$ índice de massa corporal 
A tabela 24 revela a freqüência dos resultados de dímero - D como variável qualitativa nos pacientes maiores de 60 anos.

Tabela 24 - Freqüência dos resultados do teste dímero - D e diagnósticos nos pacientes maiores 60 anos.

\begin{tabular}{lccc}
\hline & \multicolumn{3}{c}{ Diagnóstico de evento tromboembólico agudo } \\
Resultado dímero - D $\left(\right.$ VIDAS $\left.^{\circledR}\right)$ & Positivo & Negativo & Total \\
\hline Positivo & $12(100 \%)$ & $21(95,5 \%)$ & 33 \\
Negativo & 0 & $1(0,5 \%)$ & 1 \\
Total & $12(100 \%)$ & $22(100 \%)$ & 34 \\
\hline
\end{tabular}


A tabela 25 apresenta a análise da variável qualitativa do dímero-D nos pacientes estratificados pela faixa etária.

A especificidade, valor preditivo positivo e acurácia do teste foram maiores nos pacientes até de 40 anos em relação aos outros grupos. Observamos também que a tendência a TEV aguda foi maior nos pacientes mais jovens (menos de 40 anos).

Tabela 25 - Análise da variável qualitativa do teste dímero - D $\left(\right.$ VIDAS $\left.^{\circledR}\right)$ em pacientes segregados pela faixa etária.

\begin{tabular}{lccc} 
& Até 40 anos & $>40$ e até 60 anos & $>60$ anos \\
\hline Sensibilidade & $100 \%$ & $100 \%$ & $100 \%$ \\
Especificidade & $57,1 \%$ & $35,3 \%$ & $4 \%$ \\
Valor Preditivo Positivo & $64,7 \%$ & $54,2 \%$ & $36,4 \%$ \\
Valor Preditivo Negativo & $100 \%$ & $100 \%$ & $100 \%$ \\
Acurácia & $76 \%$ & $63,3 \%$ & $38,2 \%$ \\
Freqüência de TEV & $44 \%$ & $43,3 \%$ & $35,3 \%$ \\
\hline
\end{tabular}




\subsubsection{Curva ROC}

Os gráficos 6, 7 e 8 representam as curvas "Receiver Operating Characteristic"(ROC) dos pacientes segregados pela faixa etária.

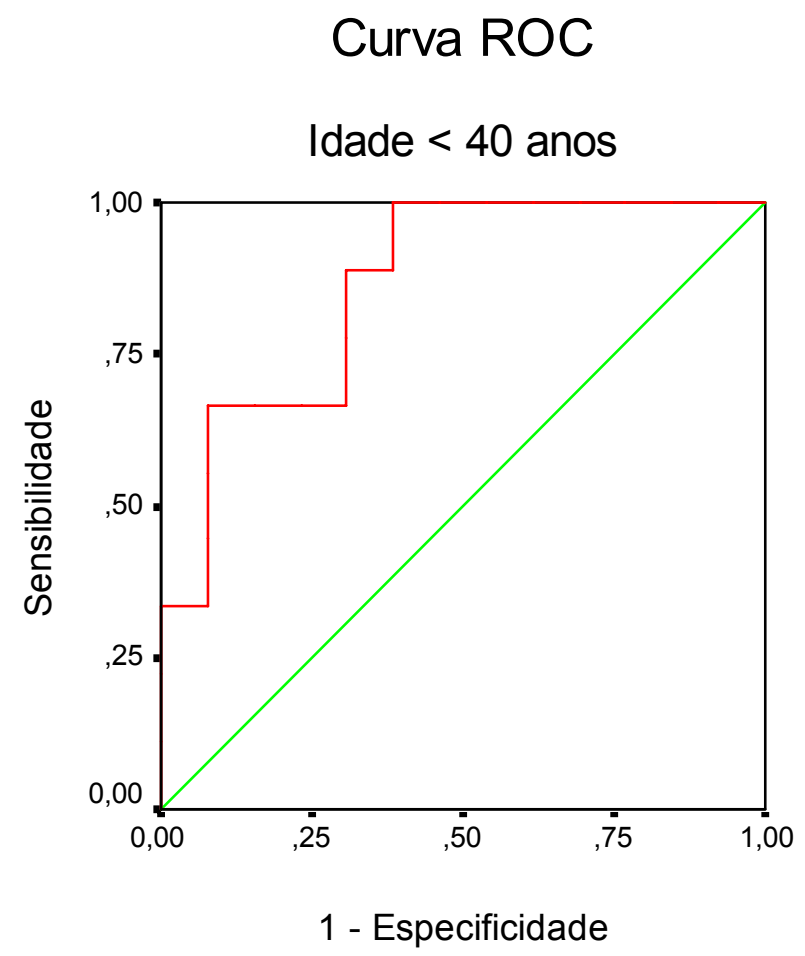

Gráfico 6 . Curva "Receiver Operating Characteristic" - Curva ROC para os pacientes com menos de 40 anos.

A área abaixo da curva $=0,863$. 
Para construção da curva ROC, para pacientes com menos de 40 anos, foram utilizados os valores de corte do dímero - D apresentados no ANEXO J (página 113). O ponto de corte para o grupo com menos de 40 anos é dado por $\geq 1.101$, pois é onde obtemos $89 \%$ de sensibilidade e $31 \%$ de especificidade.

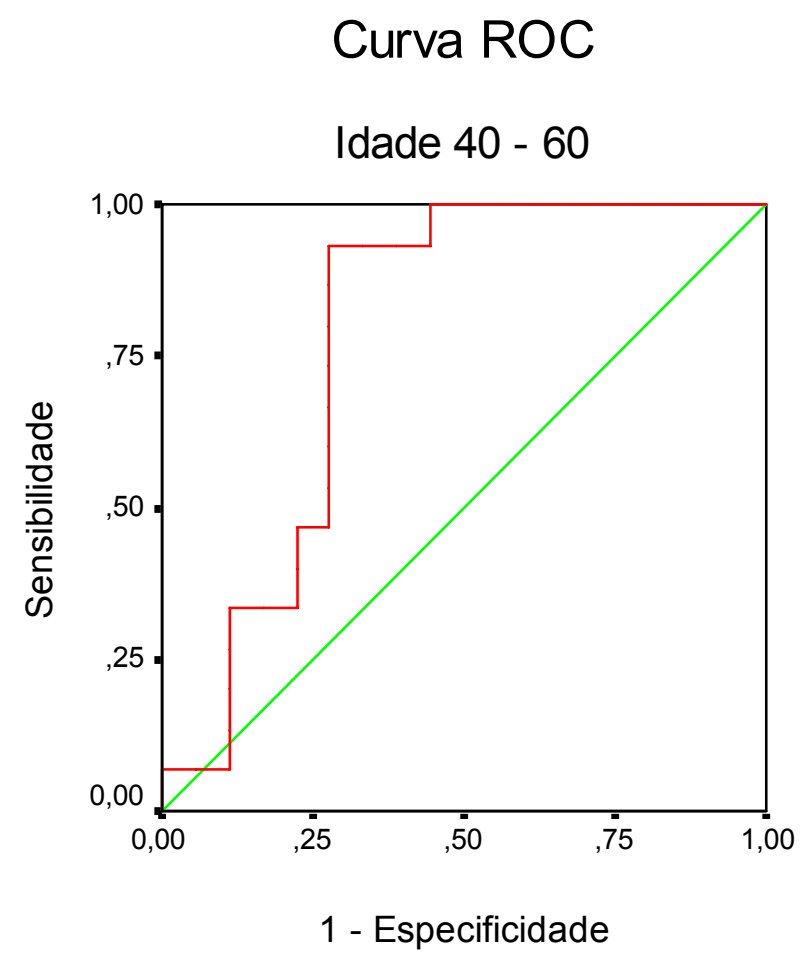

Gráfico 7 . Curva "Receiver Operating Characteristic" - Curva ROC para os pacientes na faixa etária de 40 a 60 anos.

A área abaixo da curva $=0,781$. 
Para construção da curva ROC, para pacientes com faixa etária de 40 a 60 anos, foram utilizados os valores de corte do dímero - D apresentados no ANEXO K (página 114). O ponto de corte para esse grupo é dado por $\geq 965$, pois é onde obtemos $93 \%$ de sensibilidade e $28 \%$ de especificidade.

\section{Curva ROC}

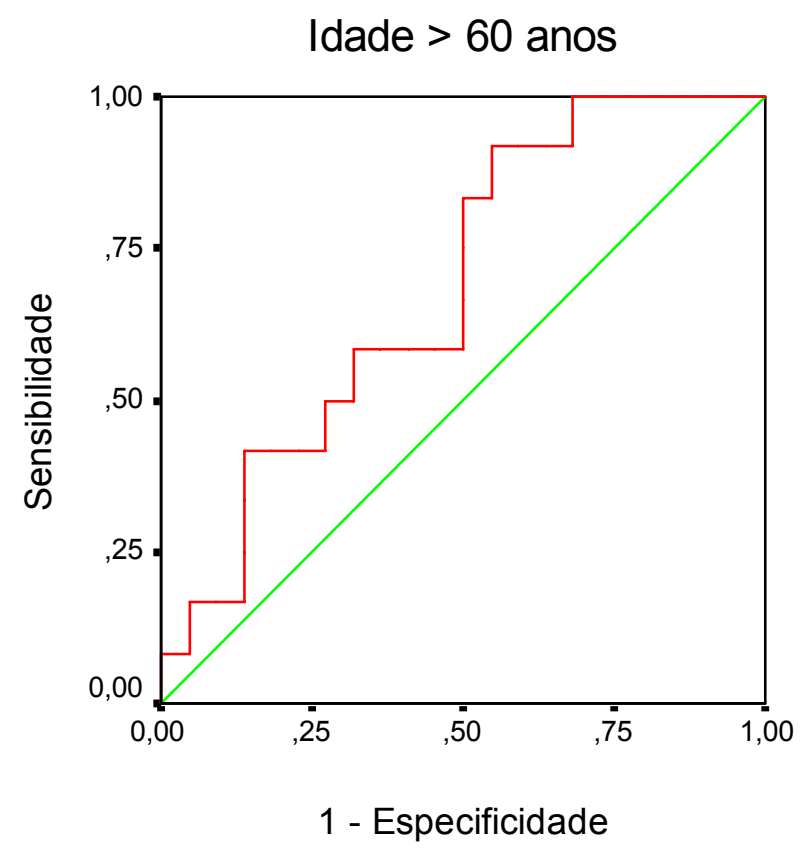

Gráfico 8 . Curva "Receiver Operating Characteristic"- Curva ROC para os pacientes com mais de 60 anos.

A área abaixo da curva $=0,686$.

Para construção da curva ROC, para pacientes com mais de 60 anos, foram utilizados os valores de corte do dímero - D apresentados no ANEXO 
L (página 115). O ponto de corte para esse grupo é dado por $\geq 1541$, pois é onde obtemos $83,3 \%$ de sensibilidade e $50 \%$ de especificidade. 


\subsection{2. Índice de Massa Corporal (IMC)}

Os pacientes com presença e ausência de trombose aguda, grupados pelo IMC, estão descritos na tabela $\mathbf{2 6}$

Observamos uma tendência maior para ocorrência de TVP nos grupo com IMC $\geq 30 \mathrm{~kg} / \mathrm{m}^{2}$.

Tabela 26 - Freqüência da ocorrência de tromboembolismo venoso agudo, grupado pelo IMC e tipo de evento agudo.

\begin{tabular}{|c|c|c|c|}
\hline TEP $=43$ & $\mathrm{TVP}=31$ & TEP + TVP = 15 & TOTAL $=89$ \\
\hline$(+)$ & $(+)$ & $(+)$ & $(-)$ \\
\hline
\end{tabular}

Total

$\begin{array}{lllllllll}\text { (n) } & 26 & 17 & 19 & 12 & 8 & 7 & 53 & 36\end{array}$

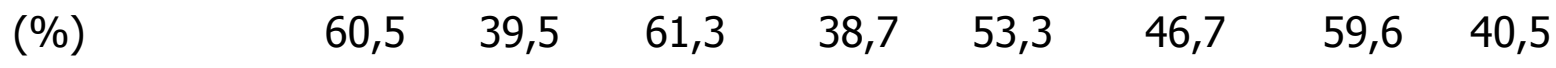

$<30 \mathrm{~kg} / \mathrm{m}^{2}$

\begin{tabular}{lcccccccc} 
(n) & 21 & 14 & 17 & 10 & 5 & 5 & 43 & 29 \\
$(\%)$ & 60 & 40 & 63 & 37 & 50 & 50 & 59,7 & 40,3 \\
$\geq 30 \mathrm{~kg} / \mathrm{m}^{2}$ & & & & & & & & \\
$(\mathrm{n})$ & 5 & 3 & 2 & 2 & 3 & 2 & 10 & 7 \\
$(\%)$ & 62,5 & 37,5 & 50 & 50 & 60 & 40 & 58,8 & 41,2 \\
\hline
\end{tabular}

Legenda: $(-)$ = ausência de evento agudo; $(+)=$ presença de evento agudo; TEP $=$ tromboembolismo pulmonar; TVP = trombose venosa profunda. 
As tabelas $\mathbf{2 7}$ e $\mathbf{2 8}$ descrevem os valores de características dos pacientes com ausência e com presença de evento agudo respectivamente, estratificados pelo IMC (IMC $<30 \mathrm{~kg} / \mathrm{m}^{2}$ e IMC $\geq 30 \mathrm{~kg} / \mathrm{m}^{2}$ ).

Tabela 27 - Medidas de tendência central e dispersão dos valores de características dos pacientes com ausência de evento agudo, estratificados pelo IMC.

\begin{tabular}{|c|c|c|c|}
\hline & \multicolumn{2}{|c|}{ Ausência de Evento Agudo } & \multirow[b]{2}{*}{$\mathrm{p}$} \\
\hline & $\mathrm{IMC}<30 \mathrm{~kg} / \mathrm{m}^{2}$ & $I M C \geq 30 \mathrm{~kg} / \mathrm{m}^{2}$ & \\
\hline $\mathrm{N}(\%)$ & $43(81,1 \%)$ & $10(18,9 \%)$ & \\
\hline Estatura $(\mathrm{cm})$ & $164,2 \pm 8 ; 160(150-186)$ & $163,2 \pm 9 ; 164,5(150-178)$ & 0,748 \\
\hline Peso $(\mathrm{kg})$ & $61,3 \pm 11,3 ; 57(44-92)$ & $91,1 \pm 14 ; 89,5(70-118)$ & $<0,001$ \\
\hline Idade (anos) & $55,4 \pm 20,8 ; 55(20-95)$ & $59,2 \pm 15,3 ; 61(37-77)$ & 0,589 \\
\hline Dímero-D (ng/ml) & $\begin{array}{c}1973,1 \pm 2267,3 ; 1061 \text { (93- } \\
8091)\end{array}$ & $\begin{array}{c}1413,9 \pm 1267,5 ; 1050,5 \\
(212-5148)\end{array}$ & 0,462 \\
\hline
\end{tabular}

Legenda: IMC $=$ índice de massa corporal

Tabela 28 - Medidas de tendência central e dispersão dos valores de características dos pacientes com presença de evento agudo, estratificados pelo IMC.

\begin{tabular}{lccc}
\hline & \multicolumn{3}{c}{ Presença de Evento Agudo } \\
& $\mathrm{IMC}<30 \mathrm{~kg} / \mathrm{m}^{2}$ & $\mathrm{IMC} \geq 30 \mathrm{~kg} / \mathrm{m}^{2}$ & $\mathrm{p}$ \\
\hline $\mathrm{N}(\%)$ & $29(80,5 \%)$ & $7(19,5 \%)$ & \\
Estatura (cm) & $165 \pm 9 ; 165(148-187)$ & $163,1 \pm 7 ; 160(158-175)$ & 0,662 \\
Peso (kg) & $63,5 \pm 11,6 ; 63(33-85)$ & $101,1 \pm 17,1 ; 98(77-130)$ & $<\mathbf{0 , 0 0 1}$ \\
Idade (anos) & $51,2 \pm 19 ; 51(13-80)$ & $53,4 \pm 12,3 ; 56(37-71)$ & 0,771 \\
Dímero-D (ng/ml) & $2988,1 \pm 2605,4 ; 1844(707-$ & $4767,7 \pm 2082,8 ; 4920$ & 0,103 \\
& $10.000)$ & $(1850-7661)$ & \\
\hline
\end{tabular}

Legenda: IMC $=$ índice de massa corporal 
A tabela 29 mostra a freqüência e os valores de característica dos pacientes com IMC $<30 \mathrm{~kg} / \mathrm{m}^{2}$.

Tabela 29 - Medidas de tendência central e dispersão dos valores de características dos pacientes com Índice de Massa Corporal (IMC) $<\mathbf{3 0}$ $\mathbf{k g} / \mathbf{m}^{2}$.

\begin{tabular}{|c|c|c|c|}
\hline & \multicolumn{2}{|c|}{ Evento Agudo } & \multirow[b]{2}{*}{$\mathrm{p}$} \\
\hline & Ausência & Presença & \\
\hline $\mathrm{N}(\%)$ & $43(59,7 \%)$ & $29(40,3 \%)$ & -- \\
\hline Estatura $(\mathrm{cm})$ & $164,2 \pm 8 ; 160(150-186)$ & $165 \pm 9 ; 165(148-187)$ & 0,684 \\
\hline Peso $(\mathrm{kg})$ & $61,3 \pm 11,3 ; 57(44-92)$ & $63,5 \pm 11,6 ; 63(33-85)$ & 0,433 \\
\hline IMC $\left(\mathrm{kg} / \mathrm{m}^{2}\right)$ & $22,7 \pm 3 ; 22,3(15,6-29,7)$ & $23,3 \pm 4 ; 22,2(15,1-29,7)$ & 0,482 \\
\hline Idade (anos) & $55,4 \pm 20,8 ; 55(20-95)$ & $51,2 \pm 19 ; 51(13-80)$ & 0,388 \\
\hline $\begin{array}{l}\text { Dímero }-D \\
(\mathrm{ng} / \mathrm{ml})\end{array}$ & $\begin{array}{c}1973,1 \pm 2267,3 ; 1061 \text { (93- } \\
8091)\end{array}$ & $\begin{array}{c}2988,1 \pm 2605,4 ; 1844 \text { (707- } \\
10.000)\end{array}$ & 0,084 \\
\hline
\end{tabular}

Legenda: IMC $=$ índice de massa corporal 
A tabela 30 revela a freqüência do teste dímero - D e diagnósticos dos pacientes com IMC $<30 \mathrm{~kg} / \mathrm{m}^{2}$.

Tabela 30 - Freqüência dos resultados do teste dímero - D e diagnósticos dos pacientes com Índice de Massa Corporal (IMC) $<\mathbf{3 0} \mathbf{~ k g} / \mathbf{m}^{2}$.

\begin{tabular}{lccc}
\hline & \multicolumn{3}{c}{ Diagnóstico de evento tromboembólico agudo } \\
Resultado dímero - D $\left(\right.$ VIDAS $\left.^{\circledR}\right)$ & Positivo & Negativo & Total \\
\hline Positivo & $29(100 \%)$ & $32(74,4 \%)$ & 61 \\
Negativo & 0 & $11(25,6 \%)$ & 11 \\
Total & $29(100 \%)$ & $43(100 \%)$ & 72 \\
\hline
\end{tabular}


A tabela 31 mostra os valores de características dos pacientes com IMC $\geq 30 \mathrm{~kg} / \mathrm{m}^{2}$.

Os pacientes com massa corporal igual ou maior a $30 \mathrm{~kg} / \mathrm{m}^{2}$ e na ausência de trombose aguda, apresentaram valores de dímero - D significativamente menores quando comparados com os pacientes com presença de trombose aguda $(p=0,001)$.

Tabela 31 - Medidas de tendência central e dispersão dos valores de características dos pacientes com Índice de Massa Corporal (IMC) $\geq \mathbf{3 0}$ $\mathbf{k g} / \mathbf{m}^{2}$.

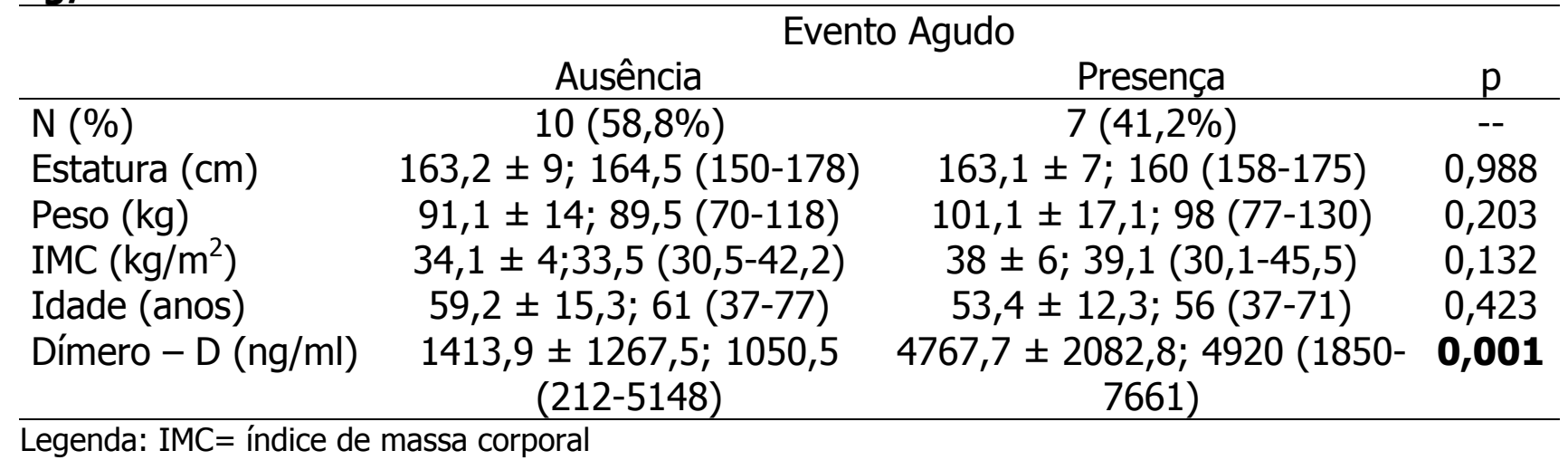


A tabela 32 revela a freqüência dos valores de dímero - D como variável qualitativa em pacientes com IMC $\geq 30 \mathrm{~kg} / \mathrm{m}^{2}$.

Tabela 32 - Freqüência dos resultados do teste dímero - D e diagnósticos dos pacientes com Índice de Massa Corporal (IMC) $\geq \mathbf{3 0} \mathbf{~} \mathbf{g} / \mathbf{m}^{\mathbf{2}}$.

Diagnóstico de evento tromboembólico agudo

\begin{tabular}{lccc} 
Resultado dímero - D $\left(\right.$ VIDAS $\left.^{\circledR}\right)$ & Positivo & Negativo & Total \\
\hline Positivo & $7(100 \%)$ & $6(60 \%)$ & 13 \\
Negativo & 0 & $4(40 \%)$ & 4 \\
Total & $7(100 \%)$ & $10(100 \%)$ & 17 \\
\hline
\end{tabular}


A tabela 33 apresenta a análise da variável qualitativa do teste dímero - D nos pacientes estratificados pelo IMC.

Os pacientes com IMC $<30 \mathrm{~kg} / \mathrm{m}^{2}$ apresentaram valores de especificidade, valor preditivo positivo e acurácia do teste menores do que os pacientes com IMC $\geq 30 \mathrm{~kg} / \mathrm{m}^{2}$.

Tabela 33 - Análise da variável qualitativa do teste dímero - D $\left(\right.$ VIDAS $\left.^{\circledR}\right)$ nos pacientes segregados pelo Índice de Massa Corporal (IMC)

\begin{tabular}{lcc}
\hline & IMC $<30 \mathrm{~kg} / \mathrm{m}^{2}$ & $\mathrm{IMC} \geq 30 \mathrm{~kg} / \mathrm{m}^{2}$ \\
\hline Sensibilidade & $100 \%$ & $100 \%$ \\
Especificidade & $25,6 \%$ & $40 \%$ \\
Valor Preditivo Positivo & $47,5 \%$ & $53,8 \%$ \\
Valor Preditivo Negativo & $100 \%$ & $100 \%$ \\
Acurácia & $55,5 \%$ & $64,7 \%$ \\
Freqüência de TEV* & $40,3 \%$ & $41,2 \%$ \\
\hline
\end{tabular}

*TEV: tromboembolismo venoso 
Os gráficos 9 e $\mathbf{1 0}$ representam as curvas "Receiver Operating Characteristic"(ROC) dos pacientes segregados pelo IMC.

Curva ROC

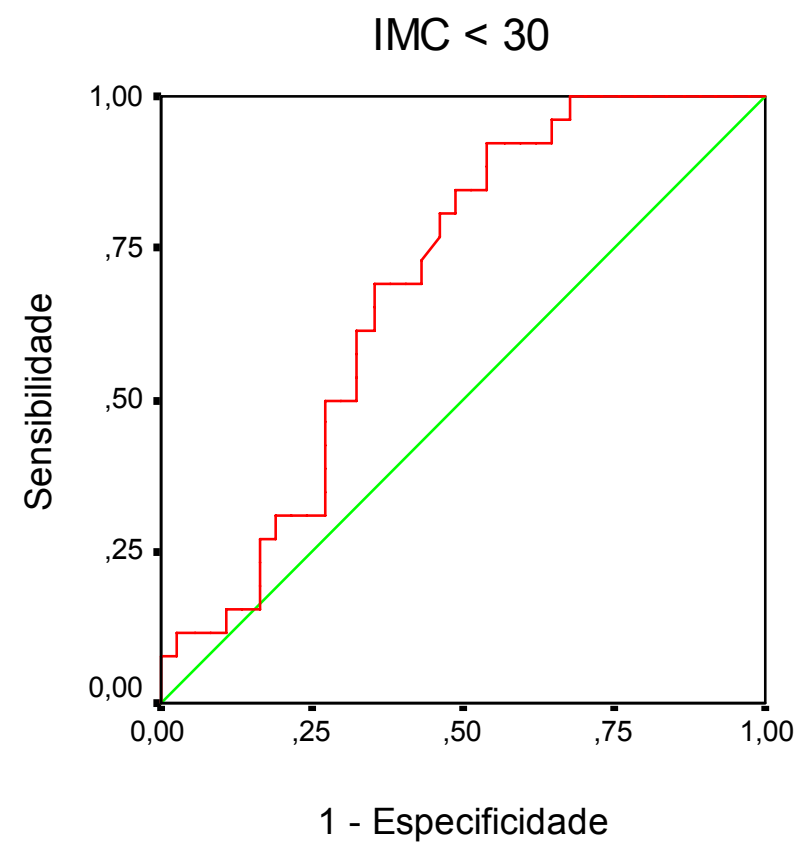

Gráfico 9 . Curva "Receiver Operating Characteristic"- Curva ROC para os pacientes com IMC $<30 \mathrm{~kg} / \mathrm{m}^{2}$.

A área abaixo da curva $=0,690$. 
Para construção da curva ROC, para pacientes com IMC $<30 \mathrm{~kg} / \mathrm{m}^{2}$, foram utilizados os valores de corte do dímero - D apresentados no ANEXO M (página 116). O ponto de corte para esse grupo é dado por $\geq 1378$, pois é onde obtemos $65,4 \%$ de sensibilidade e $35,1 \%$ de especificidade.

\section{Curva ROC}

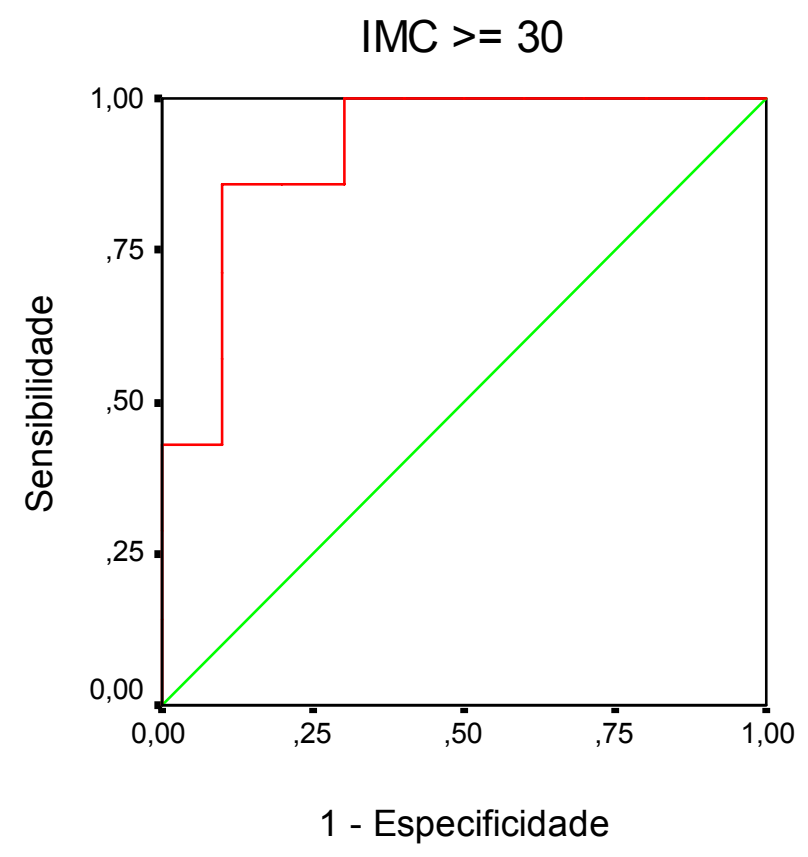

Gráfico 10. Curva "Receiver Operating Characteristic"- Curva ROC para os pacientes com IMC $\geq 30 \mathrm{~kg} / \mathrm{m}^{2}$.

A área abaixo da curva $=0,914$.

Para construção da curva ROC, para pacientes com IMC $\geq 30 \mathrm{~kg} / \mathrm{m}^{2}$, foram utilizados os valores de corte do dímero - D apresentados no ANEXO 
$\mathbf{N}$ (página 118). O ponto de corte para esse grupo é dado por $\geq 2181$, pois é onde obtemos $85,7 \%$ de sensibilidade e $100 \%$ de especificidade. 


\subsubsection{Gênero}

Os pacientes com presença e ausência de trombose aguda, grupados por gênero, estão descritos na tabela 34.

Com exceção do grupo com TEP, que apresentou números próximos de pacientes de ambos os sexos (20 (46,5\%) pacientes do sexo feminino vs 23 (53,5\%) do sexo masculino), para os demais houve prevalência de pacientes do sexo feminino: $19(61,3 \%)$ para o grupo com TVP e 12 (80\%) para o grupo com TEP + TVP.

Os pacientes do gênero masculino apresentaram maior tendência para ocorrência de TEV agudo nos três grupos. 
Tabela 34 - Freqüência da ocorrência de tromboembolismo venoso agudo, grupado pelo gênero e tipo de evento agudo.

$$
\text { TEP }=43 \quad \text { TVP }=31 \quad \text { TEP }+ \text { TVP }=15 \quad \text { TOTAL }=89
$$

$\begin{array}{llllllll}(-) & (+) & (-) & (+) & (-) & (+) & (-) & (+)\end{array}$

Total

$\begin{array}{lcccccccc}\text { (n) } & 26 & 17 & 19 & 12 & 8 & 7 & 53 & 36 \\ \text { (\%) } & 60,5 & 39,5 & 61,3 & 38,7 & 53,3 & 46,7 & 59,6 & 40,5\end{array}$

Feminino

$\begin{array}{lcccccccc}\text { (n) } & 13 & 7 & 14 & 5 & 7 & 5 & 34 & 17 \\ \text { (\%) } & 65,0 & 35,0 & 73,7 & 26,3 & 58,2 & 41,7 & 66,7 & 33,3\end{array}$

Masculino

\begin{tabular}{lcccccccc} 
(n) & 13 & 10 & 5 & 7 & 1 & 2 & 19 & 19 \\
(\%) & 56,5 & 43,5 & 41,7 & 58,3 & 33,3 & 66,7 & 50 & 50 \\
\hline
\end{tabular}

Legenda: $(-)$ = ausência de evento agudo; $(+)=$ presença de evento agudo; TEP $=$ tromboembolismo pulmonar; TVP $=$ trombose venosa profunda. 
As tabelas 35 e 36 mostram os valores de características dos pacientes com ausência e com presença de evento agudo, respectivamente, estratificados pelo gênero.

Tabela 35 - Medidas de tendência central e dispersão dos valores de características dos pacientes com ausência de evento agudo segregado pelo gênero.

Ausência de Evento Agudo

\begin{tabular}{|c|c|c|c|}
\hline & Feminino & Masculino & $\mathrm{p}$ \\
\hline $\mathrm{N}(\%)$ & $34(64,2)$ & $19(35,8)$ & \\
\hline Estatura $(\mathrm{cm})$ & $160,9 \pm 7 ; 160(150-177)$ & $169,5 \pm 8 ; 173(156-186)$ & $<0,001$ \\
\hline Peso $(\mathrm{kg})$ & $65,5 \pm 15 ; 61,5(44-96)$ & $69,6 \pm 19,2 ; 65(49-118)$ & 0,396 \\
\hline $\operatorname{IMC}\left(\mathrm{kg} / \mathrm{m}^{2}\right)$ & $25,3 \pm 6 ; 23,2(15,6-42,2)$ & $24 \pm 5 ; 22,2(18,2-39,4)$ & 0,418 \\
\hline Idade (anos) & $53,7 \pm 21,3 ; 52(20-95)$ & $60,4 \pm 16,4 ; 59(29-82)$ & 0,246 \\
\hline Dímero-D (ng/ml) & $\begin{array}{c}1699,3 \pm 2036,1 ; 956(93- \\
7765)\end{array}$ & $\begin{array}{c}2168,7 \pm 2339,7 ; 1237(103- \\
8091)\end{array}$ & 0,449 \\
\hline
\end{tabular}

Legenda: IMC= índice de massa corporal

Tabela 36 - Medidas de tendência central e dispersão dos valores de características dos pacientes com presença de evento agudo estratificados pelo gênero.

$$
\text { Presença de Evento Agudo }
$$

\begin{tabular}{lccc} 
& Feminino & Masculino & $\mathrm{p}$ \\
\hline $\mathrm{N}(\%)$ & $17(47,2)$ & $19(52,8)$ & -- \\
Estatura $(\mathrm{cm})$ & $160,1 \pm 6 ; 160(150-173)$ & $168,7 \pm 9 ; 170(148-187)$ & $\mathbf{0 , 0 2 5}$ \\
Peso $(\mathrm{kg})$ & $74,5 \pm 24,5 ; 64(45-130)$ & $67,5 \pm 13,9 ; 67(33-98)$ & 0,292 \\
$\mathrm{IMC}\left(\mathrm{kg} / \mathrm{m}^{2}\right)$ & $28,9 \pm 9 ; 27,2(17,4-45,5)$ & $23,6 \pm 4 ; 23,4(15,1-32)$ & $\mathbf{0 , 0 2 7}$ \\
Idade (anos) & $57 \pm 17,8 ; 57(25-80)$ & $46,8 \pm 16,7 ; 49(13-76)$ & 0,086 \\
Dímero-D (ng/ml) & $3537,6 \pm 2724 ; 2410(768-$ & $3152,2 \pm 2515,6 ; 2314(707-$ & 0,662 \\
& \multicolumn{1}{c}{$10.000)$} & $10.000)$ &
\end{tabular}


A tabela 37 mostra os valores de características nas pacientes do gênero feminino, segregadas pela presença ou não do evento agudo. Foi observada uma diferença significativamente maior nos valores de dímero-D entre as pacientes do gênero feminino com presença de evento agudo quando comparadas com as pacientes sem evento agudo.

As pacientes com ausência de trombose aguda apresentaram valores de dímero - D significativamente menores do que as pacientes com trombose aguda $(p=0,009)$.

Tabela 37 - Medidas de tendência central e dispersão dos valores de características dos pacientes do gênero feminino.

\begin{tabular}{lccc}
\hline \multicolumn{4}{c}{ Evento Agudo } \\
\hline $\mathrm{N}(\%)$ & $34(66,7 \%)$ & Presença & $\mathrm{p}$ \\
Estatura (cm) & $160,9 \pm 7 ; 160(150-177)$ & $160,1 \pm 6 ; 160(150-173)$ & 0,691 \\
Peso $(\mathrm{kg})$ & $65,5 \pm 15 ; 61,5(44-96)$ & $74,5 \pm 24,5 ; 64(45-130)$ & 0,110 \\
$\mathrm{IMC}\left(\mathrm{kg} / \mathrm{m}^{2}\right)$ & $25,3 \pm 6 ; 23,2(15,6-42,2)$ & $28,9 \pm 9 ; 27,2(17,4-45,5)$ & 0,086 \\
Idade $(\mathrm{anos})$ & $53,7 \pm 21,3 ; 52(20-95)$ & $57 \pm 17,8 ; 57(25-80)$ & 0,590 \\
Dímero - D (ng/ml) & $1699,3 \pm 2036,1 ; 956(93-$ & $3537,6 \pm 2724 ; 2410(768-$ & $\mathbf{0 , 0 0 9}$ \\
& $7765)$ & $10.000)$ & \\
\hline
\end{tabular}


A tabela 38 revela a freqüência dos valores de dímero - D como variável qualitativa em pacientes do gênero feminino.

Tabela 38 - Freqüência dos resultados do teste dímero - D e diagnósticos dos pacientes do gênero feminino.

\begin{tabular}{lccc}
\hline & \multicolumn{3}{c}{ Diagnóstico de evento tromboembólico agudo } \\
Resultado dímero - D $\left(\right.$ VIDAS $\left.^{\circledR}\right)$ & Positivo & Negativo & Total \\
\hline Positivo & $17(100 \%)$ & $23(67,6 \%)$ & 40 \\
Negativo & 0 & $11(32,4 \%)$ & 11 \\
Total & $17(100 \%)$ & $34(100 \%)$ & 51 \\
\hline
\end{tabular}


A tabela 39 mostra os valores de característica dos pacientes do gênero masculino, divididos pela presença ou ausência de evento agudo. Os pacientes do gênero masculino e com evento agudo apresentaram idade significativamente menor do que os pacientes sem evento agudo $(p=0,016)$.

Tabela 39 - Medidas de tendência central e dispersão dos valores de características dos pacientes do gênero masculino.

\begin{tabular}{lccc}
\hline \multicolumn{4}{c}{ Evento Agudo } \\
& \multicolumn{4}{c}{ Ausência } & Presença & $\mathrm{p}$ \\
\hline $\mathrm{N}(\%)$ & $19(50 \%))$ & $19(50 \%)$ & -- \\
Estatura $(\mathrm{cm})$ & $169,5 \pm 8 ; 173(156-186)$ & $168,7 \pm 9 ; 170(148-187)$ & 0,795 \\
Peso $(\mathrm{kg})$ & $69,6 \pm 19,2 ; 65(49-118)$ & $67,5 \pm 13,9 ; 67(33-98)$ & 0,708 \\
$\mathrm{IMC}\left(\mathrm{kg} / \mathrm{m}^{2}\right)$ & $24 \pm 5 ; 22,2(18,2-39,4)$ & $23,6 \pm 4 ; 23,4(15,1-32)$ & 0,825 \\
Idade $(\mathrm{anos})$ & $60,4 \pm 16,4 ; 59(29-82)$ & $46,8 \pm 16,7 ; 49(13-76)$ & $\mathbf{0 , 0 1 6}$ \\
Dímero - D (ng/ml) & $2168,7 \pm 233,7 ; 1237(103-$ & $3152,2 \pm 2515,6 ; 2314$ & 0,220 \\
\multicolumn{2}{c}{$8091)$} & $(707-10.000)$ & \\
\hline Legenda: IMC= índice de massa corporal & &
\end{tabular}


A tabela 40 descreve a freqüência dos valores de dímero - D como variável qualitativa em pacientes do gênero masculino.

Tabela 40 - Freqüência dos resultados do teste dímero - D e diagnósticos dos pacientes do gênero masculino.

\begin{tabular}{lccc}
\hline & \multicolumn{3}{c}{ Diagnóstico de evento tromboembólico agudo } \\
Resultado dímero - D $\left(\right.$ VIDAS $\left.^{\circledR}\right)$ & Positivo & Negativo & Total \\
\hline Positivo & $19(100 \%)$ & $15(79 \%)$ & 34 \\
Negativo & 0 & $4(21 \%)$ & 4 \\
Total & $19(100 \%)$ & $19(100 \%)$ & 38 \\
\hline
\end{tabular}


A tabela 41 mostra a análise da variável qualitativa do teste dímero D nos pacientes estratificados pelo gênero.

As pacientes do gênero feminino apresentaram especificidade do teste maior do que os pacientes do gênero masculino. Podemos observar também que as mesmas apresentaram uma tendência do valor preditivo positivo, acurácia do teste e freqüência de TEV serem menores em relação aos pacientes do gênero masculino.

Tabela 41 - Análise da variável qualitativa do teste dímero - D $\left(\right.$ VIDAS $\left.^{\circledR}\right)$ em pacientes segregados pelo gênero.

\begin{tabular}{lcc} 
& Gênero Feminino & Gênero Masculino \\
\hline Sensibilidade & $100 \%$ & $100 \%$ \\
Especificidade & $33,4 \%$ & $21,1 \%$ \\
Valor Preditivo Positivo & $42,5 \%$ & $55,9 \%$ \\
Valor Preditivo Negativo & $100 \%$ & $100 \%$ \\
Acurácia & $54,9 \%$ & $60,5 \%$ \\
Freqüência de TEV* & $33,3 \%$ & $50 \%$ \\
\hline
\end{tabular}

*TEV: tromboembolismo venoso 


\subsubsection{Curva ROC}

Os gráficos 11 e $\mathbf{1 2}$ representam as curvas "Receiver Operating Characteristic"(ROC) dos pacientes segregados pelo gênero.

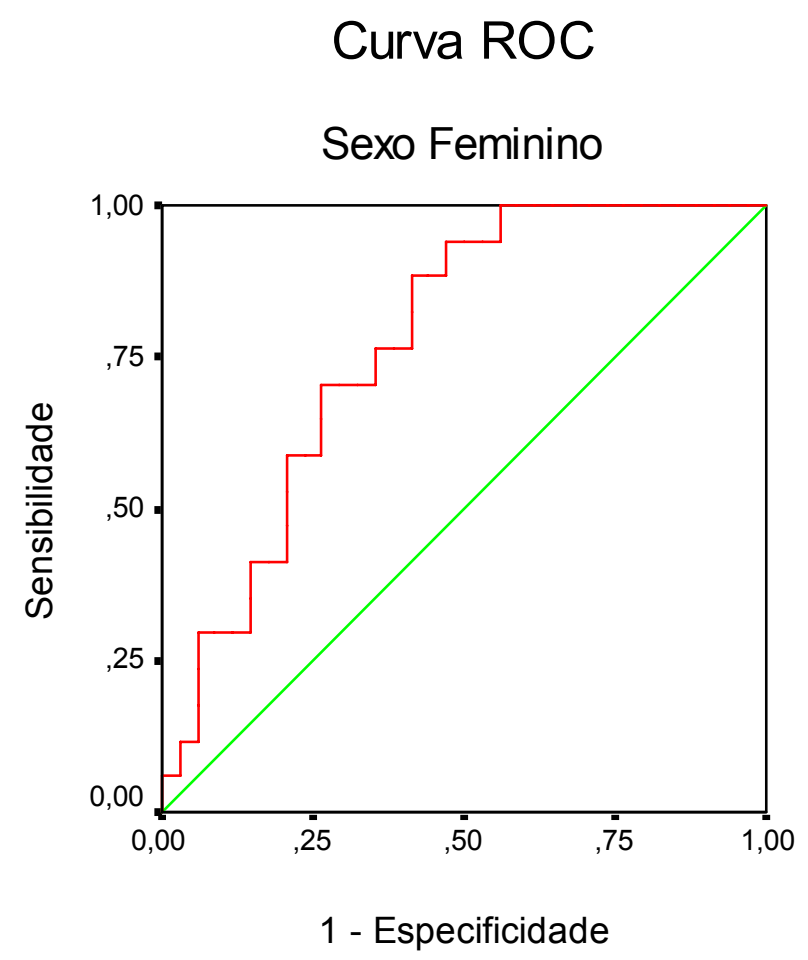

Gráfico 11. Curva "Receiver Operating Characteristic"- Curva ROC para as pacientes do gênero feminino.

A área abaixo da curva $=0,773$. 
Para construção da curva, ROC para as pacientes do gênero feminino, foram utilizados os valores de corte do dímero - D apresentados no ANEXO O (página 119). O ponto de corte para esse grupo é dado por $\geq 1560$, pois é onde obtemos $70,6 \%$ de sensibilidade e $26,5 \%$ de especificidade.

\section{Curva ROC}

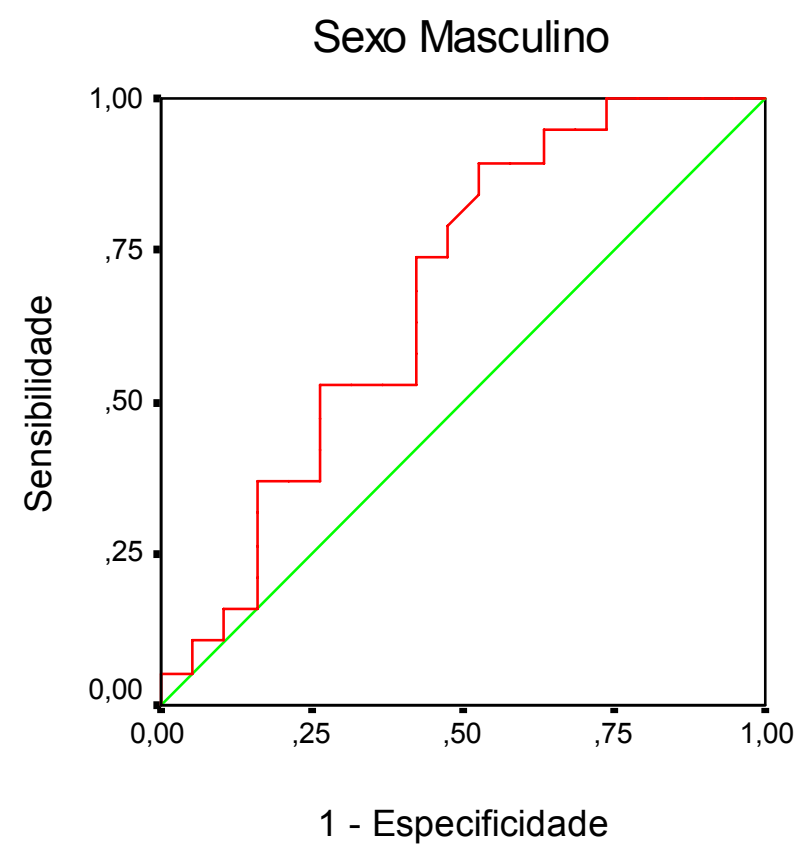

Gráfico 12. Curva "Receiver Operating Characteristic"- Curva ROC para os pacientes do gênero masculino.

A área abaixo da curva $=0,677$.

Para construção da curva ROC, para os pacientes do gênero masculino, foram utilizados os valores de corte do dímero - D apresentados no ANEXO 
$\mathbf{P}$ (página 121). O ponto de corte para esse grupo é dado por $\geq 1696$, pois é onde obtemos $63,2 \%$ de sensibilidade e $42,1 \%$ de especificidade.

\subsection{Exames por imagem}

As freqüências dos exames por imagem, realizados no total de pacientes estudados, estão descritas na tabela 42.

Tabela 42 - Freqüência dos exames por imagem realizados nos pacientes.

\begin{tabular}{lcc}
\hline Exame & N & $\%$ \\
\hline USG MI & 38 & 43 \\
Cintilografia & 18 & 20 \\
Tomografia & 28 & 32 \\
Cintilografia + USG MI & 2 & 2 \\
Cintilografia + angioplastia & 1 & 1 \\
Tomografia + USG MI & 2 & 2 \\
\hline
\end{tabular}

Legenda: USG MI= ultrassonografia de membro inferior

\subsection{Avaliações pós - alta hospitalar}

Dos 89 pacientes estudados, nenhum paciente apresentou evento tromboembólico agudo nas avaliações 30 e 60 dias após a alta hospitalar. 
5 Discussão 
Os dados apresentados em nosso estudo indicam que o correto diagnóstico do tromboembolismo venoso permanece desafiando os recursos laboratoriais e clínicos nas salas de emergência dos hospitais. Sabe-se que a investigação diagnóstica de pacientes que apresentam sinais e sintomas de tromboembolismo venoso agudo é uma tarefa complexa resultando frequentemente em erros $(23,25,32,33,61)$.

Essa condição é resultado dos baixos valores preditivos positivo ou negativo do quadro clínico, bem como da escassez dos sinais e sintomas característicos do processo, confundindo - se com outros tipos de enfermidades. Essas dificuldades podem muitas vezes interferir em um diagnóstico eficaz, retardar o tratamento para trombose e, elevar os custos de internação $(21,30,31,62-69)$.

Vários estudos realizados recentemente, utilizando a dosagem do dímero - D plasmático pelo método ELFA/ ELISA em pacientes com suspeita de TEV, tem contribuído com o aprimoramento do diagnóstico precoce da condição, bem como o tempo de internação, os custos da investigação diagnóstica e o aperfeiçoamento do tratamento do evento agudo, evitando as comorbidades conseqüentes e inclusive a morte do paciente $(7,15,30$, $33,62,64-66,70)$.

Em nosso estudo verificamos que o teste para dosagem de dímero - D plasmático pelo método quantitativo ELFA (equipamento VIDAS ${ }^{\circledR}$ ) permitiu 
excluir o tromboembolismo venoso agudo (TEP/TVP). Esse fato relevante pode ser confirmado, pela excelente sensibilidade (100\%) e valor preditivo negativo ( $\mathrm{VPN}=100 \%$ ) do teste na amostra estudada. Além disso, o diagnóstico (ausência ou presença) de TEV agudo foi confirmado através de exames por imagem indicado para cada caso.

Essa informação coincide com os dados da literatura recente, onde diversos estudos compararam o teste dímero $-\mathrm{D}$ pelo método ELFA e observaram sua similaridade com o método ELISA clássico (padrão - ouro), ressaltando a segurança dos dois testes no diagnóstico de exclusão do TEV agudo $(29,40,52)$.

Considerando que o valor ideal para a "Área Sob a Curva" (ASC), da curva ROC, é de aproximadamente 0,740 , a análise da curva ROC da amostra inteira, em nosso estudo, indicou que o teste dímero - D ELFA foi um bom preditor de trombose, uma vez que a ASC apresenta um bom valor $(0,734)$. Todos os pacientes com confirmação de TEV apresentaram valores de dímero - D positivos (acima de $500 \mathrm{ng} / \mathrm{ml}$ ), indicando uma excelente sensibilidade (100\%) do teste pelo método ELFA.

Quando selecionamos esses pacientes pela hipótese diagnóstica, observamos que a ASC do grupo TVP apresentou um excelente valor $(0,868)$. Após a elevação do valor de corte ( $\geq 1564 \mathrm{ng} / \mathrm{ml}$ ) bem como a elevação conseqüente da sua especificidade $(84,2 \%)$, e diminuição da sua sensibilidade $(83,3 \%)$, alcançamos resultados indicando que o dímero - D foi um bom preditor de trombose nesse grupo. 
Por outro lado o grupo TVP apresentou uma especificidade menor $(12,5 \%$, para o valor de corte $500 \mathrm{ng} / \mathrm{ml})$ ao estratificarmos os pacientes segundo a hipótese diagnóstica. Porém, verificamos que a característica do teste é muito semelhante entre as suspeitas clínicas, com exceção do grupo TVP pelo fato de apresentar uma tendência menor a especificidade do que os outros grupos.

Dados diferentes do grupo TVP, em relação a curva ROC, foram observados nos grupos TEP e TEP+TVP, pois a ASC apresentou valores baixos $(0,667$ e 0,625, respectivamente). Esses dados indicam que os valores aumentados de corte do teste podem comprometam a sensibilidade e/ou especificidade, tidas como muito inferiores do ideal. Esses dados não foram observados em outros relatos, uma vez que em nosso estudo ao segregarmos os pacientes pela suspeita clínica, reduzimos o número de pacientes em cada grupo.

Embora o nosso estudo tenha permitido um tratamento estatístico, outros autores realizaram estudos individualizados por tipo de suspeita clínica aumentando o tamanho da amostra e, consequentemente, otimizando a análise estatística $(7,8,29,35)$.

Através da análise de probabilidade de trombose, verificamos que o dímero - $D$ é um bom preditor de trombose também, pois a chance do diagnóstico de TEV aguda aumenta proporcionalmente com o aumento dos níveis de dímero - D. Todavia, ainda que a análise da probabilidade de risco indicar que quanto maior o valor do dímero - $D$ plasmático, maior é a 
predisposição ao evento tromboembólico, encontramos valores máximos de concentração de dímero - D muito semelhantes em pacientes com e sem tromboembolismo venoso agudo.

Ainda que a metodologia utilizada em nosso estudo não tenha um delineamento específico para avaliar a freqüência de trombose através da faixa etária, não observamos, em nosso estudo, diferenças na média de idade entre os pacientes com e sem TEV agudo, enfatizando que a freqüência de TEV foi maior nos pacientes mais jovens (até 40 anos). Isso pode ser justificado, pois a média da idade dos nossos pacientes foi inferior aos observados nos em diversos relatos $(8,13,19,27)$. Além disso, não encontramos diferença nos índices antropométricos ao selecionarmos os pacientes pelo tipo de suspeita clínica.

Por outro lado, em nosso estudo, a média da concentração do dímero D plasmático foi significativamente maior nos indivíduos maiores que 60 anos. Esses dados estão de acordo com a literatura, os quais indicam que os níveis de dímero - D aumentam proporcionalmente com a idade (43-45).

A análise da regressão logística e das características do teste nos pacientes com mais de 60 anos, indicou haver um comprometimento na qualidade do teste, pois, encontrou uma grande quantidade de resultados falsos positivos e, consequentemente, com valores de especificidade e acurácia indicando uma diminuição importante $(4,5 \%$ e $38,2 \%$, respectivamente). Assim, a informação de que nos pacientes mais idosos, o dímero - D parece elevar sua concentração plasmática, é justificável 
considerar uma alternativa de corrigir o valor de corte do dímero $-\mathrm{D}$, aumentando - o nos pacientes mais idosos. Dessa forma, podemos alcançar valores compatíveis, elevando assim, a especificidade do exame, aproximando - o da fisiologia dos idosos (71).

Uma vez, ao elevarmos o valor de corte do teste na população mais idosa e conseqüentemente a especificidade, haverá um comprometimento da sensibilidade do teste que nesse caso atingiria níveis próximos de $83 \%$ para um valor de corte do dímero - D $\geq 1541$ (vide ANEXO L, página 115).

Por outro lado, ao analisarmos as curvas ROC's dos grupos segregados pela faixa etária, observamos que o dímero - D é um excelente preditor de trombose na faixa etária com menos de 40 anos, apresentando uma ASC igual a 0,863. No grupo de 40 a 60 anos observamos uma ASC igual 0, 781, esse dado nos mostra que o dímero - D ainda é um bom preditor de trombose, porém com menor qualidade em relação ao grupo mais jovem. Já no grupo com mais de 60 anos, verificamos que o dímero - D não é um bom preditor de trombose, já que o valor da ASC foi igual a 0,686 , demonstrando mais uma vez o comprometimento da qualidade do teste nos indivíduos mais idosos.

Com relação ao índice de massa corporal, (IMC), observamos que entre os pacientes obesos (IMC $\geq 30 \mathrm{~kg} / \mathrm{m}^{2}$ ), com evento agudo, apresentaram valores de dímero - D significativamente maiores do que os pacientes sem evento agudo $(p=0,001)$. 
Observamos também uma tendência ao aumento da freqüência de resultados falsos - positivos nos pacientes não obesos. Desses pacientes, 74,4\% dos não obesos e que não apresentaram TEV agudo, possuíam valores de dímero - D acima de $500 \mathrm{ng} / \mathrm{ml}$, apresentando uma queda no índice da especificidade $(25,6 \%)$, quando comparados com os pacientes obesos (40\%).

Ao analisar a curva ROC da amostra segregada pelo IMC, verificamos que a ASC apresenta um valor distante do ideal $(\mathrm{ASC}=0,690)$, talvez tal fato explique a quantidade de falsos positivos encontrados, pois se elevarmos 0 nível de corte desses pacientes teremos um comprometimento nos níveis de sensibilidade e especificidade e consequentemente da qualidade do teste.

Por outro lado, a ASC dos pacientes obesos, apresentou um excelente valor $(0,914)$, porém não se pode afirmar a segurança em aumentar o nível de corte do dímero $-D$, uma vez que o número de pacientes limitou o poder estatístico.

A análise dos pacientes do gênero masculino apresentou maior ocorrência do evento tromboembólico agudo quando comparados com o gênero feminino ( $50 \%$ vs 33,3\%, respectivamente). Essa informação coincidiu com dados da literatura, onde Kyrle et al. (11) relataram um risco relativo de 1,4 mais vezes do gênero masculino apresentar o evento agudo, em particular nos pacientes com mais de 60 anos. Em nosso estudo encontramos esse índice aumentado nos pacientes do gênero masculino. 
Assim, alcançamos maior freqüência de TVP no gênero masculino que nos pacientes do gênero feminino $(58,3 \%$ vs $26,3 \%$, respectivamente) $(10,11)$.

Observamos também que entre os pacientes do gênero masculino, a presença de evento agudo ocorreu em idade significativamente menor do que os pacientes sem evento agudo $(46,8 \pm 16,7$ vs $60,4 \pm 16,4$ anos, respectivamente $p=0,016$ ). Além disso, a média de idade dos pacientes com evento agudo foi concordante com a da literatura (entre 40 e 59 anos) (11).

A análise da curva ROC, segregando os pacientes pelo gênero, apresentaram comportamentos semelhantes, sendo que podemos observar que a ASC do gênero feminino apresenta uma tendência melhor do que a ASC do gênero masculino $(0,773$ vs 0,677 , respectivamente).

Não há correlatos na literatura sobre a análise de curva ROC, segregando os pacientes por faixa etária, IMC e gênero.

Um seguimento de 30 e 60 dias após a alta hospitalar dos pacientes indicou que todos os pacientes que revelaram resultados do teste do dímero - D negativo não tiveram TEV posterior.

Alguns relatos indicam que nenhum paciente com ausência de evento agudo no momento da alta hospitalar e com resultado de dímero - D negativo pelo método ELFA, apresentaram TEV posterior também $(72,73)$. Todavia há de se considerar que o tempo de seguimento desses estudos foi maior.

Por se tratar de um protocolo centralizado em análise laboratorial, nosso estudo não permitiu seguir o modelo de Wells através de scores. Porém 
vários estudos sugerem distinguir os pacientes em baixa, média e alta probabilidade de evento tromboembólico agudo, tendo como base, o quadro clínico apresentado (73-75).

Alguns estudos indicam que entre os pacientes que apresentam alta probabilidade de TEV, 85\% deles, têm diagnósticos confirmados seguidos de, 33 e $5 \%$ nos pacientes com média e baixa probabilidade respectivamente (73-77).

Por esse motivo, vários autores têm estudado a associação da dosagem do dímero - D plasmático pelo método ELFA/ ELISA a exames por imagem, sugerindo um algoritmo na rotina investigatória (78-81).

Os resultados observados em nosso estudo relativo aos valores preditivos são concordantes com os apresentados por outros estudos. Todavia, nossa amostra estudada, foi pequena (89 pacientes). Estudos com amostras menores encontraram resultados semelhantes aos nossos $(26,40$, $46,47)$.

Esses dados podem ter contribuído para limitar o poder estatístico do estudo, porém indicou caminhos seguros para uma confirmação diagnóstica de certeza. 
6 Conclusões 
- A dosagem do dímero - D, pelo método ELFA, foi capaz de excluir o diagnóstico de tromboembolismo venoso agudo nessa amostra estudada.

- Os resultados obtidos nessa amostra estudada permitiram concluir que o uso do teste dímero - D em pacientes com suspeita de tromboembolismo venoso, revelou alta sensibilidade no diagnóstico dessa enfermidade. 
7 Anexos 
ANEXO A - Aprovação da Comissão Científica e de Ética do Instituto do Coração

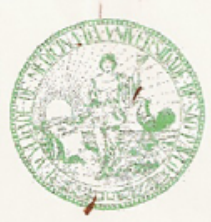

Mem.CC. 719

\section{INSTITUTO DO CORAÇÃO \\ (Fundação E. J. Zerbini) \\ Hospital das Clínicas}

Faculdade de Medicina da Universidade de São Paulo

São Paulo, 10 de julho de 2003.

Ao

Prof. Dr. Roberto Abi Rached.

A Comissão Científica e de Ética do Instituto do Coração, apreciou na sessão 431/03/10 de 10.07.2003, a inclusão de um "braço" do Protocolo de Pesquisa SDC - 1943/01/131 "Aplicação do teste de dimero-D para exclusão de eventos tromboembólicos: Impacto de sua utilização nos custos totais da investigação diagnóstica", que será utilizado como tese de Doutorado e terá como título "Valor do teste de dimero-D no diagnóstico de exclusão do tromboembolismo venoso agudo", e foi o seguinte o parecer: "Aprovado".

Atenciosamente,

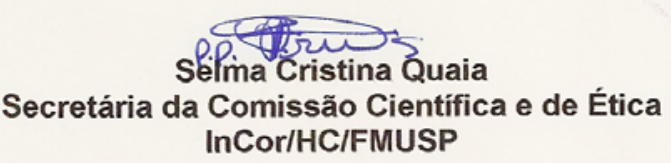


ANEXO B - Aprovação da Comissão de Ética para Análise de Projetos de Pesquisa CAPPesq

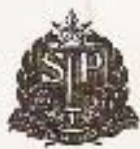

\section{Hospital das ClíNICAS \\ DA FaCULDADE DE MEDICINA dA UNIVERSIDADE DE SĂo PAULO}

CAIXA POSTAL, 8091 - SÃO PAULO - BRASIL

\section{DIRETORIA CLINICA}

\section{Comissão de Ética para Análise de Projetos de Pesquisa}

\section{APROVACÃO}

A Comissão de Ética para Análise de Projetos de Pesquisa - CAPPesq da Diretoria Clínica do Hospital das Clínicas e da Faculdade de Medicina da Universidade de São Paulo, em sessão de 28.08.03, APROVOU a inclusão de um "braço" no Protocolo de Pesquisa $n^{\circ} 803 / 01$, intitulado: "Aplicação do teste de Dimero- $D$ para exclusão de eventos tromboembólico: Impacto de sua utilização nos custos totais da investigação diagnóstica", que será utilizado como tese de Doutorado e teró como título "Valor do teste de dímero- $D$ no diagnóstico de exclusão do tromboembolismo venoso agudo.

Comissão Cientifíca e de Ética do Incor

Pesquisador(a) Responsável: Prof. Dr. Roberto Abi Rached Pesquisador(a) Executante: Sra. Luciana Pereira Almeida

CAPPesq, 2 de setembro de 2003.<smiles>CCCCCCCCCCCCC</smiles>
PROF. DR. EUCLIDES AYRES DE CASTIL.HO Presidente da Comissão Ética para Análise de Projetos de Pesquisa

OBSERVAÇÃO: Cabe ao pesquisador elobarar $e$ apresentar a CAPPesq, os relatónios parciais e final sobre a pesquisa (Resoluciöo do Conselho Nacional de Soúde $n^{\circ} 196$, de 10.10.1996, inciso IX,2, letra " $c$ ") 
ANEXO C - Termo de consentimento pós - informação

\section{Avaliação do Teste do Dímero - D no Diagnóstico de Exclusão do Tromboembolismo Venoso Agudo \\ Instituto do Coração - InCor e Hospital das Clínicas da Faculdade de Medicina da Universidade de São Paulo. \\ HOSPITAL DAS CLÍNICAS \\ DA FACULDADE DE MEDICINA DA UNIVERSIDADE DE SÃO PAULO TERMO DE CONSENTIMENTO PÓS -INFORMAÇÃO}

(Instruções para preenchimento no verso)

I - DADOS DE IDENTIFICAÇÃO DO SUJEITO DA PESQUISA OU RESPONSÁVEL LEGAL

1. NOME DO PACIENTE :

DOCUMENTO DE IDENTIDADE NO :

SEXO : .M $F$

DATA NASCIMENTO: $. / \ldots \ldots . . . . . . .$.

ENDEREÇO No APTO:

BAIRRO: CIDADE

CEP: TELEFONE: DDD ( )

2.RESPONSÁVEL LEGAL

NATUREZA (grau de parentesco, tutor, curador etc.)

DOCUMENTO DE IDENTIDADE :

SEXO: $M \quad F$

DATA NASCIMENTO.: ....................

ENDEREÇO: No APTO:

BAIRRO:

CIDADE:

CEP:

TEL: DDD

.) 


\section{II - DADOS SOBRE A PESQUISA CIENTÍFICA}

1. TÍTULO DO PROTOCOLO DE PESQUISA .APLICAÇÃO DO TESTE DE DÍMERO - D PARA EXCLUSÃO DE EVENTOS TROMBOEMBÓLICO: Impacto de sua utilização nos custos totais da investigação diagnóstica.

PESQUISADOR: Dr. Roberto Abi Rached

CARGO/FUNÇÃO: Médico Chefe do Ambulatório de Hematologia do InCor INSCRIÇÃO CONSELHO REGIONAL NO 47.946

UNIDADE DO HCFMUSP: .Instituto do Coracao

3. AVALIAÇÃO DO RISCO DA PESQUISA:

SEM RISCO $\quad \times$ RISCO MÍNIMO $\quad$ RISCO MÉDIO RISCO BAIXO RISCO MAIOR

(probabilidade de que o indivíduo sofra algum dano como consequência imediata ou tardia do estudo)

4.DURAÇÃO DA PESQUISA: 6 meses

\section{III - REGISTRO DAS EXPLICAÇÕES DO PESQUISADOR AO PACIENTE OU SEU REPRESENTANTE LEGAL SOBRE A PESQUISA, CONSIGNANDO:}

1. justificativa e os objetivos da pesquisa ; 2. procedimentos que serão utilizados e propósitos, incluindo a identificação dos procedimentos que são experimentais; 3. desconfortos e riscos esperados; 4. benefícios que poderão ser obtidos; 5. procedimentos alternativos que possam ser vantajosos para o indivíduo. 
1- Estudar a capacidade de um exame laboratorial (dímero - D) para excluir o diagnóstico de eventos tromboembólico. Analisar os custos da investigação diagnóstica.

2- Realizar um exame laboratorial com uma única amostra de sangue. Esse exame poderá indicar a necessidade de realizar outros testes para confirmar as suspeitas de um evento tromboembólico.

3- Será coletada uma única amostra de sangue (10 $\mathrm{ml})$ além dos exames normalmente realizados durante $\mathrm{o}$ atendimento de rotina. Terá o desconforto de ser picado no momento da coleta, caso a mesma não seja feita por catéter ou durante a coleta dos exames normalmente realizados. Não apresenta riscos.

4- Poderá afirmar que um paciente não apresenta evento tromboembólico com a realização de um único exame, mesmo que o paciente apresente sintomas muito parecidos.

5- Não precisará realizar exames mais complexos e mais caros. Poderá ser medicado mais rapidamente.

\section{IV - ESCLARECIMENTOS DADOS PELO PESQUISADOR SOBRE GARANTIAS DO SUJEITO DA PESQUISA:}

1. acesso, a qualquer tempo, às informações sobre procedimentos, riscos e benefícios relacionados à pesquisa, inclusive para dirimir eventuais dúvidas. SIM

2. liberdade de retirar seu consentimento a qualquer momento e de deixar de participar do estudo, sem que isto traga prejuízo à continuidade da assistência. SIM

3. salvaguarda da confidencialidade, sigilo e privacidade. SIM 
4. disponibilidade de assistência no HCFMUSP, por eventuais danos à saúde, decorrentes da pesquisa.SIM

5. viabilidade de indenização por eventuais danos à saúde decorrentes da pesquisa. SIM

\title{
V. INFORMAÇÕES DE NOMES, ENDEREÇOS E TELEFONES DOS RESPONSÁVEIS PELO ACOMPANHAMENTO DA PESQUisa, PARA CONTATO EM CASO DE INTERCORRÊNCIAS CLÍNICAS E REAÇÕES ADVERSAS.
}

\author{
Dr. Roberto Abi Rached \\ Dr. Cyrillo Cavalheiro Filho \\ Luciana Pereira Almeida De Piano
}

Av. Dr. Enéas de Carvalho Aguiar, 44- Banco de Sangue- InCor- Fone: 30695000, R 5403; 5096

\section{OBSERVAÇÕES COMPLEMENTARES}

\section{VII - CONSENTIMENTO PÓS-ESCLARECIDO}

Declaro que, após convenientemente esclarecido pelo pesquisador e ter entendido o que me foi explicado, consinto em participar do presente Protocolo de Pesquisa

São Paulo, de de

assinatura do sujeito da pesquisa ou responsável legal assinatura do pesquisador

.(carimbo ou nome Legível) 


\section{INSTRUÇÕES PARA PREENCHIMENTO}

\section{(Resolução Conselho Nacional de Saúde 196, de 10 outubro}

\section{6)}

1. Este termo conterá o registro das informações que o pesquisador fornecerá ao sujeito da pesquisa, em linguagem clara e acessível, evitando-se vocábulos técnicos não compatíveis com o grau de conhecimento do interlocutor.

2. A avaliação do grau de risco deve ser minuciosa, levando em conta qualquer possibilidade de intervenção e de dano à integridade física do sujeito da pesquisa.

3. O formulário poderá ser preenchido em letra de forma legível, datilografia ou meios eletrônicos.

4. Este termo deverá ser elaborado em duas vias, ficando uma via em poder do paciente ou seu representante legal e outra deverá ser juntada ao prontuário do paciente.

5. A via do Termo de Consentimento Pós - Informação submetida à análise da Comissão de Ética para Análise de Projetos de Pesquisa - CAPPesq deverá ser idêntica àquela que será fornecida ao sujeito da pesquisa. 
ANEXO D - Entrevista individual pacientes com sinais e sintomas sugestivos de tromboembolismo venoso agudo

\section{FICHA INDIVIDUAL}

Nome (etiqueta): Registro:

Sexo: _ Estatura: __ Peso: __ Idade: __ Data de Nascimento:

Data e hora da admissão: : hs

Contato (telefone, endereço, celular):

Informante:

Quadro Clínico do possível evento tromboembólico agudo:

(TEP: dor torácica, taquipnéia, dispinéia, síncope, tosse, hemoptise)

(TVP: dor na perna, edema, hiperemia)

Fatores de risco presentes no quadro atual (cirurgia, trauma, gestação, parto, puerpério, hormônio, imobilização (gesso, viagem, leito) especificar):

Antecedentes Trombose:
- Pessoais:
( ) $\operatorname{sim}$
( ) não

Especificar:

- Familiares:

( ) $\operatorname{sim}$

( ) não

Especificar:

Medicamentos de uso habitual (antes da internação): 
Condições gerais:

- Obesidade

- hipertensão arterial

- fumo

( ) $\operatorname{sim}$

número de cigarros

- atividade física esportista

- trombofilia conhecida (pessoal/familiar) ( ) sim /dia; período:
( ) $\operatorname{sim}$
( ) não

( ) $\operatorname{sim}$

( ) não

( ) não

( ) ex-fumante especificar:

Fatores de risco não relacionados com o quadro atual: (cirurgia, trauma, gestação, parto, puerpério, hormônio, imobilização (gesso, viagem, leito) especificar):

Doenças (diabetes, dislipidemias, câncer, cardiopatia e outros):

Medicamentos durante a internação (nome, dose e duração):

Exames e procedimentos na internação (nome e número de exames):

Data alta:

Horário de alta: h

Dímero - D VIDAS ${ }^{\circledR}$ : Látex: ( ) Positivo ( ) Negativo $\mathrm{ng} / \mathrm{ml}$ Evento tromboembólico agudo: ( ) Presença ( ) Ausência Especificar:

Pesquisador responsável: 
ANEXO E - Ficha de contacto pós -alta hospitalar dos pacientes com sinais e sintomas sugestivos de tromboembolismo venoso agudo (ficha de retorno)

\section{FICHA DE RETORNO}

Nome (etiqueta) : Registro:

Sexo: Data de nascimento: 1

Data retorno - 30 dias: especificar necessidade de novo atendimento médico com diagnóstico confirmado de evento tromboembólico

Data retorno - 60 dias: especificar necessidade de novo atendimento médico com diagnóstico confirmado de evento tromboembólico 
ANEXO F. Valores de sensibilidade e especificidade da regressão logística entre trombose presente e dímero - D.

\begin{tabular}{ccccc}
\hline $\begin{array}{c}\text { Dímero - D } \\
(\mathrm{ng} / \mathrm{ml})\end{array}$ & $\begin{array}{c}\text { Sensibilidade } \\
(\%)\end{array}$ & $\begin{array}{c}\text { Especificidade } \\
(\%)\end{array}$ & $\begin{array}{c}\text { Falsos }+ \\
(\%)\end{array}$ & $\begin{array}{c}\text { Falsos - } \\
(\%)\end{array}$ \\
\hline 0 & 100 & 0 & 59,6 & 0 \\
390 & 100 & 18,9 & 54,4 & 0 \\
Positivo $\geq \mathbf{5 0 0}$ & $\mathbf{1 0 0}$ & $\mathbf{2 8 , 3}$ & $\mathbf{5 1 , 4}$ & $\mathbf{0}$ \\
764 & 94,4 & 34 & 50,7 & 10 \\
1124 & 75 & 47,2 & 50,9 & 26,5 \\
1472 & 69,4 & 62,3 & 44,4 & 25 \\
1810 & 55,6 & 67,9 & 45,9 & 30,8 \\
2140 & 55,6 & 73,6 & 41,2 & 29,1 \\
2463 & 41,7 & 77,4 & 44,4 & 33,9 \\
2781 & 38,9 & 77,4 & 46,2 & 34,9 \\
3095 & 38,9 & 77,4 & 46,2 & 34,9 \\
3406 & 38,9 & 83 & 39,1 & 33,3 \\
3715 & 36,1 & 83 & 40,9 & 34,3 \\
4023 & 27,8 & 84,9 & 44,4 & 36,6 \\
4331 & 25 & 84,9 & 47,1 & 37,5 \\
4639 & 25 & 84,9 & 47,1 & 37,5 \\
4950 & 22,2 & 86,8 & 46,7 & 37,8 \\
5264 & 22,2 & 86,8 & 46,7 & 37,8 \\
5582 & 19,4 & 88,7 & 46,2 & 38,2 \\
5906 & 13,9 & 90,6 & 50 & 39,2 \\
6236 & 11,1 & 90,6 & 55,6 & 40 \\
6574 & 11,1 & 92,5 & 50 & 39,5 \\
6922 & 11,1 & 92,5 & 50 & 39,5 \\
7282 & 11,1 & 92,5 & 50 & 39,5 \\
7655 & 8,3 & 92,5 & 57,1 & 40,2 \\
8046 & 5,6 & 94,3 & 60 & 40,5 \\
8456 & 5,6 & 96,2 & 50 & 40 \\
8891 & 5,6 & 98,1 & 33,3 & 39,5 \\
9355 & 5,6 & 100 & 0 & 39,1 \\
9855 & 0 & 100 & 0 & 40,4 \\
\hline
\end{tabular}


ANEXO G. Valores de sensibilidade e especificidade da regressão logística entre trombose presente e dímero - D para pacientess com suspeita de TEP.

\begin{tabular}{|c|c|c|}
\hline Concentração de dímero - D (ng/ml) & Sensibilidade (\%) & Especificidade (\%) \\
\hline 102 & 100 & 100 \\
\hline 118,5 & 100 & 96 \\
\hline 147 & 100 & 92 \\
\hline 206 & 100 & 88 \\
\hline 273 & 100 & 85 \\
\hline 321 & 100 & 81 \\
\hline 388,5 & 100 & 77 \\
\hline 441 & 100 & 73 \\
\hline 492 & 100 & 69 \\
\hline 619 & 100 & 65 \\
\hline 713 & 94 & 65 \\
\hline 743,5 & 94 & 61 \\
\hline 808,5 & 88 & 61 \\
\hline 928,5 & 88 & 58 \\
\hline 1017,5 & 88 & 54 \\
\hline 1039,5 & 82 & 54 \\
\hline 1056,5 & 76 & 54 \\
\hline 1077 & 76 & 50 \\
\hline 1144 & 76 & 46 \\
\hline 1216 & 716 & 46 \\
\hline 1237,5 & 71 & 42 \\
\hline 1278 & 65 & 42 \\
\hline Positivo $\geq 1330$ & 65 & 38 \\
\hline 1378 & 59 & 38 \\
\hline 1629 & 53 & 38 \\
\hline 1847 & 47 & 38 \\
\hline 1881,5 & 41 & 38 \\
\hline 1914,5 & 41 & 35 \\
\hline 1985,5 & 41 & 31 \\
\hline 2118,5 & 41 & 27 \\
\hline 2243,5 & 41 & 23 \\
\hline 2389 & 35 & 23 \\
\hline 2763,5 & 29 & 23 \\
\hline 3088 & 29 & 19 \\
\hline 3502,5 & 29 & 15 \\
\hline 4151,5 & 23 & 15 \\
\hline 4670 & 23 & 11 \\
\hline 5096 & 18 & 11 \\
\hline 5581,5 & 18 & 7 \\
\hline 7305,5 & 12 & 3 \\
\hline 7831,5 & 5 & 3 \\
\hline 8046,5 & 0 & 3 \\
\hline 8092 & 0 & 0 \\
\hline
\end{tabular}


ANEXO H . Valores de sensibilidade e especificidade da regressão logística entre trombose presente e dímero - D para pacientes com suspeita de TVP.

\begin{tabular}{|c|c|c|}
\hline Concentração de dímero - D (ng/ml) & Sensibilidade (\%) & Especificidade (\%) \\
\hline 92 & 100 & 100 \\
\hline 114 & 100 & 95 \\
\hline 150 & 100 & 89 \\
\hline 171,5 & 100 & 84 \\
\hline 193 & 100 & 79 \\
\hline 315 & 100 & 74 \\
\hline 497 & 100 & 68 \\
\hline 614,5 & 100 & 63 \\
\hline 672,5 & 100 & 58 \\
\hline 738 & 100 & 53 \\
\hline 810,5 & 100 & 47 \\
\hline 957,5 & 100 & 42 \\
\hline 1091 & 100 & 37 \\
\hline 1141,5 & 92 & 37 \\
\hline 1210 & 92 & 32 \\
\hline 1265,5 & 83 & 32 \\
\hline 1368 & 83 & 26 \\
\hline 1463,5 & 83 & 21 \\
\hline Positivo $\geq 1564$ & 83 & 16 \\
\hline 1696 & 75 & 16 \\
\hline 1872,5 & 67 & 16 \\
\hline 2155 & 67 & 10 \\
\hline 2362 & 58 & 10 \\
\hline 2428 & 50 & 10 \\
\hline 2645 & 42 & 10 \\
\hline 3039 & 33 & 10 \\
\hline 3561 & 33 & 5 \\
\hline 4798,5 & 25 & 5 \\
\hline 5778 & 17 & 5 \\
\hline 6564,5 & 83 & 5 \\
\hline 8641 & 83 & 0 \\
\hline 10.001 & 0 & 0 \\
\hline
\end{tabular}


ANEXO I. Valores de sensibilidade e especificidade da regressão logística entre trombose presente e dímero - D para pacientes com suspeita de TEP + TVP.

\begin{tabular}{ccc}
\hline $\begin{array}{c}\text { Concentração de dímero - D } \\
(\mathrm{ng} / \mathrm{ml})\end{array}$ & $\begin{array}{c}\text { Sensibilidade } \\
(\%)\end{array}$ & $\begin{array}{c}\text { Especificidade } \\
(\%)\end{array}$ \\
\hline 211 & 100 & 100 \\
558 & 100 & 87 \\
1063 & 100 & 75 \\
1273,5 & 86 & 75 \\
1386 & 86 & 62 \\
1541 & 86 & 50 \\
2638 & 71 & 50 \\
Positivo $\geq \mathbf{3 6 5 9 , 5}$ & $\mathbf{5 7}$ & $\mathbf{5 0}$ \\
3831,5 & 57 & 37 \\
4182 & 43 & 37 \\
4763,5 & 29 & 37 \\
5475,5 & 29 & 25 \\
6106 & 29 & 12 \\
7087 & 14 & 12 \\
8882,5 & 14 & 0 \\
10.001 & 0 & 0 \\
\hline
\end{tabular}


ANEXO J. Valores de sensibilidade e especificidade da regressão logística entre trombose presente e dímero - $\mathrm{D}$ para pacientes na faixa etária menos de 40 anos.

\begin{tabular}{ccc}
\hline Concentração de dímero - D (ng/ml) Sensibilidade (\%) & Especificidade (\%) \\
\hline 92 & 100 & 100 \\
98 & 100 & 92 \\
118,5 & 100 & 85 \\
134,5 & 100 & 77 \\
147,5 & 100 & 69 \\
169 & 100 & 61 \\
193 & 100 & 54 \\
448 & 100 & 46 \\
697,5 & 100 & 38 \\
857,5 & 89 & 38 \\
Positivo $\geq \mathbf{1 1 0 1 , 5}$ & $\mathbf{8 9}$ & $\mathbf{3 1}$ \\
1216 & 78 & 31 \\
1281 & 67 & 31 \\
1383,5 & 67 & 23 \\
1463,5 & 67 & 15 \\
1895 & 67 & 8 \\
2357,5 & 56 & 8 \\
2441,5 & 44 & 8 \\
2853,5 & 33 & 8 \\
3558,5 & 33 & 0 \\
3885,5 & 22 & 0 \\
5774,5 & 11 & 0 \\
7662 & 0 & 0 \\
\hline
\end{tabular}


ANEXO K. Valores de sensibilidade e especificidade da regressão logística entre trombose presente e dímero - $D$ para pacientes na faixa etária entre 40 e 60 anos.

\begin{tabular}{|c|c|c|}
\hline Concentração de dímero - D (ng/ml) & Sensibilidade (\%) & Especificidade (\%) \\
\hline 164 & 100 & 100 \\
\hline 188,5 & 100 & 94 \\
\hline 232 & 100 & 89 \\
\hline 273 & 100 & 83 \\
\hline 321 & 100 & 78 \\
\hline 385 & 100 & 72 \\
\hline 425,5 & 100 & 67 \\
\hline 480 & 100 & 61 \\
\hline 551,5 & 100 & 56 \\
\hline 614,5 & 100 & 50 \\
\hline 712,5 & 100 & 44 \\
\hline 800,5 & 93 & 44 \\
\hline 841 & 93 & 39 \\
\hline 876,5 & 93 & 33 \\
\hline Positivo $\geq 965,5$ & 93 & 28 \\
\hline 1039,5 & 87 & 28 \\
\hline 1076 & 80 & 28 \\
\hline 1169 & 73 & 28 \\
\hline 1326 & 67 & 28 \\
\hline 1581,5 & 60 & 28 \\
\hline 1796,5 & 53 & 28 \\
\hline 1949,5 & 47 & 28 \\
\hline 2184,5 & 47 & 22 \\
\hline 2380 & 40 & 22 \\
\hline 2750 & 33 & 22 \\
\hline 3088 & 33 & 17 \\
\hline 3381,5 & 33 & 11 \\
\hline 4010 & 27 & 11 \\
\hline 4649,5 & 20 & 11 \\
\hline 5314,5 & 13 & 11 \\
\hline 5756 & 7 & 11 \\
\hline 6542,5 & 7 & 6 \\
\hline 8641 & 7 & 0 \\
\hline 10.001 & 0 & 0 \\
\hline
\end{tabular}


ANEXO L. Valores de sensibilidade e especificidade da regressão logística entre trombose presente e dímero - $D$ para pacientes na faixa etária maior de 60 anos.

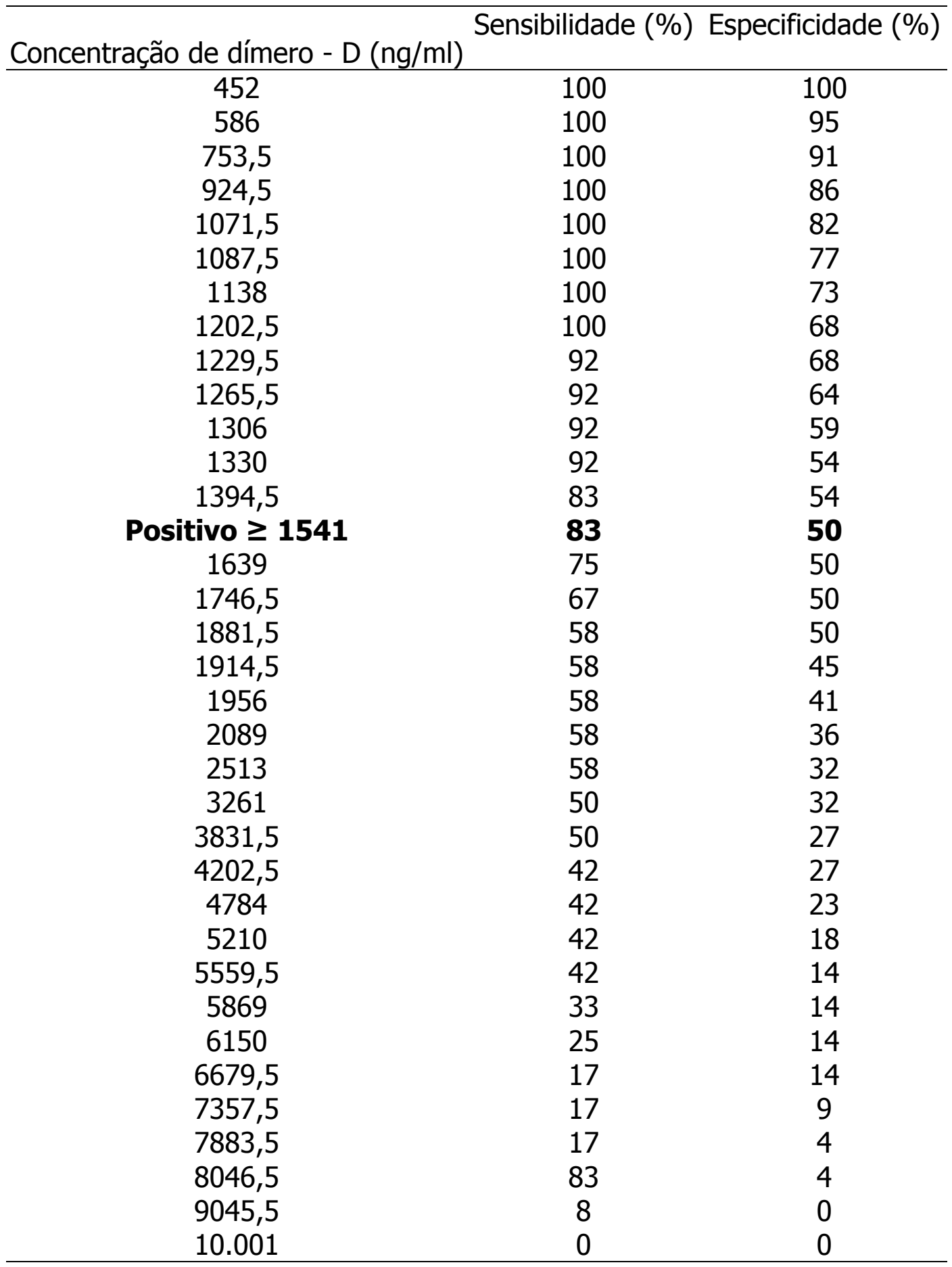


ANEXO M. Valores de sensibilidade e especificidade da regressão logística entre trombose presente e dímero - $\mathrm{D}$ para pacientes com IMC menor do que $30 \mathrm{~kg} / \mathrm{m}^{2}$. (continua)

\begin{tabular}{|c|c|c|}
\hline Concentração de dímero - D (ng/ml) & Sensibilidade (\%) & Especificidade (\%) \\
\hline 92 & 100 & 100 \\
\hline 114 & 100 & 97,3 \\
\hline 147,5 & 100 & 94,6 \\
\hline 169 & 100 & 91,9 \\
\hline 193 & 100 & 89,2 \\
\hline 278 & 100 & 86,5 \\
\hline 388,5 & 100 & 83,8 \\
\hline 441 & 100 & 81,1 \\
\hline 492 & 100 & 78,4 \\
\hline 551,5 & 100 & 75,7 \\
\hline 614,5 & 100 & 73 \\
\hline 672,5 & 100 & 70,3 \\
\hline 697,5 & 100 & 67,6 \\
\hline 713 & 96,2 & 67,6 \\
\hline 743,5 & 96,2 & 64,9 \\
\hline 778 & 92,3 & 64,9 \\
\hline 810,5 & 92,3 & 62,2 \\
\hline 841 & 92,3 & 59,5 \\
\hline 876,5 & 92,3 & 56,8 \\
\hline 965,5 & 92,3 & 54,1 \\
\hline 1039,5 & 88,5 & 54,1 \\
\hline 1056,5 & 84,6 & 54,1 \\
\hline 1071,5 & 84,6 & 51,4 \\
\hline 1091 & 84,6 & 48,6 \\
\hline 1141,5 & 80,8 & 48,6 \\
\hline 1189 & 80,8 & 45,9 \\
\hline 1216 & 76,9 & 45,9 \\
\hline 1237,5 & 73,1 & 43,2 \\
\hline 1266 & 69,2 & 43,2 \\
\hline 1306 & 69,2 & 40,5 \\
\hline 1321,5 & 69,2 & 37,8 \\
\hline 1333,5 & 69,2 & 35,1 \\
\hline Positivo $\geq 1378$ & 65,4 & 35,1 \\
\hline 1449,5 & 61,5 & 35,1 \\
\hline 1560 & 61,5 & 32,4 \\
\hline 1692 & 57,7 & 32,4 \\
\hline 1796,5 & 53,8 & 32,4 \\
\hline 1920 & 50 & 32,4 \\
\hline 2025,5 & 50 & 29,7 \\
\hline 2180 & 50 & 27 \\
\hline 2309,5 & 46,2 & 27 \\
\hline 2362 & 42,3 & 27 \\
\hline
\end{tabular}


ANEXO M. Valores de sensibilidade e especificidade da regressão logística entre trombose presente e dímero - $D$ para pacientes com IMC menor do que $30 \mathrm{~kg} / \mathrm{m}^{2}$. (conclusão)

\begin{tabular}{ccc}
\hline Concentração de dímero - D (ng/ml) & Sensibilidade (\%) & Especificidade (\%) \\
2441,5 & 38,5 & 27 \\
2658,5 & 34,6 & 27 \\
2949 & 30,8 & 27 \\
3088 & 30,8 & 24,3 \\
3178 & 30,8 & 21,6 \\
3437,5 & 30,8 & 18,9 \\
3659,5 & 26,9 & 18,9 \\
3780,5 & 26,9 & 16,2 \\
3885,5 & 23,1 & 16,2 \\
3936,5 & 19,2 & 16,2 \\
4202,5 & 15,4 & 16,2 \\
5111,5 & 15,4 & 13,5 \\
5825 & 15,4 & 10,8 \\
6398,5 & 11,5 & 10,8 \\
7116 & 11,5 & 8,1 \\
7523,5 & 11,5 & 5,4 \\
7883,5 & 11,5 & 2,7 \\
8046,5 & 7,7 & 2,7 \\
9045,5 & 7,7 & 0 \\
10.001 & 0 & 0 \\
\hline
\end{tabular}


ANEXO N. Valores de sensibilidade e especificidade da regressão logística entre trombose presente e dímero - D para pacientes com IMC igual ou maior do que $30 \mathrm{~kg} / \mathrm{m}^{2}$.

\begin{tabular}{ccc}
\hline Concentração de dímero - D (ng/ml) & Sensibilidade (\%) & Especificidade (\%) \\
\hline 2110 & 100 & 100 \\
232 & 100 & 90 \\
273 & 100 & 80 \\
358 & 100 & 70 \\
757,5 & 100 & 60 \\
1267,5 & 100 & 50 \\
1444,5 & 100 & 40 \\
1648,5 & 100 & 30 \\
1881,5 & 85,7 & 30 \\
1914,5 & 85,7 & 20 \\
Positivo $\geq \mathbf{2 1 8 1}$ & $\mathbf{8 5 , 7}$ & $\mathbf{1 0 0}$ \\
3412,5 & 71,4 & 100 \\
4649,5 & 57,1 & 100 \\
5034 & 42,9 & 100 \\
5428,5 & 42,9 & 0 \\
6059 & 28,6 & 0 \\
7035 & 14,3 & 0 \\
7662 & 0 & 0 \\
\hline
\end{tabular}


ANEXO O. Valores de sensibilidade e especificidade da regressão logística entre trombose presente e dímero - $D$ para pacientes do gênero feminino. (continua)

\begin{tabular}{|c|c|c|}
\hline Concentração de dímero - D (ng/ml) & Sensibilidade (\%) & Especificidade (\%) \\
\hline 92 & 100 & 100 \\
\hline 113,5 & 100 & 97,1 \\
\hline 134,5 & 100 & 94,1 \\
\hline 147,5 & 100 & 91,2 \\
\hline 169 & 100 & 88,2 \\
\hline 193 & 100 & 85,3 \\
\hline 210 & 100 & 82,4 \\
\hline 232 & 100 & 79,4 \\
\hline 337 & 100 & 76,5 \\
\hline 425,5 & 100 & 73,5 \\
\hline 441 & 100 & 70,6 \\
\hline 512,5 & 100 & 67,6 \\
\hline 614,5 & 100 & 64,7 \\
\hline 672,5 & 100 & 61,8 \\
\hline 703,5 & 100 & 58,8 \\
\hline 743,5 & 100 & 55,9 \\
\hline 800,5 & 94,1 & 55,9 \\
\hline 868,5 & 94,1 & 52,9 \\
\hline 956 & 94,1 & 50,0 \\
\hline 1017,5 & 94,1 & 47,1 \\
\hline 1054,5 & 88,2 & 47,1 \\
\hline 1087,5 & 88,2 & 44,1 \\
\hline 1096,5 & 88,2 & 41,2 \\
\hline 1161 & 82,4 & 41,2 \\
\hline 1270 & 76,5 & 41,2 \\
\hline 1321,5 & 76,5 & 38,2 \\
\hline 1333,5 & 76,5 & 35,3 \\
\hline 1392 & 70,6 & 35,3 \\
\hline 1444,5 & 70,6 & 32,4 \\
\hline 1466,00 & 70,6 & 29,4 \\
\hline Positivo $\geq 1560$ & 70,6 & 26,5 \\
\hline 1742,5 & 64,7 & 26,5 \\
\hline 1881,5 & 58,8 & 26,5 \\
\hline 1954,5 & 58,8 & 23,5 \\
\hline 2150,5 & 58,8 & 20,6 \\
\hline 2357,5 & 52,9 & 20,6 \\
\hline 2428 & 47,1 & 20,6 \\
\hline 2750 & 41,2 & 20,6 \\
\hline 3366 & 41,2 & 17,6 \\
\hline 3831,5 & 41,2 & 14,7 \\
\hline
\end{tabular}


ANEXO O. Valores de sensibilidade e especificidade da regressão logística entre trombose presente e dímero - D para pacientes do gênero feminino. (conclusão)

\begin{tabular}{ccc}
\hline Concentração de dímero - D $(\mathrm{ng} / \mathrm{ml})$ & Sensibilidade (\%) & Especificidade (\%) \\
\hline 5210 & 29,4 & 8,8 \\
5490,5 & 29,4 & 5,9 \\
5800 & 23,5 & 5,9 \\
6150 & 17,6 & 5,9 \\
6845,5 & 11,8 & 5,9 \\
7471,5 & 11,8 & 2,9 \\
7713 & 5,9 & 2,9 \\
8882,5 & 5,9 & 0 \\
10.001 & 0 & 0 \\
\hline
\end{tabular}


ANEXO P. Valores de sensibilidade e especificidade da regressão logística entre trombose presente e dímero - $D$ para pacientes do gênero masculino.

\begin{tabular}{|c|c|c|}
\hline Concentração de dímero - D (ng/ml) & Sensibilidade (\%) & Especificidade (\%) \\
\hline 102 & 100 & 100 \\
\hline 134 & 100 & 94,7 \\
\hline 229,5 & 100 & 89,5 \\
\hline 321 & 100 & 84,2 \\
\hline 439,5 & 100 & 78,9 \\
\hline 619 & 100 & 73,7 \\
\hline 747,5 & 94,7 & 73,7 \\
\hline 818,5 & 94,7 & 68,4 \\
\hline 950,5 & 94,7 & 63,2 \\
\hline 1056,5 & 89,5 & 63,2 \\
\hline 1122 & 89,5 & 57,9 \\
\hline 1189 & 89,5 & 52,6 \\
\hline 1216 & 84,2 & 52,6 \\
\hline 1237,5 & 78,9 & 47,4 \\
\hline 1266 & 73,7 & 47,4 \\
\hline 1354 & 73,7 & 42,1 \\
\hline 1528,5 & 68,4 & 42,1 \\
\hline Positivo $\geq 1696$ & 63,2 & 42,1 \\
\hline 1796,5 & 57,9 & 42,1 \\
\hline 1880 & 52,6 & 42,1 \\
\hline 1985,5 & 52,6 & 36,8 \\
\hline 2118,5 & 52,6 & 31,6 \\
\hline 2248 & 52,6 & 26,3 \\
\hline 2393,5 & 47,4 & 26,3 \\
\hline 2658,5 & 42,1 & 26,3 \\
\hline 2983 & 36,8 & 26,3 \\
\hline 3178 & 36,8 & 21,1 \\
\hline 3437,5 & 36,8 & 15,8 \\
\hline 3762 & 31,6 & 15,8 \\
\hline 3885,5 & 26,3 & 15,8 \\
\hline 4404 & 21,1 & 15,8 \\
\hline 5361,5 & 15,8 & 15,8 \\
\hline 5825 & 15,8 & 10,5 \\
\hline 6398,5 & 10,5 & 10,5 \\
\hline 7476 & 10,5 & 5,3 \\
\hline 8046,5 & 5,3 & 5,3 \\
\hline 9045,5 & 5,3 & 0 \\
\hline 10.001 & 0 & 0 \\
\hline
\end{tabular}


8 Referências Bibliográficas 
1. Blann A, Lip GYH. Virchow`s triad revisited: the importance of soluble coagulation factors, the endotelium, and platelets. Thromb Res. 2001;101:321-7.

2. Hyers TM, Agnelli G, Hull RD, Morris TA, Samama M, Tapson V, Weg JG. Antithrombotic therapy for venous thromboembolic disease. Chest. 2001;119:176S-193S.

3. Goldhaber SZ. Medical progress: pulmonary embolism. N Engl J Med. 1998;339:93-104.

4. Newman GE. Pulmonary embolism: a historical perspective. J Thorac Imaging. 1989;4:1-3.

5. Eisenberg PR. Does a negative D - dimer exclude trhombosis? Fibrinolysis. 1993;7:32-5.

6. Dalen JE. Pulmonary embolism: what have we learned since Wirchow? Treatment and prevention. Chest. 2002;122:1801-17.

7. Rollo HA, Fortes VB, Fortes Junior AT, Yoshida WB, Lastoria S, Maffei FHA. Abordagem diagnóstica dos pacientes com suspeita de trombose venosa profunda dos membros inferiores. J Vasc Bras. 2005;4:79-88.

8. Ilkhanipour $\mathrm{K}$, Wolfson $\mathrm{AB}$, Walker $\mathrm{H}$, Cillo J, Rolniak $\mathrm{S}$, Cockley $\mathrm{P}$, Mooradian D, Kaplan S. Combining clinical risk with D-dimer testing to rule out deep vein thrombosis. J Emerg Med. 2004;27:233-9.

9. Reitman RD, Emerson RH, Higgins LL, Tarbox TR. A multimodality regimen for deep venous thrombosis prophylaxis in total knee arthroplasty. J Arthroplast. 2003;18:161-8.

10. Kyrle PA, Eichinger S. Deep vein thrombosis. Lancet. 2005, 365:116374.

11. Kyrle PA, Eichinger $S$. Venous thromboembolism in men and women. The Journal of Men's Health Gender. 2005, 2 (3):302-8. 
12. Qaseem A, Snow V, Barry P, Hornbake E R, Rodnick J E, Tobolic T, Ireland B, Segal J, Bass E, Weiss K B, Green L, Owens D K. Current diagnosis of venous thromboembolism in primary care: a clinical practice guideline from the american academy of family physicians and the american college of physicians. Ann Fam Med. 2007;5:57-62.

13. Wood KE. Major pulmonary embolism. Review of a pathophysiologic approach to the golden hour of hemodicamically significant pulmonary embolism. Chest. 2002;121:877-905.

14. Goldhaber SZ, Elliott G. Acute pulmonary: part I epidemiology, pathophysiology and diagnosis. Circulation. 2003;108:2726-29.

15. Goldhaber SZ, Tapson VF. A prospective registry of 5,451 patients with ultrasound-confirmed deep vein thrombosis. Am J Cardiol. 2004;93:259-62.

16. Lualdi JC, Goldhaber SZ. Right ventricular dysfunction after acute pulmonary embolism: pathophysiologic factors, detection, and therapeutic implications. Am Heart J. 1995;130:1276-82.

17. Lip GYH, Lowe GDO, Metcalfe MJ, Rumley A, Dunn FG. Effects of warfarin therapy on plasma fibrinogen, von Willebrand factor, and fibrin Ddimer in left ventricular dysfunction secondary to coronary artery disease with and without aneurysms. Am J Cardiol. 1995;76:453-8.

18. Perrier A, Desmarais $S$, Miron MJ, Moerloose P, Lepage R, Slosman DD, Unger PF, Patenaude JV, Bounameaux. Non-invasive diagnosis of venous thromboembolism in outpatients. Lancet. 1999;353:190-5.

19. Fowkes FJI, Price JF, Fowkes FGR. Incidence of diagnosed deep vein thrombosis in the general population: systematic review. Eur J Vasc Endovasc Surg. 2003;25:1-5.

20. Indik JH, Alpert JS. Detection of pulmonart embolism by D-dimer assay, spiral computed tomography, and magnetic resonance imaging. Prog Cardiovasc Dis. 2000;42:261-72.

21. Rodger M, Wells PS. Diagnosis of pulmonary embolism. Thromb Res. 2001;103:V225-V238.

22. Planes A, Vochelle N, Darmon JY, Fagola M, Bellaud M, Huet Y. Risk of deep vein thrombosis after hospital discharge in patients having undergone total hip replacement: double-blind randomised comparison of enoxaparin versus placebo. Lancet. 1996;348:224-8. 
23. Janssen $M C H$, Heebels $A E$, Metz $M$, Verbruggen $H$, Wollersheim $H$, Janssen S, Schuurmans MMJ, Nováková RO. Reliability of five rapid D-dimer assys compared to ELISA in the exclusion of deep venous thrombosis. Thromb Haemost. 1997;77:262-6.

24. Dahl AO, Andreassen G, Aspelin T, et al.Prolonged thromboprophylaxis following hip replacement surgery-results of a double-blind, prospective, randomized, placebo-controlled study with dalteparin (Fragmin). Thromb Haemost. 1997;77:26-31.

25. Hull RD, Raskob GE, Brant RF, Pineo GF, Elliott G, Stein PD, Gottschalk A, Valentine KA, Mah AF. Low-molecular-weight heparin vs heparin in the treatment of patients with pulmonary embolism. Arch Intern Med. 2000;160:229-36.

26. Van der Graaf $F$, van den Borne $H$, van der Kolk $M$, Wild $P J$, Janssen GWT, van Uum SHM. Exclusion of deep venous thrombosis with D-dimer testing. Thromb Haemost. 2000;83:191-8.

27. Rocha AT, Tapson VF. Venous thromboembolism in intensive care patients. Clin Chest Med. 2003;24:103-22.

28. Lushers JM. Screening and diagnosis of coagulation disorders. Am J Obste Gynecol. 1996;175:778-83.

29. Legnani C, Fariselli S, Cini M, Oca G, Abate C, Palareti G. A new rapid bedside testing of D-dimer (Cardiac D-dimer) in the diagnostic work-up for deep vein thrombosis. Thromb Res. 2003;111:149-53.

30. Perone $\mathrm{N}$, Bounameaux $\mathrm{H}$, Perrier A .Comparison of four diagnosing deep vein thrombosis: a cost-effectiveness analysis. Am J Med. 2001;110:33-40.

31. Fedullo PF, Tapson VF. The evaluation of suspected pulmonary embolism. N Engl Journal Med. 2003;349:1247-56.

32. Kearon C, Ginsberg J, Hirsh J. The role of venous ultrasonography in the diagnosis of suspected deep venous thrombosis and pulmonary embolism. Am Coll Physicians. 1998;129:1044-9.

33. Wells PS, Anderson DR, Rodger M, Stiell I, Dreyer JF, Barnes D, Forgie M, Kovacs G, Ward J, Kovacs M. Excluding pulmonary embolism at the bedside without diagnostic imaging: management of patients with suspected pulmonary embolism presenting to the emergency department by using a simple clinical model and D-dimer. Ann Inter Med. 2001;135:98-107. 
34. Anderson DR, Wells PS, Stiell I, MacLeod B, Simms M, Gray L, Robinson KS, Bormanis J, Mitchell M, Lewandowski B, Flowerdew G. Management of patients with suspected deep vein thrombosis in the emergency department: combining use of a clinical diagnosis model with D-dimer testing. J Emerg Med. 2000;19:225-30.

35. Humphreys CW, Moores LK, Shorr AF. Cost-minimization analysis of two algorithms for diagnosis acute pulmonary embolism. Thromb Res. 2004;113:275-82.

36. Ghanima W, Sandset P M. Validation of a new D - dimer microparticle enzyme immunoassay (AxSYM D - Dimer) in patients with suspected pulmonary embolism (PE). Thromb Res. 2006;Dec 7.

37. Parent F, Maître S, Meyer G, Raherison C, Mal H, Lancar R, Couturaud F, Mottier D, Girard P, Simonneau G, Leroyer C. Diagnostic value of D - dimer in patients with suspected pulmonary embolism: results from a multicentre outcome study. Thromb Res. 2007;120(2):195-200.

38. Penaloza A, Mélot C, Dochy E, Blocklet D, Gevenois P A, Wautrecht J C, Lheureux $P$, Motte $S$. Assesment of pretest probability of pulmonary embolism in the emergency department by physicians in training using the Wells model. Thromb Res. 2007;120(2):173-9.

39. Meythaler JM, Fisher WS, Rue LW, Johnson A, Davis L, Brunner RC. Screening for venous thromboembolism in traumatic brain injury: limitations of D-dimer assay. Arch Phys Med Rehabil. 2003;84:285-90.

40. Freyburger G, Trillaud $H$, Labrouche $S$, Gauthier $P$, Javorschi S, Bernard $\mathrm{P}$, Grenier N. D-dimer strategy in thrombosis exclusion. Thromb Haemost. 1998;79:32-7.

41. Doh HJ, Song KS, Kang MS, Kim DS, Kim KA, Kang J, Jang Y, Chung KH. Novel monoclonal antibody that recognizes new neoantigenic determinant of D-dimer. Thromb Res. 2006;118:353-60.

42. Gaffney PJ. D-dimer. History of the discovery, characterisation and utility of this and other fragments. Fibrinolysis. 1993;7:2-8.

43. Giavarina D, Mezzena G, Dorizzi RM, Soffiati. Reference interval of Ddimer in pregnant women. Clin Biochem. 2001;34:331-3.

44. Eichinger S, Minar E, Bialonczyk C, Hirschl M, Quehenberger $P$, Schneider B, Weltermann A, Wagner O, Kyrle PA. D-dimer levels and risk of recurrent venous thromboembolism. JAMA. 2003;290:1071-4. 
45. Parolari A, Colli S, Mussoni L, Eligini S, Naliato M, Wang X, Gandini S, Tremoli $E$, Biglioli $P$, Alemanni F. Coagulation and fibrinolytic markers in a two-month follow-up of coronary bypass surgery. J Thorac Cardiovasc Surg. 2003;125:336-43.

46. D'Angelo A, D'Alessandro G, Tomassin L, Pittet JL, Dupuy G, Crippa L. Evaluation of a new rapid quantitative D-dimer assay in patients with clinically suspected deep vein thrombosis. Thromb Haemost. 1996;75:4126.

47. Moerloose P, Desmarais S, Bounameaux H, Reber G, Perrier A, Dupuy G, Pittet JL. Contribuition of a new, rapid, individual and quantitative automated D-dimer ELISA to exclude pulmonary embolism. Thromb Haemost. 1996;75:11-3.

48. Pittet JL, Moerloose P, Reber G, Durand C, Villard C, Piga N, Rolland D, Comby S, Dupuy G. VIDAS ${ }^{\circledR}$ D-dimer: fast quantitative ELISA for measuring D-dmer in plasma. Clin Chem. 1996;42:410-5.

49. Bounameaux $\mathrm{H}$, Moerloose $\mathrm{P}$, Perrier A, Miron MJ. D-dimer testing in suspected venous thromboembolism: an update. Q J Med. 1997;90:437-42.

50. Goldhaber SZ. Pulmonary embolism. Lancet. 2004;363:1295-305.

51. Elias A, Aptel I, Huc B, Chalé JJ, Nguyen F, Cambus JP, Boccalon H, Boneu B. D-dimer test and diagnosis of deep vein thrombosis: a comparative study of 7 assays. Thromb Haemost. 1996;76:518-22.

52. Perrier $A$, Bounameaux $H$. Cost - effective diagnosis of deep vein thrombosis and pulmonary embolism. Thromb Haemost. 2001;86:475-87.

53. MacCallum PK, Mead TW. Haemostatic function, arterial disease and the prevention of arterial thrombosis. Bailliere`s Clin Haematol. 1999;12:57799.

54. Michiels J], van der Gadisseur A, Pianken M, Schroyens W, De Maesenger M, Hermsen JT, Trienekens PH, Hoogsteden $H$, Pattynama PMP. Different accuracies of rapid enzyme-linked immunosorbent, turbidimetric, and agglutination d-dimer assays for thrombosis exclusion: impact on diagnostic work-ups of outpatients with suspected deep vein thrombosis and pulmonary embolism. Semin Thromb Hemost. 2006;32:678-93.

55. Oudega R, Hoes AW, Toll DB, Moons KGM. The Value of clinical findings and $\mathrm{D}$-dimer tests in diagnosing deep vein thrombosis in primary care. Semin Thromb Hemost. 2006;32:673-7. 
56. VIDAS ${ }^{\circledR}$ D Dimer New. Rio de Janeiro. Bio Mérieux Ltda, 2000. Bula para diagnóstico in vitro.

57. Geerts WH, Pineo GF, Heit J A, Bergqvist D, Lassen M R, Colwell C W, Ray J G.Prevention of venous thromboembolism. The seventh ACCP conference on antithrombotic and thrombolytic therapy. Chest. 2004;126:338S-400S.

58. Rosner B. - Fundamentals of biostatistics. $2^{\text {nd }}$ ed. Boston: PWS Publishers;1986. 584p.

59. Fletcher RH, Fletcher SW, Wagner EH. Epidemiologia clínica: elementos essenciais. $3^{\mathrm{a}}$ ed São Paulo: Artmed Editora, 2002. 281p.

60. Martinez EZ, Louzada - Neto F, Pereira B B. A curva ROC para testes diagnósticos. Cadernos Saúde Coletiva. 2003;11(1):7-31.

61. Wells PS, Anderson DR, Bormanis J, Guy F, Mitchell M, Gray L, Clement $\mathrm{C}$, Robinson KS, Lewandowski B. Value of assessment of pretest probability of deep-vein thrombosis in clinical mangement. Lancet. 1997;350:1795-8.

62. Bucek RA, Koca N, Reiter M, Haumer M, Zontsich T, Minar E. Algorithms of the diagnosis of deep-vein thrombosis in patients with low clinical pretest probability. Thromb Res. 2002;105:43-7.

63. Wells PS, Hirsch J, Anderson DR, Lensing AWA, Foster G, Kearon C, Weitz J, Dòvidio R, Cogo A, Prandoni P, Girolami A, Ginsberg JS. Accuracy of clinical assessment of deep-vein thrombosis. Lancet. 1995;345:1326-30.

64. Rodger MA, Gagné-Rodger C, Howley HE, Carrier M, Coyle D, Wells PS. The outpatients treatment of deep vein thrombosis delivers cost savings to patients and their families, compared to inpatients therapy. Thromb Res. 2003; 112:13-8.

65. Quiroz R, Schoepf J. CT pulmonary angiography for acute pulmonary embolism: cost-effectiveness analysis and review of the literature. Semin Roentgenol. 2005;40:20-4.

66. Risch L, Monn A, Luthy $R$, Honegger $H$, Huber AR. The predictive characteristics of D-dimer testing in outpatients with suspected venous thromboembolism: a Bayesian approach. Clin Chim Acta. 2004;345:79-87.

67. Perrier A, Nendaz R, Sarasin FP, Howarth N, Bounameaux H. Costeffectiveness analysis of diagnostic strategies for suspected pulmonary embolism including helical computed tomography. Am J Respir Crit Care Med. 2003;167:39-44. 
68. Van Beek EJR, Schenk BE, Michel BC, van den Ende B, Brandjes Dees PM, van der Heide $Y$, Bossuyt PMM, Buller HR. The role of plasm D-dimer concentration in the exclusion of pulmonary embolism. Br J Haematol. 1996;92:725-32.

69. Kovacs MJ, MacKinnon KM, Anderson D, O`Rourke K, Keeney M, Kearon C, Ginsberg J, Wells PS. A comparison of three rapide D-dimer methods for the diagnosis of venous thromboembolism. Br J Haematol. 2001;115:1404.

70. Bonnin $F$, Hadjiikostova $H$, Jebrak $G$, Denninger $M H$, Vera $P$, Rufat $P$, Seknadji P, Bok B. Complementarity of lung scintigraphy and D-dimer test in pulmonary embolism. Eur J Nucl Med. 1997;24:441-7.

71. White RH. The epidemiology of venous thromboembolism. Circulation. 2003;107(23S):14-8.

72. Baglin $\mathrm{T}$, Luddington $\mathrm{R}$, Brown $\mathrm{K}$, Baglin $\mathrm{C}$. Incidence of recurrent thromboembolism in relation to clinical and thrombophilic risk factors: prospective cohort study. Lancet. 2003;362:523-6.

73. Carrier M, Wells PS, Rodger MA. Excluding pulmonary embolism at the bedside with low pre-test probability and D - dimer: safety and clinical utility of 4 methods to assign pre-test probability. Thromb Res. 2006;117:469-74.

74. Yamaki T, Nozaki M, Sakurai H, Takeuchi M, Soejima K, Kono T. Prospective evaluation of a screening protocol to exclude deep vein thrombosis on the basis of a pretest clinical probability score. J Am Coll Surg. 2005;201(5):701-9.

75. Wolf SJ, McCubbin TR, Feldhaus KM, Faragher JP, Adcock DM. Prospective validation of Wells criteria in the evaluation of patients with suspected pulmonary embolism. Ann Emerg Med. 2004;44:503-10.

76. Chunilal SD, Ginsberg JS. Strategies for the diagnosis of deep vein thrombosis and pulmonary embolism. Thromb Res. 2000;97:V33-V48.

77. Perrier A, Roy PM, Aujesky D, Chagnon I, Howarth N, Gourdier AL, Leftheriotis G, Barghouth G, Cornuz J, Hayoz D, Bounameaux H. Diagnosing pulmonary embolism in outpatients with clinical assessment, D-dimer measurement, venous ultrasound, and helical computed tomography: a multicenter management study. Am J Med. 2004;116:291-9. 
78. Von Lode P, Rainaho J, Laiho MK, Punnonen K, Peltola O, Harjola VP, Pettersson K. Sensitive and quantitative, $10-$ min immunofluorometric assay for D - dimer in whole blood. Thromb Res. 2006;118(5):573-85.

79. Vermeer HJ, Ypma P, van Strijen MJL, Muradin AA, Hudig F, Jansen RW, Wijermans PW, Gerrirs WBJ. Exclusion of venous thromboembolism: evaluation of $D$ - dimer PLUS for the quantitative determination of $D$ dimer. Thromb Res. 2005;115:381-6.

80. Stein PD, Hull RD, Pineo GF. The role of newer diagnostic techniques in the diagnosis of pulmonary embolism. Curr Opin Pulm Med. 1999;5:212-8.

81. Stein PD, Hull RD, Patel KC, Olson RE, Ghali WA, Brant R, Biel RK, Bharadia V, Kalra NK. D-dimer for the exclusion of acute venous thrombosis and pulmonary embolism: a systematic review. Ann Intern Med. 2004;140:589-602. 
Apêndices 
APÊNDICE A. Padronização das Coletas de Amostras de Sangue para Testes de Coagulação.

Visando menor desconforto aos pacientes, o Ambulatório de Hematologia do InCor, juntamente com o Laboratório Clínico do InCor, vêm sugerir nova padronização de coleta de sangue para os testes de coagulação. Inicialmente, sugerimos que as coletas sejam realizadas, preferencialmente, através de cateter, evitando repetidas punções venosas. No entanto, nos casos em que não houver cateter ou que não for possível realizar coleta por esta via (de forma adequada), colher as amostras através de punção venosa, segundo os termos sugeridos adiante.

\section{Coletas por Cateter:}

1. Conectar a primeira seringa ao cateter. Colher um volume de $10 \mathrm{ml}$ mais o volume total do "espaço morto", referente ao cateter utilizado. Este volume deverá ser desprezado. Conectar outra seringa (diferente da utilizada para desprezar o volume descrito). Quando houver solicitação de outros exames (que não da hemostasia), coletá-los primeiro, deixando os exames de hemostasia por último. Reforçamos que o desprezo do volume de sangue referente ao "espaço morto" mais os $10 \mathrm{ml}$ objetiva evitar a contaminação da amostra por outras substâncias presentes na via do cateter. Em pacientes pediátricos, pode-se desprezar apenas os primeiros 
$5 \mathrm{ml}$ mais o volume total do "espaço morto", referente ao cateter utilizado.

2. O sangue coletado na seringa deve ser imediatamente transferido para o(s) tubo(s) apropriado(s) ao exame a ser realizado. $\mathrm{O}$ sangue deve fluir pela parede do tubo, nunca deve ser esguichado no centro dele, visto que isto poderia provocar hemólise e ativação das plaquetas e dos fatores de coagulação. A presença de hemólise interfere nos testes de coagulação e invalida os resultados.

3. Após a transferência do sangue para o tubo, e quando houver anticoagulante, inverter o tubo gentilmente por cinco vezes, promovendo assim a mistura do sangue com o anticoagulante presente. Vigorosa agitação deve ser evitada, pois resulta em hemólise e ativação da coagulação.

\section{Coleta por Punção:}

\section{Sistema Vacutainer}

1. Sugere-se que o primeiro tubo coletado por este sistema, após a punção venosa, não seja utilizado para testes de coagulação. Quando apenas o teste de coagulação é necessário, o primeiro tubo então, deve ser descartado. Isto evita a contaminação da amostra por fluidos teciduais.

2. Caso o tubo contenha anticoagulante, inverter gentilmente o tubo por cinco vezes, promovendo assim a mistura do sangue com o mesmo. 


\section{Sistema Butterfly}

1. A coleta de sangue por agulha butterfly reduz a ativação das plaquetas e dos fatores de coagulação causada pela turbulência dos tubos à vácuo. $\mathrm{A}$ contaminação por fluidos teciduais é eliminada pelo desprezo dos primeiros 2 a $3 \mathrm{ml}$ coletados numa primeira seringa.

2. Uma segunda seringa (ou seringas adicionais) é conectada ao sistema e, então, a amostra é coletada.

3. O sangue deve ser transferido imediatamente após a coleta para o(s) tubo(s) apropriado(s) e, quando houver anticoagulante, o tubo deve ser gentilmente invertido por cinco vezes.

\section{Observações:}

- Lembramos que quanto maior o calibre da agulha, menor será a chance de ocorrer hemólise da amostra, por outro lado, haverá maior desconforto para o paciente e maior lesão local com liberação de fluidos teciduais. Devese optar então, por um calibre médio, utilizando-se agulhas de diâmetro próximo de $21 \mathrm{G}$.

- Excesso de manipulação da agulha provoca maior injúria tecidual, promovendo liberação de fluidos teciduais que contaminam a amostra. Devese evitar ainda o uso prolongado do torniquete, visto que isto reduz 0 retorno venoso, provocando estase e elevação de certos fatores da coagulação, podendo alterar os resultados. Portanto, a punção menos traumática possível e o uso correto do torniquete são essenciais. 
APÊNDICE B. Relação do pacientes incluídos e estudados no protocolo (continua)

\begin{tabular}{|c|c|c|c|c|c|c|}
\hline $\mathrm{N}^{\circ}$ & $\begin{array}{c}\text { Nome } \\
\text { (iniciais) }\end{array}$ & RG hospitalar & $\begin{array}{c}\text { Gênero } \\
M / F\end{array}$ & $\begin{array}{l}\text { Idade } \\
\text { (anos) }\end{array}$ & Valor Dímero-D & $\begin{array}{l}\text { TEV } \\
\text { agudo }\end{array}$ \\
\hline 1 & MD & $55327673 \mathrm{I}$ & M & 41 & 294 & NÃO \\
\hline 2 & DWV & $55323715 \mathrm{H}$ & $\mathrm{F}$ & 20 & 93 & NÃO \\
\hline 3 & FMFL & $\mathrm{S} / \mathrm{RG}$ & $\mathrm{F}$ & 29 & 160 & NÃO \\
\hline 4 & GASC & 5146592D & $M$ & 29 & 103 & NÃO \\
\hline 5 & JAS & $5052813 C$ & $M$ & 56 & 348 & NÃO \\
\hline 6 & NMBA & $5257515 G$ & $\mathrm{~F}$ & 55 & 252 & NÃO \\
\hline 7 & AFL & 5095922B & $\mathrm{F}$ & 34 & 134 & NÃO \\
\hline 8 & LBS & $5029610 \mathrm{H}$ & $\mathrm{F}$ & 42 & 429 & NÃO \\
\hline 9 & S] & $5002541 \mathrm{E}$ & $\mathrm{F}$ & 82 & 453 & NÃO \\
\hline 10 & GA & $5371172 \mathrm{H}$ & $M$ & 82 & 2182 & NÃO \\
\hline 11 & DRL & $9458359 \mathrm{C}$ & $M$ & 74 & 8091 & NÃO \\
\hline 12 & EMG & 5073445B & M & 70 & 6950 & NÃO \\
\hline 13 & EPS & $5351870 \mathrm{E}$ & $\mathrm{F}$ & 31 & 1008 & NÃO \\
\hline 14 & JLF & $2131349 \mathrm{I}$ & $\mathrm{F}$ & 95 & 5272 & NÃO \\
\hline 15 & LV & 13556376G & $M$ & 63 & 1061 & NÃO \\
\hline 16 & LUMC & $5008353 \mathrm{~K}$ & $\mathrm{~F}$ & 78 & 4420 & NÃO \\
\hline 17 & MMS & $5361012 C$ & M & 59 & 3122 & NÃO \\
\hline 18 & SV & $2394493 \mathrm{H}$ & M & 77 & 1237 & NÃO \\
\hline 19 & SMMM & $13503092 \mathrm{G}$ & $\mathrm{F}$ & 41 & 3054 & NÃO \\
\hline 20 & JS & $5366442 \mathrm{H}$ & $\mathrm{F}$ & 84 & 719 & NÃO \\
\hline 21 & SJK & 55329896D & M & 51 & 531 & NÃO \\
\hline 22 & MCNF & 2147187D & $\mathrm{F}$ & 67 & 1913 & NÃO \\
\hline 23 & JG & $32222254 \mathrm{~A}$ & M & 44 & 2055 & NÃO \\
\hline 25 & ASCF & 5183760I & $\mathrm{F}$ & 51 & 1318 & NÃO \\
\hline 26 & EMB & 3251884J & $\mathrm{F}$ & 68 & 1093 & NÃO \\
\hline 27 & ESL & 55329412D & $M$ & 47 & 1238 & TEP \\
\hline 28 & $\mathrm{JC}$ & $5326802 \mathrm{~F}$ & $M$ & 71 & 8002 & TEP \\
\hline 29 & INFS & $55370331 G$ & M & 49 & 1414 & TEP \\
\hline 30 & MAC & $55325980 \mathrm{G}$ & $\mathrm{F}$ & 37 & 7661 & TEPTVP \\
\hline 31 & NMP & $2748655 C$ & $\mathrm{~F}$ & 64 & 5891 & TEPTVP \\
\hline 32 & PD & $55328451 \mathrm{I}$ & $M$ & 45 & 4920 & TEP \\
\hline 33 & AFC & 2327994 & M & 31 & 3883 & TEP \\
\hline 34 & ARK & 2334581 & M & 26 & 2473 & TEP \\
\hline 35 & PAC & $5160897 \mathrm{E}$ & $M$ & 36 & 707 & TEP \\
\hline 36 & AZV & $3536684 \mathrm{~F}$ & $\mathrm{~F}$ & 78 & 1342 & TEP \\
\hline 37 & MNA & $5005926 \mathrm{H}$ & $\mathrm{F}$ & 32 & 2305 & TEP \\
\hline 38 & RMB & $5366016 \mathrm{G}$ & $\mathrm{F}$ & 40 & 1027 & TEP \\
\hline 39 & BMS & $3286566 \mathrm{E}$ & $F$ & 65 & 1850 & TEP \\
\hline
\end{tabular}


APÊNDICE B. Relação do pacientes incluídos e estudados no protocolo (continua)

\begin{tabular}{|c|c|c|c|c|c|c|}
\hline No & $\begin{array}{c}\text { Nome } \\
\text { (iniciais) }\end{array}$ & RG hospitalar & $\begin{array}{c}\text { Gênero } \\
\mathrm{M} / \mathrm{F}\end{array}$ & $\begin{array}{c}\text { Idade } \\
\text { (anos) }\end{array}$ & Valor Dímero-D & $\begin{array}{l}\text { TEV } \\
\text { agudo }\end{array}$ \\
\hline 40 & LCS & 5106538G & M & 55 & 1844 & TEP \\
\hline 41 & GSC & $5255907 \mathrm{~B}$ & M & 51 & 1052 & TEP \\
\hline 42 & JPF & $55327177 C$ & M & 13 & 1195 & TEP \\
\hline 43 & RAS & 2075560K & $\mathrm{F}$ & 50 & 768 & TVP \\
\hline 62 & ACS & $3124166 \mathrm{H}$ & M & 58 & 849 & NÃO \\
\hline 63 & PCP & $13557580 \mathrm{H}$ & $\mathrm{F}$ & 31 & 208 & NÃO \\
\hline 64 & NAS & $2415120 C$ & $\mathrm{~F}$ & 37 & 135 & NÃO \\
\hline 65 & ETL & $3117136 \mathrm{H}$ & $\mathrm{F}$ & 52 & 422 & NÃO \\
\hline 66 & AS & $5237336 \mathrm{I}$ & $\mathrm{F}$ & 30 & 178 & NÃO \\
\hline 67 & PSB & S/REG & $M$ & 40 & 165 & NÃO \\
\hline 68 & OS & 2307895 & $\mathrm{~F}$ & 37 & 1442 & NÃO \\
\hline 69 & OF & $7017143 \mathrm{E}$ & $\mathrm{F}$ & 75 & 1996 & NÃO \\
\hline 70 & JJV & 13575454D & $M$ & 76 & 1643 & TVP \\
\hline 71 & MTG & $5351689 A$ & $M$ & 56 & 2446 & TVP \\
\hline 72 & CMS & 5368270J & $M$ & 77 & 788 & NÃO \\
\hline 73 & $\cos$ & $2764743 \mathrm{~A}$ & $\mathrm{~F}$ & 72 & 1082 & NÃO \\
\hline 74 & FAO & 2361060 & $\mathrm{~F}$ & 25 & 2410 & TVP \\
\hline 75 & MTAP & $44207701 \mathrm{~K}$ & $M$ & 34 & 688 & NÃO \\
\hline 76 & MLD & 2331428 & $\mathrm{~F}$ & 55 & 833 & NÃO \\
\hline 77 & DGS & 2336994 & $\mathrm{~F}$ & 51 & 572 & NÃO \\
\hline 78 & CCS & $13574953 \mathrm{~A}$ & $M$ & 75 & 1294 & NÃO \\
\hline 79 & ABS & 13570447G & $\mathrm{F}$ & 24 & 1485 & NAO \\
\hline 80 & MTL & $13575168 \mathrm{I}$ & $\mathrm{F}$ & 55 & 7282 & NÃO \\
\hline 81 & EMO & 3124679D & $\mathrm{F}$ & 50 & 657 & NÃO \\
\hline 82 & RBN & $2640554 \mathrm{~K}$ & $M$ & 37 & 3234 & NÃO \\
\hline 83 & CE & 2314684 & $M$ & 30 & 3888 & TVP \\
\hline 84 & MSL & 13574194I & $\mathrm{F}$ & 79 & $>10.000$ & TVP \\
\hline 85 & NRL & $3349050 \mathrm{C}$ & $\mathrm{F}$ & 57 & 5709 & TVP \\
\hline 86 & $A C$ & $13576398 \mathrm{I}$ & $M$ & 66 & 5847 & TVP \\
\hline 87 & CVS & 2300198 & $M$ & 40 & 1749 & TVP \\
\hline 88 & ECC & 2318828 & $M$ & 27 & 1237 & TVP \\
\hline 89 & FAS & $13556959 \mathrm{H}$ & $M$ & 55 & 2314 & TVP \\
\hline 90 & $C X$ & 2600335D & M & 61 & 2844 & TVP \\
\hline 105 & BAAO & $5227501 \mathrm{~J}$ & $\mathrm{~F}$ & 45 & 1100 & TVP \\
\hline 106 & IFB & 2366678 & $\mathrm{~F}$ & 71 & 6409 & TVP \\
\hline 107 & VSS & 3158782J & M & 51 & 3641 & TEPTVP \\
\hline 108 & MBS & 5323604E & $\mathrm{F}$ & 69 & 3985 & TEP \\
\hline 109 & AMG & 5365183A & $\mathrm{F}$ & 80 & 1635 & TEPTVP \\
\hline 110 & MJR & 5352287C & $\mathrm{F}$ & 78 & 1222 & TEP \\
\hline 111 & $\mathrm{OE}$ & $13575882 C$ & M & 60 & $>10.000$ & TVP \\
\hline
\end{tabular}


APÊNDICE B. Relação do pacientes incluídos e estudados no protocolo (conclusão).

\begin{tabular}{|c|c|c|c|c|c|c|}
\hline $\mathrm{N}^{\circ}$ & $\begin{array}{c}\text { Nome } \\
\text { (iniciais) }\end{array}$ & RG hospitalar & $\begin{array}{c}\text { Gênero } \\
\mathrm{M} / \mathrm{F}\end{array}$ & $\begin{array}{l}\text { Idade } \\
\text { (anos) }\end{array}$ & Valor Dímero-D & $\begin{array}{c}\text { TEV } \\
\text { agudo }\end{array}$ \\
\hline 112 & RBR & 2090966B & $\mathrm{F}$ & 44 & 212 & NÃO \\
\hline 113 & OS & $13439265 \mathrm{H}$ & $\mathrm{F}$ & 20 & 1325 & NÃO \\
\hline 114 & MLCM & 3191000I & $\mathrm{F}$ & 69 & 3678 & NÃO \\
\hline 115 & NP & $2204029 A$ & $M$ & 81 & 1183 & NÃO \\
\hline 116 & MGSS & 2313660 & $\mathrm{~F}$ & 52 & 904 & NÃO \\
\hline 117 & GNP & $13437261 \mathrm{~K}$ & $\mathrm{~F}$ & 43 & 4379 & TVP \\
\hline 118 & $M C$ & 2797808D & $M$ & 74 & 1916 & NÃO \\
\hline 119 & MFC & $2326422 \mathrm{G}$ & $\mathrm{F}$ & 77 & 1447 & NÃO \\
\hline 120 & MFC & $2326422 G$ & $\mathrm{~F}$ & 77 & 5148 & NÃO \\
\hline 121 & MST & $3324979 \mathrm{~K}$ & $\mathrm{~F}$ & 74 & 7765 & NÃO \\
\hline 122 & SJB & 5273732D & M & 59 & 5803 & NÃO \\
\hline
\end{tabular}


APÊNDICE C -. Freqüências dos sintomas nos pacientes com suspeita de TEV agudo.

\begin{tabular}{lccc}
\hline \multicolumn{1}{c}{ Sintomas } & Total $=89$ \\
& Neg.: $53(59,6 \%)$ & Pos.: $36(40,4 \%)$ & $\begin{array}{c}\text { p (teste exato de } \\
\text { Fisher) }\end{array}$ \\
\hline Dor - MI* & $23(43,4)$ & $16(44,4)$ & 1,000 \\
Edema - MI* & $22(41,5)$ & $16(44,4)$ & 0,241 \\
Formigamento - hipoestesia - MI & $4(7,5)$ & $3(8,3)$ & 1,000 \\
Hiperemia - MI* & $5(9,4)$ & $1(2,8)$ & 0,488 \\
Prurido - MI & $1(1,9)$ & 0 & 0,194 \\
Hematoma - MI & $3(5,7)$ & 0 & 1,000 \\
Dispnéia** & $26(49,1)$ & $20(55,6)$ & 1,000 \\
Dor peito** & $24(45,3)$ & $14(38,9)$ & 0,194 \\
Tosse & $17(32,1)$ & $11(30,6)$ & 0,075 \\
Cansaço/ fraqueza & $4(7,5)$ & $10(27,8)$ & 0,431 \\
Tontura & $4(7,5)$ & $1(2,8)$ & 0,168 \\
Hemoptise & $2(3,8)$ & $3(8,3)$ & 1,000 \\
Vômitos/ náusea & $3(5,7)$ & $2(5,6)$ & 1,000 \\
Formigamento no braço & $1(1,9)$ & 0 & 0,155 \\
Desconforto no tórax & 2 & 0 & 0,289 \\
Taquicardia/ palpitação & $1(1,9)$ & $3(8,3)$ & 1,000 \\
Sudorese & $2(3,8)$ & 0 & 0,289 \\
Calafrio & $1(1,9)$ & 0 & 1,000 \\
Síncope & $1(1,9)$ & 0 & 0,155 \\
Cianose periférica & $1(1,9)$ & $1(2,8)$ & 1,000 \\
Cefaléia & $2(3,8)$ & 0 & 1,000 \\
Dor no abdômen & $3(5,7)$ & $1(2,8)$ & 0,194 \\
\hline
\end{tabular}

Legenda: $\mathrm{MI}=$ membro inferior

Obs.:*sintomas dos critérios de inclusão para TVP; **sintomas dos critérios de inclusão para TEP. 
APÊNDICE D -. Freqüências dos sintomas nos pacientes com suspeita de TEP.

\begin{tabular}{lcc}
\hline Sintomas & \multicolumn{2}{c}{ TEP $=43(48,3 \%)$} \\
& Neg. $=26(60,5 \%)$ & Pos. $=17(39,5 \%)$ \\
\hline Dispnéia* & $20(76,9)$ & $15(88,2)$ \\
Dor peito* & $17(65,4)$ & $11(64,7)$ \\
Tosse & $16(61,5)$ & $9(52,9)$ \\
Cansaço/ fraqueza & $3(11,5)$ & $7(41,2)$ \\
Tontura & $4(15,4)$ & $1(5,9)$ \\
Hemoptise & $2(7,7)$ & $3(17,6)$ \\
Vômitos/ náusea & $3(11,5)$ & $2(11,8)$ \\
Formigamento no braço & $1(3,8)$ & 0 \\
Desconforto no tórax & $2(7,7)$ & 0 \\
Taquicardia/ palpitação & $1(3,8)$ & $2(11,8)$ \\
Sudorese & $2(7,7)$ & 0 \\
Calafrio & $1(3,8)$ & 0 \\
Síncope & $1(3,8)$ & 0 \\
Cianose periférica & $1(3,8)$ & $1(5,9)$ \\
Cefaléia & $2(7,7)$ & 0 \\
Dor no abdômen & $1(3,8)$ & $1(5,9)$ \\
\hline
\end{tabular}

Obs.:*sintomas dos critérios de inclusão para TEP. 
APÊNDICE E -. Freqüências dos sintomas nos pacientes com suspeita de TVP.

Sintomas TVP $=31(34,8 \%)$

Dor - membro inferior*

Edema - membro inferior*

Formigamento - hipoestesia - membro inferior

Hiperemia - membro inferior*

Prurido - membro inferior

Hematoma - membro inferior

Dor peito
Neg.: $19(61,3 \%)$ Pos.: $12(38,7 \%)$

$17(89,5)$

$15(78,9)$

$2(10,5)$

$3(15,8)$

$1(5,3)$

$3(15,8)$

$1(5,3)$
$11(91,7)$

$11(91,7)$

$2(16,7)$ 0 0

Obs.:*sintomas dos critérios de inclusão para TVP. 
APÊNDICE F -. Freqüências dos sintomas nos pacientes com suspeita de TEP+TVP.

\begin{tabular}{|c|c|c|}
\hline \multirow[t]{2}{*}{ Sintomas } & \multicolumn{2}{|c|}{ TEP+TVP = $15(16,9 \%)$} \\
\hline & Neg.: $8(53,3 \%)$ & $\begin{array}{c}\text { Pos.: } 7 \\
(46,7 \%)\end{array}$ \\
\hline Dor - MI* & $6(75)$ & $5(71,4)$ \\
\hline Edema - MI* & $7(87,5)$ & $5(71,4)$ \\
\hline Formigamento - hipoestesia - MI & $2(25)$ & $1(14,3)$ \\
\hline Hiperemia - MI* & $2(25)$ & $1(14,3)$ \\
\hline Dispnéia** & $6(75)$ & $5(71,4)$ \\
\hline Dor peito** & $6(75)$ & $2(28,6)$ \\
\hline Tosse & $1(12,5)$ & $3(42,9)$ \\
\hline Cansaço/ fraqueza & $1(12,5)$ & 0 \\
\hline Taquicardia/ palpitação & 0 & $1(14,3)$ \\
\hline Dor no abdome & $1(12,5)$ & 0 \\
\hline
\end{tabular}

Legenda: $\mathrm{MI}=$ membro inferior

Obs.:*sintomas dos critérios de inclusão para TVP; **sintomas dos critérios de inclusão para TEP. 
APÊNDICE G - Freqüência de antecedentes de trombose pessoal e familiar, segregado pelo tipo de suspeita clínica e ausência ou presença de trombose aguda.

\begin{tabular}{|c|c|c|c|c|c|c|c|c|c|}
\hline \multirow{3}{*}{$\begin{array}{l}\text { Antecedentes } \\
\text { de Trombose }\end{array}$} & \multicolumn{9}{|c|}{ Suspeita Clínica } \\
\hline & \multicolumn{3}{|c|}{ TEP } & \multicolumn{3}{|c|}{ TVP } & \multicolumn{3}{|c|}{ TEP + TVP } \\
\hline & $\begin{array}{c}\text { Ausência } \\
26 \\
(60,5)\end{array}$ & $\begin{array}{c}\text { Presença } \\
17 \\
(39,5 \%)\end{array}$ & $\begin{array}{c}\text { Total } \\
43 \\
(48,3 \%)\end{array}$ & $\begin{array}{c}\text { Ausência } \\
19 \\
(61,3 \%)\end{array}$ & $\begin{array}{c}\text { Presença } \\
12 \\
(38,7 \%)\end{array}$ & $\begin{array}{c}\text { Total } \\
31 \\
(34,8 \%)\end{array}$ & $\begin{array}{c}\text { Ausência } \\
8 \\
(53,3 \%)\end{array}$ & $\begin{array}{c}\text { Presença } \\
7 \\
(46,7 \%)\end{array}$ & $\begin{array}{c}\text { Total } \\
15 \\
(16,9 \%)\end{array}$ \\
\hline $\begin{array}{l}\text { Pessoal } \\
\text { Familiar }\end{array}$ & $\begin{array}{c}4 \\
(15,4 \%) \\
6 \\
(23,1 \%)\end{array}$ & $\begin{array}{c}5 \\
(29,4 \%) \\
5 \\
(29,4 \%)\end{array}$ & $\begin{array}{c}9 \\
(20,9 \%) \\
11 \\
(25,6 \%)\end{array}$ & $\begin{array}{c}8 \\
(42,1 \%) \\
8 \\
(42,1 \%)\end{array}$ & $\begin{array}{c}2 \\
(16,7 \%) \\
3 \\
(25 \%)\end{array}$ & $\begin{array}{c}10 \\
(32,3 \%) \\
11 \\
(35,5 \%)\end{array}$ & $\begin{array}{c}3 \\
(37,5 \%) \\
3 \\
(37,5 \%)\end{array}$ & $\begin{array}{c}2 \\
(28,6 \%) \\
0\end{array}$ & $\begin{array}{c}5 \\
(33,3 \%) \\
3 \\
(20 \%)\end{array}$ \\
\hline
\end{tabular}


APÊNDICE H - Utilização de medicamentos rotineiramente antes da internação, segregado pelo tipo de suspeita clínica e ausência ou presença de trombose aguda.

\begin{tabular}{llcc}
\hline & & Evento Agudo & \\
Suspeita Clínica & Ausência & Presença & Total \\
\hline TEP & $22(62,9 \%)$ & $13(37,1 \%)$ & 35 \\
TVP & $15(60 \%)$ & $10(40 \%)$ & 25 \\
TEP +TVP & $5(41,7 \%)$ & $7(58,3 \%)$ & 12
\end{tabular}

APÊNDICE I - Freqüência de hipertensão arterial sistêmica segregado pelo tipo de suspeita clínica e ausência ou presença de trombose aguda.

\begin{tabular}{lccc}
\hline & & Evento Agudo & \\
Suspeita Clínica & Ausência & Presença & Total \\
\hline TEP & $12(60 \%)$ & $8(40 \%)$ & 20 \\
TVP & $6(60 \%)$ & $4(40 \%)$ & 10 \\
TEP +TVP & $4(44,4 \%)$ & $5(55,6 \%)$ & 9 \\
\hline
\end{tabular}

APÊNDICE J - Freqüência de tabagismo segregado pelo tipo de suspeita clínica e ausência ou presença de trombose aguda.

\begin{tabular}{lccc}
\hline Suspeita Clínica & Ausência & $\begin{array}{c}\text { Evento Agudo } \\
\text { Presença }\end{array}$ & Total \\
\hline TEP & $17(56,7 \%)$ & $13(43,3 \%)$ & 30 \\
TVP & $9(64,3 \%)$ & $5(35,7 \%)$ & 14 \\
TEP +TVP & $4(66,7 \%)$ & $2(33,3 \%)$ & 6 \\
\hline
\end{tabular}

APÊNDICE K - Freqüência de sedentarismo pelo tipo de suspeita clínica e ausência ou presença de trombose aguda.

\begin{tabular}{lccc}
\hline Suspeita Clínica & Ausência & $\begin{array}{c}\text { Evento Agudo } \\
\text { Presença }\end{array}$ & Total \\
\hline TEP & $21(58,3 \%)$ & $15(41,7 \%)$ & 36 \\
TVP & $17(63 \%)$ & $10(37 \%)$ & 27 \\
TEP +TVP & $5(50 \%)$ & $5(50 \%)$ & 10
\end{tabular}

APÊNDICE L - Freqüência de presença de trombofilia segregado pelo tipo de suspeita clínica e ausência ou presença de trombose aguda.

\begin{tabular}{lccc}
\hline Suspeita Clínica & Ausência & $\begin{array}{c}\text { Evento Agudo } \\
\text { Presença }\end{array}$ & Total \\
\hline TEP & $2(50 \%)$ & $2(50 \%)$ & 4 \\
TVP & $3(75 \%)$ & $1(25 \%)$ & 4 \\
TEP +TVP & 0 & 0 & 0 \\
\hline
\end{tabular}


APÊNDICE M - Freqüência dos fatores de risco não relacionados com o quadro atual, segregado pelo tipo de suspeita clínica e ausência ou presença de trombose aguda.

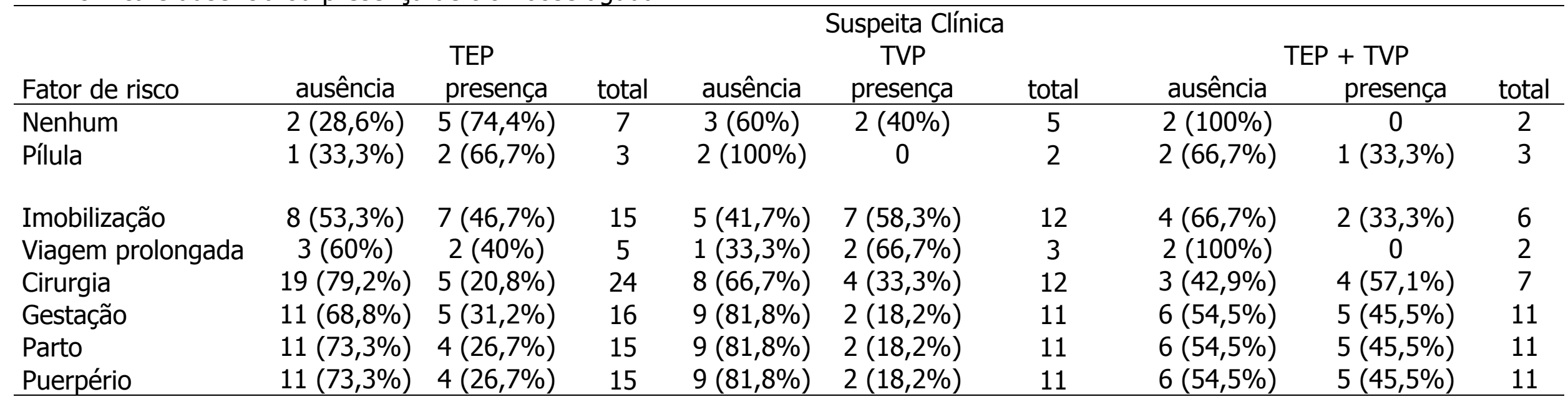


APÊNDICE N - Freqüência de doenças crônicas, segregado pelo tipo de suspeita clínica e ausência ou presença de trombose aguda.

\begin{tabular}{|c|c|c|c|c|c|c|c|c|c|}
\hline \multirow[b]{2}{*}{ Doenças Crônicas } & \multicolumn{9}{|c|}{ Suspeita Clínica } \\
\hline & ausência & $\begin{array}{l}\text { TEP } \\
\text { presença }\end{array}$ & total & ausência & $\begin{array}{c}\text { TVP } \\
\text { presença }\end{array}$ & total & ausência & $\begin{array}{l}\text { TEP + TVP } \\
\text { presença }\end{array}$ & Total \\
\hline Nenhuma & $5(50 \%)$ & $5(50 \%)$ & 10 & $9(69,2 \%)$ & $4(30,8 \%)$ & 13 & $2(100 \%)$ & 0 & 2 \\
\hline Diabetes & $5(71,4 \%)$ & $2(28,6 \%)$ & 7 & 0 & $2(100 \%)$ & 2 & 0 & 0 & 0 \\
\hline Câncer & $3(75 \%)$ & $1(25 \%)$ & 4 & $5(62,5 \%)$ & $3(37,5 \%)$ & 8 & $1(33,3 \%)$ & $2(66,7 \%)$ & 3 \\
\hline Cardiopatia & $19(65,5 \%)$ & $10(34,5 \%)$ & 29 & $4(57,1 \%)$ & $3(42,9 \%)$ & 7 & $3(37,5 \%)$ & $5(62,5 \%)$ & 8 \\
\hline Dislipidemia & $6(75 \%)$ & $2(25 \%)$ & 8 & $2(50 \%)$ & $2(50 \%)$ & 4 & $1(100 \%)$ & 0 & 1 \\
\hline Outras & $5(50 \%)$ & $5(50 \%)$ & 10 & $2(50 \%)$ & $2(50 \%)$ & 4 & $1(100 \%)$ & 0 & 1 \\
\hline
\end{tabular}


APÊNDICE O - Freqüência da utilização de medicamentos durante a internação, segregado pelo tipo de suspeita clínica e ausência ou presença de trombose aguda.

\begin{tabular}{|c|c|c|c|c|c|c|c|c|c|}
\hline \multirow[b]{3}{*}{ Freqüência } & \multicolumn{9}{|c|}{ Suspeita Clínica } \\
\hline & & TEP & & & TVP & & & TEP + TVP & \\
\hline & ausência & presença & total & ausência & presença & total & ausência & presença & total \\
\hline Nenhum medicamento & $11(84,6 \%)$ & $2(15,4 \%)$ & 13 & $15(65,3 \%)$ & $8(34,8 \%)$ & 23 & $5(71,4 \%)$ & $2(28,6 \%)$ & 7 \\
\hline 1 medicamento & $2(100 \%)$ & 0 & 2 & $2(50 \%)$ & $2(50 \%)$ & 4 & 0 & 0 & 0 \\
\hline 2 medicamentos & 0 & 0 & 0 & 0 & $1(100 \%)$ & 1 & 0 & 0 & 0 \\
\hline 3 medicamentos & $1(100 \%)$ & 0 & 1 & $1(100 \%)$ & 0 & 1 & 0 & 0 & 0 \\
\hline 4 medicamentos & $2(100 \%)$ & 0 & 2 & 0 & 0 & 0 & 0 & 0 & 0 \\
\hline 5 medicamentos & 0 & $2(100 \%)$ & 0 & 0 & 0 & 0 & 0 & $1(100 \%)$ & 1 \\
\hline$>5$ medicamentos & $20(60,6 \%)$ & $13(39,4 \%)$ & 33 & $1(50 \%)$ & $1(50 \%)$ & 2 & $3(42,9 \%)$ & $4(57,1 \%)$ & 7 \\
\hline
\end{tabular}


APÊNDICE P - Análise estatística dos medicamentos utilizados durante a internação, segregado pelo tipo de suspeita clínica e ausência ou presença de trombose aguda.

\begin{tabular}{lccccc}
\hline Suspeita Clínica & Média & Desvio - padrão & Mediana & Mínimo & Máximo \\
\hline Total TEP & 9,5 & 10,3 & 7 & 0 & 36 \\
Ausência TEP & 7,9 & 10,9 & 2 & 0 & 33 \\
Presença TEP & 12 & 9 & 10 & 0 & 36 \\
p & 0,207 & & 0 & 0 & 8 \\
Total TVP & 0,84 & 2,6 & 0 & 0 & 8 \\
Ausência TVP & 0,68 & 1,9 & 0 & 0 & \\
Presença TVP & 1,1 & 2,6 & 5 & 0 & 4 \\
p & 0,625 & 11,3 & 0 & 0 & 44 \\
Total TEP+TVP & 7,4 & 15,4 & 9 & & 10 \\
Ausência TEP+TVP & 8,5 & 4,5 & & & \\
Presença TEP+TVP & 6,1 & & & & \\
P & 0,703 & & & & \\
\hline
\end{tabular}


APÊNDICE Q - Freqüência dos dias de internação, segregado pelo tipo de suspeita clínica e ausência ou presença de trombose aguda.

\begin{tabular}{|c|c|c|c|c|c|c|c|c|c|}
\hline \multirow[b]{2}{*}{ Dias de internacão } & \multicolumn{9}{|c|}{ Suspeita Clínica } \\
\hline & ausência & $\begin{array}{c}\text { TEP } \\
\text { presença }\end{array}$ & total & ausência & $\begin{array}{l}\text { TVP } \\
\text { presença }\end{array}$ & total & ausência & $\begin{array}{l}\text { TEP + TVP } \\
\text { presença }\end{array}$ & Total \\
\hline 1 & $7(77,8 \%)$ & $2(22,2 \%)$ & 9 & $15(55,6 \%)$ & $10(37 \%)$ & 27 & $4(100 \%)$ & 0 & 4 \\
\hline 2 & $8(72,7 \%)$ & $3(27,3 \%)$ & 11 & $1(100 \%)$ & 0 & 1 & 0 & $4(100 \%)$ & 4 \\
\hline 3 & $3(60 \%)$ & $2(40 \%)$ & 5 & 0 & $2(100 \%)$ & 2 & 0 & 0 & 0 \\
\hline 4 & $1(100 \%)$ & 0 & 1 & 0 & 0 & 0 & 0 & 0 & 0 \\
\hline 5 & $1(100 \%)$ & 0 & 1 & 0 & 0 & 0 & $1(50 \%)$ & $1(50 \%)$ & 2 \\
\hline mais de 5 & $6(37,5 \%)$ & $10(62,5 \%)$ & 16 & $1(100 \%)$ & 0 & 1 & $3(60 \%)$ & $2(40 \%)$ & 5 \\
\hline
\end{tabular}


APÊNDICE R - Análise estatística dos dias de internação, segregado pelo tipo de suspeita clínica e ausência ou presença de trombose aguda.

\begin{tabular}{|c|c|c|c|c|c|}
\hline Suspeita Clínica & Média & Desvio - padrão & Mediana & Mínimo & Máximo \\
\hline Total TEP & 7,4 & 8,3 & 3 & 1 & 34 \\
\hline Ausência TEP & 4,8 & 6,4 & 2 & 1 & 29 \\
\hline Presença TEP & 11,2 & 9,5 & 13 & 1 & 34 \\
\hline $\mathrm{p}$ & 0,011 & & & & \\
\hline Total TVP & 2,5 & 7,5 & 1 & 1 & 43 \\
\hline Ausência TVP & 3,3 & 9,6 & 1 & 1 & 43 \\
\hline Presença TVP & 1,3 & 0,78 & 1 & 1 & 3 \\
\hline $\mathrm{p}$ & 0,496 & & & & \\
\hline Total TEP+TVP & 6 & 8,7 & 2 & 1 & 35 \\
\hline Ausência TEP+TVP & 8,3 & 11,7 & 3 & 1 & 35 \\
\hline Presença TEP+TVP & 3,6 & 2,4 & 2 & 1 & 7 \\
\hline p & 0,318 & & & & \\
\hline
\end{tabular}


